
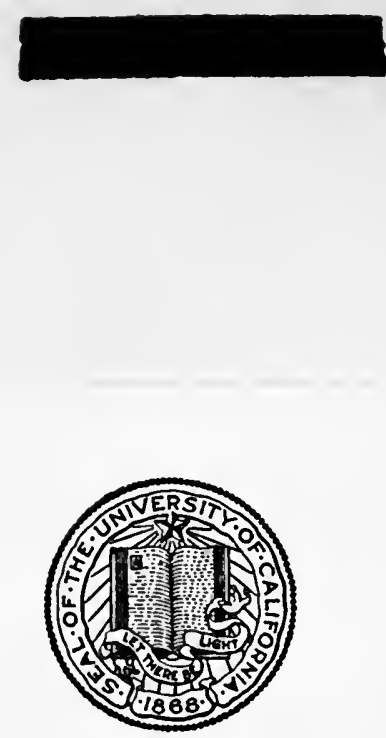

THE LIBRARY OF

THE UNIVERSITY OF CALIFORNIA LOS ANGELES 
Digitized by the Internet Archive in 2007 with funding from Microsoft Corporation 

COLLECTED PAPERS ON THE PSYCHOLOGY OF PHANTASY 


\section{COLLECTED PAPERS}

\section{ON THE \\ PSYCHOLOGY OF PHANTASY}

\section{DR. CONSTANCE E. LONG}

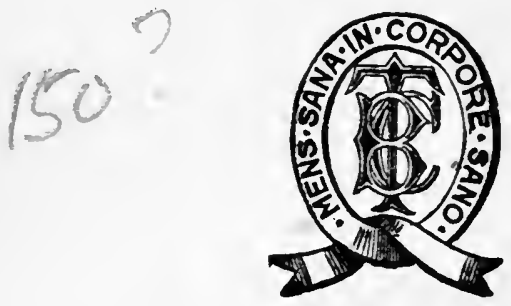

\section{LONDON}

\section{BAILLIÈRE, TINDALL AND COX}

8, HENRIETTA STREET, COVENT GARDEN

1920 
PRINTED IN GREAT BRITAIN

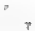




\section{PREFACE}

I HAVE often been asked to publish the following papers in book form. I have at length done so, chiefly because they deal with points that are matters of constant inquiry.

In a collection of papers of this sort there is inevitably a good deal of repetition. I regret this, but it is always open to readers to skip passages, whereas those who are unfamiliar with the terms of analytical psychology will find the repetition not without value.

It will easily be seen by those to whom it is not already known, that I am an adherent of Jung's school of analytical psychology, but I have never concealed my great admiration of Freud's work, nor minimized the debt we owe to him for his opportune discovery of dream analysis, and for the formulation of his illuminating theories of neurosis.

The adherents of the Swiss School use Freud's technique of dream analysis, and do not repudiate any of his discovered facts, but they repudiate the claim of some of his disciples that he and his school are in possession of the whole truth. They are unable to believe that his interpretation of the facts is always as unimpeachable as the facts themselves.

The great value of dream analysis, and the real importance of the discovery, are attested by the fact that the results can be applied in many very different fields of work. The method has approved itself whenever investigators have had sufficient knowledge and skill to do justice to it.

The Freudians are anxious that the term psycho-analysis should be reserved for their special school. As a practical matter it is almost impossible completely to disentangle psycho-analysis from analytical psychology, because having sprung from a common root they are closely bound together. 
Just as analytical psychology is indebted to Freud for its origin, so in turn the Freudians are quietly incorporating in their writings some of the findings of the Swiss School. This may; be an unconscious assimilation, or it may equally well be that they are arriving independently at similar conclusions.

In my last reading of Freud's "Dream Interpretation" I was forcibly struck by the fact that many ideas are implicit in it which, when presented from outside, he and his disciples are fain to controvert. This implicitness is characteristic of a work of genius. That the author should be blind to much that is in his own creation is no new thing, and further discoveries must not be regarded as a breach of patent.

It was my good fortune to obtain my first insight into the unconscious mind with Dr. Jung's help, an experience which has earned my lasting appreciation. While the following papers afford an introduction to his views, I do not pretend to represent them at all adequately. I have pointed out certain major differences between the two schools, but in any case, those who write on psycho-analysis or analytical psychology will inevitably bring their own subjective views to bear when they attempt to explain psychological theories. However desirous we may be to assume the contrary, analysts, and analytical writers, though presumably enlightened, are just as prone as others to the common human prejudices. Unless we are on our guard this can easily be the case, because analysis can never really empty the unconscious mind. New material is always being created, and fresh repressions can arise, particularly while we are giving too exclusive attention to those which are already unearthed.

Perhaps one of Jung's most valuable ideas is that of the compensatory function of the unconscious mind. He regards it as being the creative mind, and as having a balancing tendency also. Thus repression is not referred to sexuality and the primitive instincts alone, but to all the neglected and under-valued material belonging to the various psychological functions of thinking, feeling, seusation, and intuition. Whatever is repressed, or under-expressed, links itself up with 
unconscious elements. From the psychic tension produced between what is conscious and what is unconscious, the phantasies arise, representing in symbolic form what is missing from conscious consideration. The symbols so created are functionally useful as indicating not only the cause of error, but the way of progress. Dream and phantasy are thus regarded as valuable functions of the psyche. In order to avail ourselves of these functions, reasonable contact with the unconscicus mind is to be sought through analysis, and should be maintained when analysis is over. This view provides a most hopeful outlook for the future of psychotherapy.

I have called my book the "Psychology of Phantasy." It was not until I had collected these papers together that I realized how much the subject of phantasy had occupied me in the last four years. A candid friend, who is an academic psychologist, bade me refrain from using such a title, saying that the book had nothing to do with psychology. However, I have retained it, because to my mind the book deals with an aspect of phantasy to which academic psycho$\log y$ is paying considerable attention at present. At the same time I warn my readers they will find in it nothing about such matters as "the relation of imagination to perception," etc. I approach the subject solely from the standpoint of medical psychology, and from direct experience and observation of the unconscious mind. It would seem to me both unfitting and unnecessary to dwell upon a side with which the academic psychologist knows, so very much better than I, how to deal.

I take this opportunity of thanking my friends, Dr. Eleanor Bertine and Mrs. M. C. Clare, for their criticism and help, and also Miss Joan Corrie for kindly correcting the proofs.

48, Gordon Square, W.C. 1.

October, 1920. 



\section{CONTENTS}

PAPER

$\bullet \quad \bullet \quad \bullet \quad \cdot$

Quotation from Dr. Jung on "Psychological Types" . xi

I. Mental Conflicts in Calldren . . . . 1

L-II. Evidences of the Unconsciods Mind in the Child . 16

LiIf. Fgar in the Child and the Authority Complex . . 40

IV. Unconsciods Factors affecting Discipline • • 61

V. The ush of Subliminal Material in Analytical PSYchOLOGY . • . . . . . . . 77

VI. The Censor and Unconscious Symbolism in Dreams 109

VII. Sex as a Basis of Character . • . • . . 127

VIII. Unconsciods Factors in Sex Education . . . . 144

IX. The Significance of Phantasy in the Proddction of The Psychoneuroses . . . . . . . 160

X. Review of "The Psycholocy of the Unconsciods" . 182

XI. Psychological Adaptation - • . . . . . 195

INDEX . . . . . . . . . . . 211 

“. . . Idea and thing meet in man's psyche, which holds the balance between them. What is the idea, indeed, if the psyche does not endow it with vital value? What is the objective thing if the psyche withdraws the conditioning power of the perceptual impression? What is reality if it be not an actually existing thing in us, an esse in anima? Living reality is not exclusively reached through the actual objective relation of things, nor through the formulating of ideas, but only through the comprehension of both in the living psychological process, the esse in anima. Only through the specifically vital activity of the psyche does sense-perception attain that depth of impression, and the idea that operating power, both of which are indispensable to living reality. ... The psyche creates subjective reality daily, and I cannot call this activity by any other name than phantasy. Phantasy contains as much of feeling as of thought, it is just as intuitive as it is perceptive. There is in it no psychic function which is not inextricably mingled with other psychic functions. It appears at one time as primordial, at another as the last and most striking product of all accumulated knowledge. ...

Phantasy is the creative activity which gives birth to the answers to all questions admitting of answers. It is the mother of all possibilities in which. . . the inner and the outer world are united in a living whole. It was, and always is, phantasy which builds the bridge between the irreconcilable claims of the object and of the subject, of extraversion and introversion. In phantasy alone are both processes united. . . .

Phantasy is for the most part a product of the unconscious. It does indeed contain elements of consciousness, but for all that it is a special characteristio that it is essentially spontaneous, and quite foreign to the conscious content. It shares this quality in common with the dream, though the latter is wholly involuntary 
and far more bizarre in character. A man's relation to his phantasy is largely governed by his relation to the unconscious in general. This relation in its turn depends in a special way upon the spirit of the age. According to the degree of rationalism prevailing, an individual will be the more, or the less inclined to be influenced by his unconscious and its products. . . .

Intellect remains imprisoned within itself so long as it does not voluntarily sacrifice its supremacy, and admit the value of other claims. It shrinks from taking $a$ step beyond itself, and will not allow that it does not possess universal validity, for everything outside its own view is nothing but phantasy. But what great thing has there ever been that was not phantasy first? . . Every happy idea and every creative act had its beginning in imagination, and in what we are accustomed to call childish fancy. Not only the artist but every creator owes to phantasy everything that is greatest in his life. The dynamic basis of phantasy lies in its playfulness, which is suited to childhood, and thus appears irveconcilable with serious work. Yet without this play of fancy no creative work has ever seen the light. It must not be forgotten that what is most valuable in a man may lie in his imagination. I say ' may lie,' for on the other hand phantasies in themselves are practically worthless, since in the form of raw material they possess merely potential value."-C. G. Juna, "Psychological Types," 1920. 


\section{COLLECTED PAPERS ON THE}

\section{PSYCHOLOGY OF PHANTASY}

I

\section{MENTAL CONFLICTS IN CHILDREN ${ }^{1}$}

Since Professor Freud launched his psycho-analytic theories upon the world some twenty-five years ago, a most valuable instrument for the examination of the mind of the child has been put into our hands. That these theories arose in the line of medical research does not detract from their pedagogical application, for it is disclosed to us that the childmind still persists in the adult, in the unconscious realm of the psyche.

Psycho-analysis is a method of treating psychical illnesses, such as hysteria and other neuroses which are based upon unconscious mental conflicts. By its practice extensive knowledge of the processes going on in the subliminal regions of the personality is acquired. Psychical illness arises in the realm of ideas rather than in the physical factors. The unconscious ideas express themselves in bodily symptoms, which are a result and not the cause of the illness. Freud claimed that the root cause of all neurosis of later life is to be found in the first five years of childhood.

It is rare to meet a broken-down man or woman who does not attribute most of the mental and physical difficulties of life to incidents and influences of childhood. This is the conscious view, and when we deal with the individual analytically, we find it confirmed and more profoundly important in the view of the unconscious.

I Address delivered at the Teachers' Guild of Great Britain and Ireland. January, 1916. Revised. 
The unconscious is all that exists in the psyche, of which we are not aware at a given moment. It has been compared with the submerged part of an iceberg, which greatly exceeds in bulk the part floating above the sea level. Whatever floats above the surface represents the conscious part of the mind. It is conceivable that an iceberg may turn over, or about, owing to the melting or the parting of its fragments, and another portion will then come uppermost. So with the personality-now one part is conscious, now another, a little at a time-and some portions never reach consciousness at all.

The unconscious, the subconscious, or the subliminal (as it is called by different authors), contains all our memories from our earliest existence to the present. ${ }^{1}$ All that has happened to us continues to exist. At any given moment we use, or are conscious of using, comparatively few memories; vast stores remain untouched in the subliminal regions-as Samuel Butler says," "The life of a creature is the memory of a creature; we are all the same stuff to start with, but we remember different things; if we did not do so, we should be absolutely like each other." Therefore every time we come in touch with another person, it is the contact merely between two small knowns and two huge unknowns. This doubtless accounts for many of the misunderstandings that arise between any two persons, no matter how great their goodwill. This is true of our contact with the child. Let him beware who thinks he fathoms the mind of the child. It is possible to do so, of course, to an extent, but only by taking the unconscious into serious consideration as well as the conscious. The child at the school age is already a complex being, full of memories, not only of facts but also of the inventions of his imagination -dreams, phantasies, and the like. For him the cardboard box was the ammunition waggon, or the big sofa a liner on the ocean. He has phantasies or imaginings about his father, and his mother, and his God, about his teachers and himself,

1 The racial memorios are also stored as potentialities in the psyche. The view that the unconsclous mind is the rosult of repression only, is not accepted by the author, and is discussed later on.

2 "Life and Habit." Fifield. 
and he does not by any means always discriminate between fact and fancy. These phantasies influence his conduct to a much greater extent than is generally supposed, none the less that they are unconscious productions, and their meaning is hidden from him, just as it is from parent and teacher. Phantasies act upon the child much like the memories of experiences; they have "the same psychic value." 1 Sometimes they are more real to him than reality itself.

A great deal of emotion is attached to the phantasies which are an expression and a gratification of the emotional needs of the individual; and when they cease to be remembered, and are carried or dragged down into the unconscious, much of their emotional tone is carried down too. Nothing happens to us that does not produce a definite emotional reaction, such as love, hate, jealousy, approval, acquiescence, indifference, or desire. Nor do these states of feeling exist simply and singly, but contain certain mixed elements and opposing tendencies, such as love and hate, trust and distrust.

The presence of the emotional factors can be demonstrated in a simple way as often as one will take the trouble by means of the psychological experiment known as the word-association test. Drs. Jung and Riklin published some work in 1904 on the application of the association method to unconscious mental processes. ${ }^{2}$ The work was particularly valuable because from a completely different angle of observation it confirmed what Freud had discovered through his use of dream analysis. "This confirmation by experimental methods compelled many who had hitherto looked askance at the psycho-analytic theories to investigate the phenomena for themselves" (Eder).

In this test a list of about one hundred words is given to the person to be examined; "the words are called out one by one, and are carefully selected, and partially arranged in such a manner as to strike easily almost all the common groups of

1 See "Dream Interpretation." Freud.

2 "Studies in Word Association." Authorised translation by Dr. M. D. Eder. Heinemann, 1918. 
associated ideas. ' Before the test begins the person under examination is told to answer as quickly as possible with the first word that comes into his head." The answering word or phrase is called his "reaction." This seems to be a very simple process, and with a little patience it is a thing that even a child or a feeble-minded person can do. But, in spite of that, it is by no means as simple as it looks. The reason it is not simple is because of the ideas which are constellated in the unconscious mind. No idea exists singly-it has roots and connections spreading to many other ideas-but certain ideas tend to group themselves together, so that if you touch one of the ideas in the group, other members of the group or constellation are stimulated, and the emotional current travels in all associated directions. Such a group of associated ideas Jung calls a Complex. ${ }^{2}$ Such complexes exist in consciousness. For example, a child decides to make a little museum of his own, and he begins to collect and beg all sorts of things for his new enterprise, he thinks of it by day, and dreams of it by night; this may be called his " museum complex"; he now begins to have desires for many things, and finds means of acquiring them-probably not all of them honest. Perhaps fossils take his fancy, and he becomes aware there are certain specimens in the cabinet in the drawing-room-he annexes one or two, and now his museum grows, but he is also aware of a certain growing uneasiness, so that a new and painful emotional feeling is added to the feelings already constellated about the museum-idea. He resorts to devices to hide his guilt. Perhaps his feelings become so unpleasant that he decides to give up the museum and forget about his sins, or a stern parent discovers his theft, and in high moral indignation, descends upon him with a cane. This brings his intcrest in his museum to an end-he covers his hurt feelings, and tries to forget all about it. The ideas around this museum complex have now become distinctly painful, and it is pushed out of mind as completely

I See "Collected Papers on Analytical Psychology." Jung. Bailliero, Tindall \& Cox.

"See a "Paychology of Dementia Prxcoz." Monograph Series. 
as possible, pushed, that is, into the unconscious. He succeeds in forgetting all about it, and yet, years after, the word "fossil" or the opening of the drawing-room cabinet, or the clearing of the paternal throat, will give him an uncomfortable sensation; he cannot think why. It is because the constel. lated ideas and emotions still exist in the unconscious, and something so-called accidental has set them vibrating.

The word-association test takes advantage of the fact of the existence of these repressed emotions in the unconscious, for their presence has striking effects. When the test is applied, the length of time between the test or stimulus word and the answering word is noticed, and recorded as a "time reaction"; that is the time taken in reacting. Then later on the same list is used again, and changes in the replies, that is, changes in their reproduction, are noticed. As a rule the same word is used in the reply as before. Very long reaction times, or very unusual reactions, and failures to reply at all, as well as faulty reproductions and various other things, evidence that an emotional complex of importance is aroused by the stimulus word. No matter how determined a person is to conceal his mental conflict he is unable to control the process in his unconscious. The "word" is the symbol for something that exists psychically. It strikes a real memory picture, and has in a degree the same effect as the scene itself.

Jung cites a case of a theft in an institution. The suspected persons were all subjected to a word-association test, and the guilty one was tracked down from the evidence obtained; she afterwards confessed the theft, thus confirming the experiment. A great deal of exact scientific work has been done upon this subject, which repays careful study. The purpose of introducing it here is to give a concrete example of what has previously been said, that an individual is made up of memories; not only of facts but of phantasies too.

The following are reactions to twenty-five words, given by three children aged respectively 7,11 , and 4 . The little girls of 7 and 11 were exceedingly poor, of Jewish race, and had been rescued from degraded surroundings. From these reactions we get some notion of their ruling ideas, which 
would be impossible in children brought up under happier conditions.

The third child of 4 years and 5 months came from entirely different surroundings, is a "well brought up child" in comfortable circumstances.

\section{Fanny (æt. 7).}

\section{Stimulus}

Word. Reaction.

Reproduction.

Dog. . Frightens . . . . . Fright.

Work To go to work when the bell rings To go to work when the bell rings.

*Girl . . Play wif her . . . . When she plays wif her.

Mouse . A pussy bitos it . . . A pussy bites it.

Stick. It 'its yer . . . . It 'its yer.

Chair . Sit down . . . . . Sit down.

To rab . Wash the floor. . . Wash the floor.

Egg. . Cook it . . . . . To cook.

To steal . Eat it . . . . . To kill the men's-

Babies . Sleep . . . . . . Sleep.

Sleep . Wake up . . . . . Wake up.

Hand . Touch somefink . . . Touch somefink.

Sin . When you swcar . . . When you swear.

Key. . Open the door . . . . Open the door.

Room . Sweep . . . . . Sweep.

Money . Buy somefink . . . . Buy somefink.

Fruit . To cat . . . . . To eat.

Tea . . To drink . . . . . To drink.

Cow. . To mind the sheep . . . The sheep.

- Puro . Nil . . . . . . Coke.

Jam . To make bread and butter . To take the bread, cut it, and put the jam on.

School. To read . . . . When tho bell rings wo go to

Good . Prizo . . . . . Prize.

*Hungry . When you ain't got nofink to cat Whon you ain't got nofink to eat.

Carpet . To put round your neck . . Nil.

Fire . To mako your hands warm . Nil.

Coal . Coke. . . . . Coal comes from God; (who) makes you; makes your shoes; makes clothes : lives up a hill.

SARAiI (at. 11).

Dog. . Some dogs bite you . . The dogs bite you.

Work Some people go to work . The men go to work.

* The reaction time is particularly long in these words marked with an asterisk. 
Stimulus

Word.

Reaction.

Girl. A girl does cleaning?̦.

Reproduction.

Mouse . A mouse gnaws the bread . A mouse gnaws the bread.

Stick . You hit everybody with a stick We hit people with a stick.

Chair - You sit on a chair . . . You sit on a chair.

*To rub . We rub our hands . . . We rub our hands.

Egg. . We oat an egg. . . . Wo oat an egg.

*To steal . Some gir-boys steal . . We steal-vegetables.

Babies . Tho baby cries . . . The baby cries.

Sleep . We go to sleep at night . . We go to sleep at night.

Hand . We eat with our hand . We warm our hands.

Key. We unlock the door with a key We open the door with a key.

Room . People walk in the room . We walk in the room.

Money . Wo hold money in hands . We have money in our pockets.

Sin . . God gives us a sin . . Wo have a sin (telling lies).

Pure . The milk is pure . . . Tho tea is pure.

Cow . We have pure milk from a cow Wo have pure milk from a cow.

Tea . . We drink tea . . . We drink tea.

Good . We have good things . . We have good milk.

Fruit . Fruit is good . . . Fruit is not bad.

Jam . Jam is good . . . Jam is pure.

School. We go to school . . We go to school.

Hungry . Wo go hungry . - . . The dog is hungry.

Carpet . On the floor is the carpet . . The carpet is white.

Fire . The fire is alight . . The fire is burning.

Coal . The coal is burning . . . The coal gives flames.

\section{JANET (æt. 4 years 5 months).}

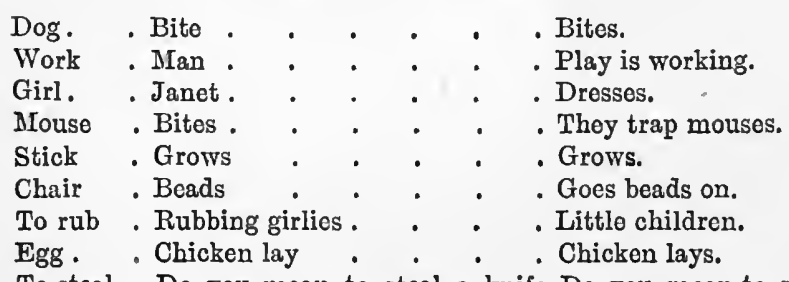

To steal. Do you mean to steal a knife Do you mean to steal a chickie or to steal something to eat or a pig or something?

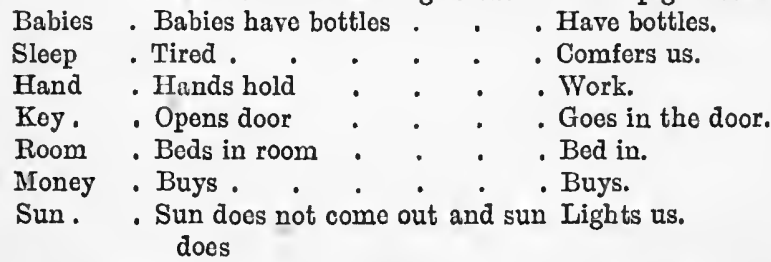

* The reaction time is particularly long in these words marked with an asterisk. 
Stimulus

Word.

Reaction.

Reproduction.

Sin . I don't know what sin moans. What is sin?

Pure I don't know what pure is: I don't know what pure is. what is it?

Tea . Wo eat and drink . . . Tea to cat or tea to drink?

Cow. . Sends milk . . . . Lays milk.

Good . Good girlios . . . . Littlo children.

Fruit . Grows on trces . . . Grows on trees.

Jam Grows from strawberrios and From strawberries and fruit. things

School . Children go to school . Little children go to school.

Hungry . Little children want food whon Poor little children.

they are hungry

Carpet . Goes on tho floor . Goes on the floor and people walk on it.

Fire . Light . . . . . Light

Coal . Coal men bring coal. I don't Coal comes from coal sweepers.

know where the coal comes

from

The young child lives very close to the unconscious, and the mechanisms are vory clearly seen. What becomes plain from these answers is that they are all determined by the memory contents of the mind, and are inevitably just what they are, and that emotional causes, to a much greater extent than intellectual ones, account for them. Compare, for instance, the answers to the word "stick." The little slum-bred children may never have seen one growing. The third child had no conception of its use as an instrument of punishment.

To understand the mental conflicts of children we must look at their emotional life. Whether we regard them from the standpoint of teacher or doctor, we must take into account the enormous importance of the home-either in its positive or its negative aspect. Teachers sometimes say, "I could do a great deal with that child were it not for home influences." Doctors too feel they could cure him if his environment could bo changed. But this represents exactly what we have to do- to teach or to heal, in spite of other influences.

The meaning of certain kinds of so-called naughtinesshatred of certain lessons, special forgetfulness, repetition of identical mistakes, inability to get on with certain teachers or classmates-may have its origin in the remote causes of 
parental influence. As the father or mother thinks or acts towards such and such a person or thing, so unconsciously thinks and acts the child. Say the father thinks little of a certain study or teacher, or the mother says she got on very well without knowing such and such a thing - just in so far as the child's psychology is adapted to the parents', there will be unconscious imitation of their attitude. This is of immense importance; the child behares as he thinks in his infantile way the parent would behave.

The whole emotional life of the individual follows a curre, and one should be at a given place on this curve at a given epoch. The earliest emotions are egocentric, the babe is his own centre; next comes the mother, who represents " gratification in nutrition," 1 and is the first external object of love; next the father enters the infantile horizon, as an element of power that can raise or depress the infant joy. Then brothers and sisters, nurses, and so forth; then comes school life, which is designed to wean the child from his sole dependenee on the family, and carry him from the home to the world, bringing over his emotions from the infantile to the adolescent stage. Next comes business or college life - the call and the drive to maturity, and to the main tasks of life, the creative years, begetting and rearing children, the making of the business or professional life, tailing off into the quieter years of declining ambition, but of greater valuation of the individual himself; and finally the withdrawing again into the self, when, if the body-structure lasts too long, there is a development of second childishness.

Theoretically this emotional curre should be smooth; practically it is anything but smooth: there are dashes forward towards precocity, lapses into backwardness, and many kinds of deviations.

The teacher is, in any case, quite unable to disregard the immense importance of the emotional relation between parent and child. Even when the child is in happy and normal relationship in his home and with his teachers, he makes a transference of a large part of his emotional values on to the

1 Jung, "Psychoanalysis," Monograph Series, No. 19. 
teacher, who now in a sense replaces the parent as an authority. The importance of this emotional transference is not fully realised. It may be of a positive or of a negative kind-i.e. liking or love, dislike or hate.

Children who have broken down in conduct at school are sometimes brought to the doctor. The breakdown is often caused by a misunderstanding, not always on the child's side only. The unredeemed psychology of the teacher can get in the way. A word or a smile, a little yielding, will sometimes win a campaign that otherwise might drag on indefinitely in mutual hostility. On the other hand, judicious severity, the transmutation of a sentimental emotion into real feelings, even of a painful kind, can bring home very necessary lessons to a young heart.

Sometimes it is necessary to let the child fall into complete error before it can find its own way: Too much shepherding is bad, how can the child realise that its wishes and desires are on a wrong path while the crook constantly draws it back into the right one? A child is not a lamb! Many a stormy trouble would be over sooner if it were allowed to burst. Then the child does something really wrong, and has its overt acts as well as its inner light to point the moral. Over-correction cripples the energy, it leads to repression and promotes the fermenting of trouble in the dark, which bursts out of the unconscious in irresponsible acts, such as lying and thieving. It is better far for the child to do wrong deliberately, than for it to be impelled to it by unconscious motives.

The good teacher should be like the skilled gymnast in ju-jitsu, he should make the enemy's force serve his end. He receives the blow, and in receiving directs the energy so that it overthrows the attacker, not the attacked. If the child is overthrown by himself, as the calm and self-possessed teacher meets his passion with skill, then the pupil learns his lesson, and picks himself up to fight better in future, and apply himself to his aim with more humility and foresight.

Those teachers are most successful who have learned to deal with their own lives, and whose own main stream of energy is flowing easily and fully in a forward direction. 
They give out of their fullness. The pupil is unconsciously attending to what they are, and will begin to behave himself as he thinks the teacher behaves, now exchanging him for the paternal ideal. The child reads the teacher intuitively, and, whether one likes it or not, this fact is very important. The good teacher uses this power either consciously or unconsciously, but fortunately although this transference of love to the teacher carries the pupil past many a difficulty, it does not prevent him from having to exercise personal effort, for the child must come up to the teacher's standard. The teacher, however, is always retiring from the ground to which he entices his pupil, so that he is never reached; and in the meantime, what is valuable is becoming the possession of the pupil. He is gaining the power that he sees in the teacher, within, and for himself.

Much childish naughtiness is due to unconscious resistances; that is, a feeling within the self against a task or a teacher to which the child cannot give a clue-he does not recognise these resistances for what they are. He thinks he "cannot do his work, his task is too hard," or that his "teacher is unjust."

There is often a conscious effort to do the right thing, but a pull from the unconscious towards the wrong. He is at the mercy of opposing feelings. Sometimes in judging motives we are almost constrained to feel a person does a thing because he wishes to do its exact opposite (we see this very markedly in the action of certain lunatics). In the normal individual this conflict depends upon the presence of associated memories in the unconscious, and not only with memories of actual facts and experiences, but also of the ruling phantasies. These constellated memories, forming the complexes, have a painful content in common, and they act somewhat independently or out of harmony in the psyche; there is exquisite sensitiveness to stimulation of any part of the constellation-thus an attack of irritability or an explosion of temper may be due not so much to the nature of the stimulus itself, as to the vibration set up in the constellated emotions in the unconscious.

There is another point of importance I would venture to 
touch upon, as vitally concerning my subject, and that is the great difference in psychological types to be seen in human beings.

William James, in "Pragmatism," has defined these two types as the tough and the tender-minded. The terms used here are those introduced by Dr. Jung, of Zürich, who characterises the tough-minded as extravert, the tender-minded as introvert. ${ }^{1}$

Whether a person is extraverted or introverted depends upon whether the prevailing interest of life, or the main current of libido is directed outwards to the object, or inwards to the ego. The extravert tends to get lost in materialism. The external world, persons, things, and causes are very attractive to him, the life of thought and the cultivation of the inward eye being of less moment. The extravert is enthusiastic, outgoing, adventurous in deeds, apt to undertake enterprises with too little thought as to their justification or value. His libido carries him to the object, he is apt to be a busybody in affairs, or to be busy about the wrong thing, he believes in himself, and is not hindered by self-criticism, hence he often makes a better show in the world than he actually deserves; he is always more interested in things than the ultimate tendency of things.

The tender-minded, or the introverted type, adapts himself with more difficulty to his surroundings, preferring his own inner world of thought and his own ideas to anything that is thrust upon him from without. He is very sensitive, selfconscious, and personal in his way of feeling - too thin-skinned and tender-minded to enjoy his contact with his fellows, or feel quite rightly about them. $\mathrm{He}$ is reserved and difficult of access, timid in taking up enterprises, his critical faculty is over-developed, and he is paralysed by it when he wishes to produce his work, because his ideas so far excel his capacity for expression, and his brilliant promises are apt to

1 In the formulation of these two types Dr. Jung was aware that other types existed. His whole concoption of the types has undergone a reformulation since the made his first eontribution (see "Analytical Psychology," chap. xi.). He no longer regards the extravert as the feeling type, and tho introvert as the thinking type, but finds both the thoughts and feelings turn to the object in the one, and to the ego in the other. 
come to nothing, partly because he cannot bear to make mistakes, and therefore he makes nothing at all.

These types exist in all degrees of mixture. In religion they are represented by "faith and works"; an excess of either means a deficit of the other. All individuals lean to one type or the other. You see the tendency in the youngest infant; one accepts your blandishments with a smile, and wants to play with you; the other turns away, will have nothing to do with you, and is only won by waiting.

Each child brings with it an extraverted or an introverted psychology. The extravert is the more adaptable, the introvert more thinking and apprehensive. A former type can be more effectively reached through the object, the latter by an appeal to the idea. One will make many friends, the other few. The sins of the extraverted child will be those of commission, those of the introverted will be those of omission.

The aim of education should not be to obliterate the types, but to understand and develop each out of its strength. If we convert the one into the other we make a cruel mistake, because we work against the main stream of the child's energy; yet it is obvious the introvert must be lured from the ego, and the extravert from the object, not by driving them out of themselves, but by developing the less valuable function in each. Let me give an example. A woman came to me suffering from an introversion neurosis. The home of her childhood had been a very unhappy one, full of privations. She was richly endored with beautiful imaginative thoughts, and poorly endowed with practical feelings. She was a promising and brilliant scholar, and gained much attention and praise at school. At home her poor little efforts at loving and serving met with rebuff after rebuff. Her parents were at variance, and love was not called out in the home. She developed her best life at school, where she met with a great deal of encouragement. The ambitious ideas of the teachers began to be projected on the child. "She will bring us much credit," they said, and she was naturally pushed on to take scholarships. She finally reached college-again her brilliance 
won respect-and it was felt "she will bring us credit," and with this end in view she was pushed on to undertake work involving an enormous amount of extraversion-immense acquisitiveness was demanded for the task imposed, which was to bring back credit to her college. So the life of thought, which was her strong point, was of necessity pushed aside; there was no time to follow the development that would have been natural to her. What happened? She gained great credit for her college and obtained a high place, but the original work expected from her came to nothing; her critical sense prevented her from doing what she could, and she could not do what she would, because she had no energy available. The distinction she had achieved irked her, and required far too much adaptation from her, because it demanded that she should lead a life that was not in accordance with her psychology. Her passionate longing to follow her nature (which she had incidentally lost sight of to a great extent), and the necessity of following the life the unwise pushing of others and her own ambition had imposed upon her, brought about a terrible conflict, and a neurosis supervened, which made her ineffectual, ill, and unhappy.

This is typical of many similar tragedies, where a precocious child is sacrificed to the ambitions of parents or teachers. The child, in virtue of his childishness, is not in a position to discriminate, and only too easily succumbs to the lure of fame. The child in question belonged to the introverted type, and was forced into excessive extraversion, and fell between two stools.

The wisdom of the teacher should have been directed to developing that promising young life in the direction of its own main-stream. Does not the machinery of education leave too little room for the cultivation of what is out of the common? Teachers must look out for their own complexes here, for what is best for the child is often disadvantageous for the teacher, and that is why he who has learnt to deal with his own life, and put the accent on the real values, will make the best teacher.

Not only do children belong to these two different types, but teachers also. The opposite types do not very easily 
understand one another, although, as we know, opposites attract one another, and are complementary the one to the other. It is well to study this question; it gives a view which repays some expenditure of time and has a practical bearing upon the mental conflicts of children. It is a means of helping them to understand themselves, and to get the best out of themselves. But as Jung himself says, "The task of elaborating a psychology which pays equal attention to the two types of mentality belongs to the future." 1

1 "Collected Papers on Analytical Psychology," p. 298. 


\section{EVIDENCES OF THE UNCONSCIOUS MIND IN THE CHILD ${ }^{1}$}

We have long known that the most important time in the nurture of the child is that in which its brain is increasing in size and its body in weight at a greater rate than in any subsequent period of its growth.

Its early psychical development is of equal consequence. The first impressions made on the infant mind are of enormous significance. They become a kind of pattern for subsequent experience printed off again and again. It is also a matter of common observation and intuitive knowledge that the mental states of the pregnant woman and the nursing mother have far-reaching effects on the character of the offspring. The normal infant arrives in the world already in possession of a highly differentiated brain, but with as yet no differentiated mental functions, although the potentialities of all future developments exist in the unconscious psyche.

The unconscious mind is pre-existent to the conscious mind. It is a racial possession, common to all, and is not acquired during the lifetime. To distinguish this primordial portion of the mind Jung calls it the collective or impersonal unconscious. Its organ, the brain, is an ancestral inheritance, and possesses the pre-formed instincts and archetypes of apprehension, which are present as potentialities of future thought and feeling. As consciousness emerges out of unconsciousness, the mind climbs up its genealogical tree as the body has done; that is, its function becomes more and more differentiated. The dawn of reason was a great achievement in man, marking his separation from his anthropoid

1 Revised and reprinted from the Jontrnal of Experimental Pedagogy, 1916, by kind pormission. 


\section{THE UNCONSCIOUS MIND IN THE CHILD 17}

ancestors. This achievement is repeated in the individual, and shows itself in the differentiation between subject and object. The earlier ideas are subjective. "Our intellect is born out of mythology: it is nothing but a translation of inner experience into the language of pictures." 1 As the child develops consciousness, and his experience accumulates, the personal unconscious begins to come into existence. Not everything that happens can be assimilated into consciousness nor can everything that enters it be retained in it. These things as well as those which aro forgotten leave traces in the personal unconscious, so do those things that do not possess sufficient intensity to rise above the threshold of consciousness, such as subliminal sense impressions, and impressions of ideas not yet ready for consciousness. The under-expressed elements of the psyche are here. Finally, the most notable contents of the personal unconscious are the repressed materials which are incompatible with the conscious personality. These elements have a painful emotional tone and are more or less deliberately pushed out of consciousness. The repression of painful contents begins very early, as we shall see subsequently from examples. In this view the personal unconscious is regarded as the acquisition of the individual's life, and is differentiated from the impersonal unconscious which is a historic inheritance.

In/ the earliest weeks of life the young infant is very subconscious. Its reactions are almost exclusively instinctive. It reaches out for satisfactions in every direction open to it. It is dominated mainly by its nutritive function, and its first great relinquishment in life occurs at the weaning stage; over this process a certain amount of repression must occur, especially in sensitive subjects in whom nervous reactions are evinced that are typical of subsequent ones. The earliest neurotic tendencies can be observed in relation to feeding, and the first evidence of dreams is seen in the infant who sucks an imaginary breast in sleep. The training of the

1 "Psychological Foundations of Belief in Spirits." Jung. Proceedings of the Society for Psychical Research, May, 1920. 
young child consists in a manner in dragging him out of his unconsciousness, and tearing his energy loose from his instinctive processes. Scarcely has he arrived at any personal satisfaction, such as being suckled, than he has to give it up, and learn to feed himself, an unconscious instinctive process being exchanged for one that is conscious and full of difficulties. No sooner does he delight to crawl on all fours than he has to change this safe posture for the perils of walking. Throughout many months a considerable degree of effort is expended in gaining control of the excretory functions, and a considerable amount of infantile thinking centres round his body. His outward behaviour to the aforementioned functions is a sort of criterion of his social advancement, and education is necessarily fraught with the renunciation of many a darling wish. On a primitive stage thought and feeling are very physical or sensational. The actions of the bladder and bowels are mysterious and partly pleasurable acts, and of a peculiarly personal character. Acts of creation they seem to the child. His excretions are interesting matters, which stimulate psychic images into existence. The thinking in the infantile period has none of the abstract qualities of later life, but is by "representation"; by means of it the child passes on to apprehend the next thing in life, by analogy, as his primitive forefathers did. Hence it is that in later years images or phantasies connected with the bodily functions can easily be reanimated by the regressive thinking in dreams, or in the hallucinations of those who have lost their mental balance.

Nutritive and excretory functions play a rôle in the sexual phantasies of children when they are thinking round the very natural and perplexing question, "Where does the baby come from?" That this question is of sufficient importance, when accompanied by the repression of an emotional strain, to lead to neurotic fear is shown in the analysis of a child reported by Dr. Jung.

The subject is a four-year-old girl, the even tenor of whose life had been disturbed by the birth of a baby brother. 
Little Anna was instinctively jealous of the new arrival. She imagined herself neglected on account of a real or apparent loss of attention which now had to be shared with another. She felt herself deceived by her parents on account of the theories of birth she had gathered. The earthquake in Messina had recently happened, and she heard it talked about at table. She asked endless questions about it in a most wearisome manner, and developed a precocious desire for learning. This eager desire for knowledge was transferred from the real object of curiosity (viz. the baby's arrival) to a surrogate object, viz. the earthquake. She began to call out at night, and by her nocturnal terrors secured for herself a degree of tenderness and attention she had not needed since the first year of her life. This regression from a four-year-old adaptation to an earlier and more infantile one is an unconscious mechanism which analytical work makes familiar to us. It is caused by a longing to escape from the new demands of life by an easier path. Anna had not gone far in childhood before she wanted to be an infant again, and creep once more into her mother's arms, now so often occupied by her supposed rival, about whose advent there was such a mystery. The night terrors constituted the neurotic symptom which aimed at bringing about the fulfilment of an unconscious wish. The introverted libido now seized upon the most convenient object of curiosity and fear, viz. the earthquake. This offered a rationalisation both for curiosity and the "dispossessed" love; day-dreams and brooding supervened, in which the introverted libido became occupied with typical infantile sexual phantasies. Phantastic ideas of the origin of the baby now succeeded one another. Such as birth from the breast, mouth, or rectum. After some weeks, Anna, with the aid of her parents, found a working solution to her question. Her curiosity led to the acquisition of some serviceable ideas with which she was able to get along, and the neurosis disappeared. 1

1 One of Anna's phantasies ran as follows: "I am going to take an orange and swallow it down into my stomach and then II shall get a baby." This is a very transparent wish-fulfilling phantasy. The following dream 
The origin of the unconscious mind is still under discussion. Freud attributes it entirely to repression, a view with which the foregoing brief account does not coincide. Whatever theories the different schools may hold about its origin, there is no doubt about its existence, nor about its extreme importance on account of its dynamic nature. It provides the motive power in life.

To sum up in a rather different form, we may say the unconscious mind contains all that mental life of which we are unaware at a given moment. All we have ever known or thought, or felt, or perceived, or dreamed, leaves some traces in the unconscious mind. All that we have discarded as being no longer valuable, or that has such slight associations with the rest of life that we never fully assimilated it into consciousness still exist in the psyche, and under suitable conditions a personal memory of them may be revived. These elements have at one time been conscious, and can again become so, as the result of more or less effort. Other elements have at one time been conscious, but have been definitely pushed out of consciousness, although the individual may be unaware of the fact, because they were too painful to be tolerated. Other contents have never yet reached consciousness at all, although hypothetically they are capable of doing so. Some of these would serve no useful purpose by becoming conscious, but are survivals of an earlier stage of human derelopment, where they once fulfilled some useful

which occurred in a married woman of forty, mother of four children, deals with the same idea though much more thoroughly veiled in accordance with the greater age of the dreamer. "I had my head out of the window and was looking at a little girl sitting on the doorstep below. She was eating a banana. Two rough-looking men came down the street. I felt I must pull my head in so that I might not see what happened. Presently tho little girl came up to my room; she had been outraged." This dream is founded on an infantile theory that the eating of fruit leads to impregnation. The rough men stood for the father and husband of the dreamor. Pulling in the head represented her resistance against the real facts which seemed like an outrage against the infantile personality, viz. the little girl who symbolised her still persistent unconscious wish never to grow up. (Peter-Pan motif.) The father-husband situation gave the key to her present unhappiness which unmistakably arose from dragging the emotional life of her infantile past into her marriage, and expecting to find a father in her husband. 
function. ${ }^{1}$ Other contents are prevented from ever becoming conscious by the strength of the barrier set up between the conscious and the unconscious by our resistances, which may be conventional, or cultural, or moral.

The subliminal material is not unconscious in itself; a certain kind of awareness belongs to it, but this awareness is outside or beneath the ordinary threshold of consciousness. The contents of consciousness vary, so that what is unconscious at one moment may become conscious at another. The repressed contents may rush up, unexpectedly, in disguise, perhaps as some emotion which interferes with our clear thinking or free activities. Unconscious material breaks through into consciousness in various ways, spontaneously or against the will; harmlessly, as in a dream; harmfully, as in a neurosis, or as in an outburst of madness, during which outbreak the man lives in his dream, and hence is incorporated with or identified with the unconscious.

An interesting example of two different ways in which the unconscious mind works is seen in the Babylonian story of Nebuchadnezzar's dream. ${ }^{2}$

The story runs as follows: Nebuchadnezzar obtains a warning from the heavenly powers; he says "a message from a watcher and a holy one came down from heaven"; he "saw a dream, had thoughts in his bed, and visions in his head troubled him." He was warned, as Daniel interpreted the dream to him, that he was as a mighty tree, under which the beasts of the field took shelter, were fed and rested, but that

1 Dr. H. R. Rivers puts forward the view that certain experiences become unconscious for reasons of utility, "If the modes of consciousness connected with those forms of reactions persisted without modification in later life, they could only interfere with the very different and far more complex reactions of the adult. There is a very definite reason why the conscious states connected with infantile reactions should become unconscious. Even in an animal whose life history is as uniform as that of man, the different phases are sufficiently distinct to provide an ample reason why experience should become unconscious. The reason is to be found in the diversity of the different phases of the life history, and the incompatibility of the reactions of one phase with another." Contribution to a Symposium at a Joint Session of the British Psychological Society, Aristotelian Society, and the Mind Association, 1918.

2 Daniel iv. 
having overstepped the limits of his power and over-exalted himself, that unless he cut off his power, and stripped himself of his pride, and scattered his fruits, and left only a remnant of himself, his heart would be changed from a man's to a beast's. Daniel pointed out how he might evade his doom, saying, "Wherefore, $\mathrm{O}$ King, let my counsel be acceptable unto thee, and break off thy sins by righteousness and thine iniquities by showing mercy to the poor: if it may be a lengthening of thy tranquillity."

It was clear that the heart of the king had already gone far on the road to become that of a beast, for in spite of his appreciation of the meaning and value of the dream, and the honour paid to Daniel as "one who was able, and in whom the spirit of the holy gods dwelt," we find him a year later disregarding the interpretation and still ignoring his task of stripping himself of his power and his pride and his riches. He still neglected to show mercy to the poor; objectively the poor people in his kingdom, subjectively the poor and undeveloped parts of his own nature. Hence the doom foretold in the message from his own unconscious, fell suddenly upon him. He became like the beasts of the field, and in his madness he ate grass like the ox, and he was driven forth from men in accordance with the custom of his time, and his body was wet with the dew of heaven. Only after a long time was his reason restored to him, and out of his sufferings he could praise the King of Heaven, who "was able to abase those that walked in pride."

This is a beautiful example of the two ways in which the unconscious works-first, it called attention to the presence of an inner conflict by a dream; next, the warning neglected, it broke through into consciousness and possessed the man; he now in an attack of madness lived in his dream, which formerly he had been able to regard objectively. In the first instance the man had the unconscious, in the second the unconscious had the man!

This story illustrates another point of importance. Freud showed that the dream contains a manifest and a latent content. The manifest content is that part of the dream which 
is remembered on waking, which is generally a remnant of something much more extensive. It cannot be interpreted, however, until we have obtained information about the latent content. It must not be imagined psycho-analysts arrive at their interpretations as easily as Daniel appears to have done; there are intervening steps of fundamental importance which Daniel's intuition may have allowed him to overleap, or which more probably are left out of the Bible narrative. Dream analysis is not guesswork-it is a technique; it follows laws. Only on unearthing the latent content, by following the free associations of the dreamer and bringing them into intelligible juxtaposition, can we arrive at the meaning of the dream. The latent content represents the antecedents of the dream, and the thoughts connected with it, which unlike the manifest content are logical and have a significant bearing upon the patient's life. Our material is somewhat like the mixed pieces of a jig-saw puzzle; we sort, we fit, we make trial, we reject piece after piece, until slowly and laboriously the parts are arranged, and we have the complete picture. This is a work requiring great pationce and observation. There is no magic about the process, though the effect may appear magical, on account of the insight given into the problems of human psychology.

Night dreaming is not the only form of dreaming. Day dreaming is of equal, if not greater, importance. This is "undirected thinking." The dreamer builds phantastic palaces and, directly or indirectly, is the hero of his romance, wise, witty, or wicked, according to his wishes. The psychic energy (libido) flows along the line of least resistance, the direction being determined by the subconscious wishes of the moment, in a stream of images connected with one another by mere association. Jung says:1 "We have two forms of thinking, directed thinking and dream or phantasy thinking. The first, working for communication with speech elements, is troublesome and exhausting; the latter, on the contrary, goes on without trouble, working spontaneously, so to speak, with memories. The first creates innovations, adaptations,

2 "The Psychology of the Unconscious," chap. i. 
imitates reality and seeks to act upon it. The latter, on the contrary, turns away from reality, and sets free subjective wishes."

The alluring part of such mental activity is that it fulfils the heart's desire with an ease that makes the dull facts of lifo seem very tedious. Herein lies its peril; it absorbs the libido and divides the attention, and distracts from the tasks of the moment. It brings about evasion of real thinking and intellectual work which would involve effort and perhaps bring about a modification of conduct. Sometimes the day dreaming takes a precise form, making a more or less finished picture, which we call a phantasy, which rises from the unconscious and is super-imposed upon the conscious thinking.

It must not be thought that phantasy is always mischievous. Far from it, it serves very useful purposes. In due proportion it is a refreshment to the mind. It is also a means of understanding and interpreting the universe. In primitive times man always explained what he could not understand by making phantasies or myths about phenomena. We could have no better example of this than the story of Creation in Genesis. The explanation is a projection of man's own psychological understanding; ; it is his interpretation of the facts, which served a valuable purpose at that stage of his development. It delivered him from fear, and led him on in his spiritual development through law towards grace. "The antique spirit created not science but mythology." 1 When, centuries later, scientists disclosed the work of creation in the rocks and stones, and learned of the age-long evolution of the earth and its inhabitants, those who could not give up the literal interpretation of these once useful myths in exchange for the new truths, were forced back into regressive paths.

This conflict between old and new ideas is described in a book I shall have occasion to quote several times in this paper, viz. "Father and Son." 2 This book illustrates other

1 "Psychology of the Unconscious."

" "Father and Son: A Study of Two Temperaments." By Edmund Gosse. Heinemann. 
things besides the differences of interpretation and understanding that arose in two generations. The elder Gosse, who was a naturalist of repute, was confronted with the facts of evolution. These clashed with the beliefs consequent upon his theological standpoint. Unable to effect a reconciliation in his mind between the two, he sacrificed his scientific intellect. The mind that refuses to entertain or weigh a new truth because the path is difficult and obscure, and even dangerous, tends to become fixed and unconsciously infantile. The father was outstripped by the son. The tragedy does not lie in the forward push of the son, nor in the backward move of the father; it lies in the fact that the ties of love and obedience on the part of the child, and the weight of parental authority, can prevent the liberation of thought and action that should belong to progressive life.

We are recalled to our subject of the unconscious mind by a dream of the younger Gosse. It was a recurring dream of his childhood, in which, "bound hand and foot, helpless and terrified, he was carried on a galloping steed, always making for a goal "; he could just see that goal, a ruby coloured point waxing and waning, and it bore, or, to be exact, consisted of the letters of the word " carmine." This vision caused him inexpressible distress, but later on he says: "The fact that the word 'carmine' appeared as the goal of my visionary pursuits is not so inexplicable as it may seem. My father was at this time producing numerous water-colour drawings. ... These he executed in the manner of a miniature with amazing fidelity of form, and a brilliancy of colour which remains unfaded after fifty years. By far the most castly of his pigments was the intense crimson which is manufactured out of the very spirit and essence of cochineal. I had lately become an imitator of his works of art, but was strictly forbidden to let a hair of my paint brush touch the little broken mass of carmine which was all he possessed. We believed, but I do not know whether this could be a fact, that carmine of this superlative quality was sold at a guinea a cake. Carmine, therefore, became my shibboleth of self-indulgence; it was a symbol 
of all that taste and art and wealth could combine to produce."

He then relates a phantasy. He says, "I imagined that at Belshazzar's feast the loftiest épergne of gold, surrounded by flowers and jewels, carried the monarch's proudest possession, a cake of carmine."

From the interpretive standpoint, carmine (which has a phallic significance here) symbolised the glory and power of bis father, with whom he identified himself. The ill-health and hysteria from which the little lad suffered were evidences that a severe mental conflict was going on. His roving intellect and perfectly natural interests attracted him to the world which had been condemned in an unqualified way by his father. While he strove to be obedient, his psychic energy was largely deroted to his unconscious phantasies, and appeared in these terrifying dreams. His mental sufferings and struggle for his own individuality in later years showed the severity of his unconscious conflict, the longing to live like other boys, battled with his desire to please his dominating father with whose love and opinions one side of him wished to remain identified.

From the standpoint of analytical psychology we have learnt that neurotic symptoms prove the existence of an unconscious conflict. There is a disturbance of the energising force in the psyche. The libido that should be applied to life (as in the foregoing case of little Anna) introverts and lights up the phantasies. This libido or psychic energy is conceived by Jung ${ }^{1}$ as a hypothetical force which operates in the psyche. It is analogous to physical energy in the physical world. A definite amount can be applied here or there. A violent disturbance in one place implies a diminished effect elsewhere. This psychic energy is operative in the conscious and in the unconscious part of the mind. At night in sleep it is mainly with the unconscious, as the dream demonstrates. By day it is, or should be, mostly with consciousness. A misapplication of this energy produces a splitting or thinning of the stream of attention, and a weakening

2 "The Theory of Psycho-Analysis." Nerrous Mental Diseases Monograph Series, No. 19. 
of the moral power of the individual. Such a thinning of the stream of attention naturally tends to make a child difficult to teach, and to interfere with his memory, his prompt obedience, and his reliability generally. He is not "on the spot," which means that a part of him is on another spot.

Absent-minded acts are symptomatic of repressed emotion and interest. ${ }^{1}$ Such lapses always have their origin in the subconsciousness. This is also true of much forgetting. It is caused by a resistance or emotional opposition to something not clearly realised. The emotion is misplaced or transferred to some associated object. For example, a child forgets to bring his smudgy exercise book to class, and when he has incurred his teacher's rebuke he pinches or quarrels with his sister by way of getting rid of his own hurt feelings. Discipline and respect prevent his venting them on his teacher. Here the psychic energy is not applied at the point of stimulus; it is a back-wash, so to speak, the result of an obstacle on the path, but at some distance from the commotion.

The attacks of lying that are so common in childhood have a meaning which can better be understood when one realises that the psychic energy thus displayed serves some purpose in the child's mind. Such attacks may arise from an overvivid phantasy wherein the dream life is so real that distinctions are not clearly drawn between fact and idea; here the child is mixed between what is objective and subjective. Or they may be a device to aggrandise the self ; this kind often occurs with depreciated children. A little girl of eight recently returned home from a walk in the Park declaring she had met Mr. A., a person in whom her elder sisters were interested. The lie had no other purpose than to call her sisters' attention to herself, and so relieve her self-depreciation. This, though undoubtedly a deceit, has a very different origin from lies told for purposes of concealment. Some children would rather be naughty and receive punishment than be ignored.

Children often tell lies from the unconscious impulse to 1 "Psychopathology of Everyday Life." Freud. 
take revenge on the powers that be. Two little girls were at their mother's garden party. The Bishop's wife noticed them and asked them their names. To their parents' annoyance the elder answered "Sodom," and the younger instantly climed in, "And mine's Gomollah !"

One child will exert power over another by means of the phantasy he invents and imposes. It appears that Sodom used to terrorise "Gomollah" by such a phantasy. She was a timid, podgy child, "as fat as a pig, therefore she must indeed be a little pig, taken from the sty and adopted as an experiment." Whenever she was tiresome in the manner of younger sisters, Sodom threatened her with a return to the pigsty - it was the proper place of punishment for fat and naughty babies. No one at that time knew why Gomollah always shrieked whenever she accompanied the grown-up members of the family on their Sunday visit to the pigs, nor why a sudden wink of Sodom's would always reduce her to instant submission. If in later life a patient in an asylum calls herself Gomollah, and makes noises like a pig; or if some nervous ailment supervenes in which she gets an attack of asthma whenever she sees a pig even in the distance, one may fail to find the links. They will certainly not be in the conscious mind, and could only operate where the emotional content was heaped up and fed from other sources.

When we seek to investigate the unconscious mind of the child our methods must necessarily differ considerably from those we employ with adults. This is partly because the child is so much nearer the unconscious. If we can catch "the growing boy" before the "shades of the prison house" deepen too grimly, our task is relatively easy.. As yet his conscious and unconscious are little differentiated. Repression and the abundance of experience and objective thinking have not yet resulted in a wide separation between the two spheres of the mind, so that the unconscious content passes readily over into consciousness.

It is useless to ask a child a direct question about things of importance to himself. He early learns to evade the questions of his elders, and here his attitude is like that of 
primitive man. M. Willmoes D'Obri, who has lived long in the Belgian Congo, recently told me that no native of those parts will give a direct and true answer to a stranger. One day earlier in his sojourn in the Congo he was sitting with a primitive by a camp fire. The native suddenly picked up a stone and threw it. M. D'Obri did the same, remarking, " $\mathrm{Oh}$, do you do that too?" The native, however, was not to be entrapped so easily into giving his confidence, and only long afterwards did the questioner learn that the stone was flung at the eyes of the dead who haunt camp fires.

He told of a certain well-known ethnologist of European fame, who was making researches in folk-lore. One night M. D'Obri heard a great palaver going on in the village, and asked his servant the meaning of it. The reply was that the chiefs and the young men were making up stories to tell "the Old Sheep," which was the nickname of the learned traveller, who wore his hair rather long. How many travellers have been misled in this way; they sometimes hear the phantasies rather than the histories of the peoples. Such material has a psychological value, but not of the kind desired. Who has not fallen a victim to similar plots on the part of the youngsters? The ethnologist here fails to enter into the mind of the primitive and so gain his complete confidence, just as the grown-up person fails to enter into the mind of the child.

We may again refer to "Father and Son" to confirm this view. Gosse says: "The discretion of little boys is extraordinary. ... I had grown cautious about making confidences-one never knew how awkwardly they might develop, or to what disturbing excess of zeal (on the part of my father) they might precipitously lead. I was on my guard against my father, who was only too openly yearning that $I$ should approach him for help and comfort, for ghostly counsel." This motherless little boy had night terrors and terrible dreams. His father sought to exorcise by prayer what he regarded from his antique standpoint as the devil. He would pray at his bedside, the child striving hard to keep awake. "One unhappy night," he writes, "I gave even worse offence 
than slumber would have given. My father was praying aloud, in the attitude I have described, and I was half sitting, half lying in bed, with the clothes sloping from my chin. Suddenly a rather large insect, dark and flat, with more legs than a self-respecting insect ought to need, appeared at the bottom of the counterpane, and slowly advanced. I think it was nothing worse than a beetle. It walked successfully past my father's sleek black ball of a head, and climbed straight up at me, nearer, nearer, till it seemed all a twinkle of horns and joints. I bore it in silent fascination till it almost tickled my chin, and then I screamed 'Papa! papa!' My father rose in great dudgeon, removed the insect (what were insects to him!), and then gave me a tremendous lecture.

"The sense of desperation which this incident produced I shall not easily forget. Life seemed really to be very harassing when to visions within and beetles without there was joined the consciousness of having grievously offended God by an act of disrespect. It is difficult for me to justify to myself the violent jobation which my father gave me in consequence of my scream, except by attributing to him something of the human weakness of vanity. I cannot help thinking he liked to hear himself speak to God in the presence of an admiring listener. He prayed with fervour, in pure Johnsonian English, and I hope I am not undutiful if I add my impression that he was not displeased with the sound of his own devotions. My cry for help had needlessly, as he thought, broken in upon this holy and seemly performance. 'You, the child of a naturalist,' he remarked in awesome tones, "you to pretend to feel terror at the advance of an insect?' It could but be a pretext, he declared, for avoiding the testimony of faith in prayer. 'If your heart were fixed, if it panted after the Lord, it would take more than the movements of a beetle to make you disturb oral supplication at His footstool. Beware! for God is a jealous God, and He consumes them in wrath who make a noise like a dog." "

This example belongs to a phase of life and faith that has passed away; the exact form of this tragedy is not likely to be repeated. But dominating adults make it difficult for 


\section{THE UNCONSCIOUS MIND IN THE CHILD 31}

children to be natural. The following notes show how easy it is to read children if we have the clue, but how energetically they build up defences against being understood.

Freddy is a boy of eight, undersized, with thick curly hair, a pasty complexion and a furtive expression. He is extremely intelligent. He was brought to me because he was constantly giving trouble at school with thieving and lying. He had a curious power over the other children.

One day he started with his teachers and schoolfellows on a railway journey with a halfpenny in his pocket, and a copy of Comic Cuts in his hand. He ended his journey in possession of elevenpence. He had sold halfpenny peeps at Comic Cuts to his companions and so accumulated all their wealth.

On another occasion he possessed one farthing; another little boy brought some toy wax candles to school. Freddy bought them from him, but there were no matches with which to light them. He promptly suggested that this other boy should spend his farthing in lights, which he submissively did. Thus the farthing bought all, and yet justice was not infringed ! From these stories it will be seen that the boy is clever and resourceful; he would naturally overpower the lesser intelligences around him. He is the child of a mésalliance. His mother, a pretentious woman deserted by his father, works in a large retail business house in London. The father is said to be a rich American. It is certain that there had been times of comparative affluence in the child's life; these coloured all his phantasy.

One of his recent delinquencies had been a theft of paint brushes. I was anxious not to question the child directly about this until he gave me some reason for doing so. For this purpose, and in order to get at other points in his psychology, I made use of the word-association test. ${ }^{1}$ The words used in this test act to a certain extent like the thing they symbolise. I had, in addition to the use of this scientific test, an aid from the child's unconscious, in a symptomatic act. Whenever he was disturbed in his mind by emotions

1 For particulars of this test, cf. Chapter I. 
connected with the words called out to him he would give himself away by the utterance of a little clucking sound.

In arranging the words for the test, I strung together such as would have a cumulative effect upon the emotions. The result was very striking. When the word "paint-brush" was reached he betrayed his agitation by a cluck, which developed into a series as the succeeding words were given. The reaction time was markedly retarded. The child suddenly became suspicious of me, and was determined to outwit me. He hit upon a device I have never seen so obviously manifested before or since. Following a series of words which struck a guilty affect I gave hin the word "cannon." Thereupon he made a tactical move and associated most of the subsequent words with this one. In response to my stimulus word, to which he scarcely listened, he shot out rapidly a succession of words like Zeppelin, aeroplane, blue, airship, gun, camp, khaki, etc. This deliberate attempt to conceal himself, of course, really had the effect of showing his anxiety; moreover, he could not reproduce the words correctly. The value of this test has been proved in countless cases, otherwise to quote it in an isolated instance would be unjustifiable; but this example shows how impossible it is to keep the emotional content of the mind in abeyance under the circumstances of the test. One can easily see that it would have been useless to ask Freddy direct questions as to why he did and said such and such things; he would have been on the defensive at once.

One day he was asked to sing his favourite song. He chose "Jesus loves me." When asked who Jesus was, he said, "He is a nice, kind man like my daddy."

I got him to talk to me about his favourite story, and asked him to make a drawing to illustrate it. The favourite story proved to be one of Hans Andersen's, called "The Little Matchgirl." This is a pathetic tale of privation, in which the little girl strikes match after match, seeing beautiful, wishfulfilling visions each time, and finally falls dead in the snow, the victim of cold and exposure.

This is the story Freddy was supposed to illustrate, and it was interesting to see the picture he produced. In the 
forefront was the matchgirl, carrying a plentiful supply of match boxes; she had very masculine features and an air of grim determination. Behind her stood an elegant gentleman in a top hat and long overcoat, with beautiful boots and an umbrella! When I asked him to explain the story, he said in his curt little way: "She finds a man she likes; he goes and marries her, and they go to a restaurant to have dinner - a beautiful place, all lights and things." He added later that this man was a rich American.

Now, here we have a curious and informing thing. The boy had heard the story of "The Little Matchgirl" only that very day, and yet a few hours later, when asked to draw it and tell the story, he has added to it a fresh creation of his own phantasy, quite different from the original story, and as completely wish-fulfilling as the visions of the little heroine. How comes this about? Does it give us any insight into his psychology? To the trained analyst this added phantasy, which is the product of the child's unconscious mind, is of utmost importance. It indicates points of special interest, and where a deviation is made from the story, particularly precious unconscious wishes are expressed.

In this recital Freddy has shown that he identifies himself with the matchgirl. In the story she is taken to heaven. This is not the kind of happiness Freddy wants. But he, too, desires to be delivered from privations and strike bright lights and see beautiful visions. $\mathrm{He}$ lives with his mother, who works for her bread; he is her sole companion in their one room. His memories of greater comfort and evanescent splendour are connected with a glorious, half-mythical father, and all the tales of wonder his mother tells him are of a rich American who for a brief spell delivered them from dullness and hardship. His mother's phantasies and experiences become his own by adoption, and through the medium of the little matchgirl he identifies himsclf with his mother, and is thus rescued by the man of the picture.

Now, it is a fact verified by thousands of dream analyses, that the dreamer appears in various guises in the dream. He can play both the male and female rôle. Our little boy also is 
here present as the dashing and powerful father, who can transport him to happiness, all by the simple magic of marriage.

Here is a modernised fairy prince who becomes the husband and deliverer of the mother-matchgirl-a fond wish of his childish heart. His phantasy represents his compelling attach. ment to the mother and shows him in the rôle of the powerfuı father, a rôle which turns up again and again in his dominating attitude to his school companions. His financial operations, we must admit, have an American flavour also, in which he makes his corners in Comic Cuts and candles. This story illustrates the undue spiritual and mental bondage of the child which acts ambivalently in the direction of either parent. The phantasy which represents this bondage acts emotionally like a predisposition or prejudice. Freddy's conduct shows trends which belong to this unconscious attitude.

The circumstances of the boy's life were such as threw him into too exclusive a relationship with the mother. Already in his unconscious he was so bound to her as to weaken the ordinary influences of school and education. A stronger power than his teachers' held him, and one which they were not in a position to combat. With more happily-placed children, life itself tends to break up these too close bonds, but here all the external circumstances reinforce the influences that are going on in the unconscious.

This child was naturally imaginative, and the circumstances of his life as well as his psychological bias led him to heap phantasy upon his mother, thus increasing her power over him.

The way in which such an unconscious bondage does sometimes influence a life recently came under my notice in the case of a young man, who was sensitive, imaginative, and clever, and very devoted to his home. He was sent to a preparatory school, where he contracted all sorts of illnesses, infectious and otherwise, and was constantly being sent home to be nursed, or having a term off. Later he went to a public school, and six weeks turned him into an invalid, so that he was pronounced unfit for school life. He was next taught by 
tutors at home, and later went to the university, where after a few weeks he broke down, and had to be sent home as a "case of nerves." He was able to take his degree subsequently, and does his mental work passably well while living at home, but he is not able to take up any career that takes him away from home.

The key to a child's inability to work well, or to fulfil the ordinary requirements of a healthy schoolboy, is often to be found in his home life; and when this is the ease, it is in that direction that the fundamental changes should be made.

My next case is that of a little girl of thirteen. She is brought to me on account of nervousness. She has a morbid fear of wasps, she cannot leave her parents' care, and is a great tax upon them. This fear of wasps keeps her much at home in the summer, interferes with the opening of windows, and with the family holiday, etc. She is somewhat precocious in her physical development, unusually mature-looking for her age. She is distressed at all the signs which assure her she is growing up, and though she is perfectly well, she insists periodically that her mother should wash her and treat her as if she were a young child again.

We had many talks, and sometimes we analysed dreams. She often dreamed of Zeppelins. She was very frightened of them; particularly so, because her father was a special constable, and when they came he had to leave home. One day, we discussed her favourite story, which was Hans Andersen's "Little Mermaid." In this tale the little mermaid makes a great sacrifice in order to become a mortal and experience human love; however, she finally renounces her human lover in order to follow the higher spiritual developments of her nature. The choice of this as the favourite story is not without its significance for Phyllis, as you will see.

Another day she brought her doll to me. This is a huge doll, the size of a child of a year old. The interesting point was that Phyllis had only recently taken to playing with dolls. She used to be a great bookworm, but lately had developed a perfect passion for this doll, spending hours making its clothes and talking to it. In her talks she would 
assume the rôle of mother, nurse, father, teacher, etc., and answered for the doll in a special voice like a ventriloquist. Her talks were clever and amusing. The mother rather encouraged this pastime as taking Phyllis away from her books, and leading her to the useful arts of sewing and laundering.

This playing with a doll was incompatible with her intellectual development, for not only was she clever, but she was a beautifully-grown girl of thirteen, tall and rosy, although she had an abrupt and suspicious manner, and an aggressive way of speaking. With her relatives she was positive and dictatorial, and rough in her demonstrations of affection. She was, however, a delight to her teachers on account of her mental ability, though somewhat of a disappointment because of the inequality of her work. Her intellectual was far in advance of her emotional development, hence she cut a better figure at school than at home.

Amongst material that came up for analysis was a little poem she had written some months earlier. The choice of the subject of the poem is again of great significance, showing the problem with which the phantasy from her unconscious is engaged.

The incidents she selected for her story were as follows. Apollo had offended Cupid, who in revenge struck him with a golden arrow, while he planted a leaden one in Daphne's breast. This made the god love without return. He pursued Daphne, who fled from him until her strength seemed about to fail. She called loudly for her father's help, who came to her rescue and turned her into a laurel tree before which the rejected god could only deplore his loss.

The unconscious problem in this child's mind is one that is typical for the age of puberty. It is the coming of love. She -does not want to grow up. (Peter Pan motif.) The adaptations demanded by the love life begin to be apprehended ahead by the unconscious, involving as they do the acceptance of sexuality, not only its outer manifestations but its inner impulses.

Children who are neurotic, that is extra sensitive, often develop nervous symptoms at puberty just because this is a 
stage when a great many new adjustments are required. The childish dependence must be given up, if the human being would fit himself or herself for maturity. Here the child is at a point where the emotional life must be developed, since in this case it is behind the intellectual life. This demand for new adjustments presents itself as an obstacle; this is the spark which causes the conflagration already prepared for in the subconscious. Afraid of the task, which is only unconsciously realised, she turns back to a childish attitude. Instead of going on and learning to develop and express differently her love for her mother, her teachers, and her friends, and to take up new human relationships, she takes a leap backwards and, by means of her phobia, once more'establishes herself as a little sheltered child, whose appropriate home is in the arms of her mother. What Phyllis would tell you is that she wants above all things to grow up and marry and have children of her own and keep a school, and so on. Her unconscious has other wishes, however : it wants to remain irresponsible and be always in the parents' charge. The sensitiveness of the subject is so great, and the unconscious conflict is so severe that a phobia, which is a symbol formation, breaks through into consciousness. The onset of menstruation is the determining factor of the neurosis. The symbol is a fear of wasps: "they are such wicked things when they put out their stings." The effects of the fear are sufficiently severe to cause grave anxiety to the parents, who are forced in this way to pay a special amount of attention to the child. Here we have to recognise the same springs of conduct that animated little Anna's night terrors.

To verify our conclusions we have only to look a little deeper into the meaning of the dreams and phantasies. The favourite story depicts in the guise of "The Little Mermaid " a heroine who loves an impossible prince, and is therefore unable to marry, and escapes the practical and difficult experience of human love by following her spiritual aims.

The poem about Apollo and Daphne tells of a nymph who, when pursued by the great god Apollo as a lover, flies him, and seeking the protection of the father continues her existence in the vegetative form, thus becoming fixed in a certain stage of 
her development. Phyllis's choice of a doll as a plaything, at a time long separated from her real interest in such toys, is brought about by the heaping up of her psychic energy, which, unable to go forward to fill the new channels of duty and selfdependence, flows back into old paths, and reanimates interests which now are better forgone.

The value of psychological analysis shows itself in a case like this. It is not possible for such an intelligent child to understand the situation without wishing to alter it. No amount of argument solves a case like this, but the material of the unconscious is self-convincing when it is analytically interpreted.

It must be noted that the analytical $u$ ork is on the unconscious mind. Many misunderstandings of the method arise here, because this is not sufficiently understood. Sympathetic insight into and handling of a child's troubles is not analytical psychology, though it often works so well and efficiently that no further treatment is needed. Psycho-analysis comes in just when this fails, because it is a technique for reaching what is unconscious or subconscious in the mind, and that by a special and difficult method which only a fully-trained analyst can pursue. I have seen it stated that " the chief requisites for psycho-analysis are a thorough knowledge of psychology, great patience, and a sympathetic attitude." These are indeed important, but one indispensable requisite is omitted, that is, that the analyst must have a thorough knowledge of his own unconscious mind; hence no one is competent to undertake the psychological analysis of a child who has not first submitted himself to a searching analysis. Unless he knows and allows for his own complexes and tendencies he will inevitably project some of his own unredeemed infantile views on to the child. Moreover, he must delve into the infantile processes in his own unconscious to be able to interpret what he finds in the precious but delicate little mind.under review. It is as if an oculist who was unaware of the degree of short sight that belonged to his own vision should prescribe glasses for a patient. In such a case he would be in danger of adding his own error of vision to that of his patient.

As yet, psycho-analysis has been but seldom applied directly 
to children, that is, in the sense in which $I$ speak, as a technique for the understanding of the unconscious.

There are reasons for this. It results in a kind of reeducation. Parents and teachers are not very willing to believe that the little child to whom they have given so much love and care needs re-education so early, and they often think, and naturally, that the doctor is the last person to undertake this. Parents and teachers should perhaps be the best psychoanalysts, but the one essential condition is lacking, they have not themselves been analysed. Hence they still carry, unknown to themselves, marked effects of their own infantile mind, and this operates all unconsciously to prevent a fair and detached attitude. The book, "Father and Son," is full of instances showing how a deeply-loving but strangely deluded parent and a docile and devoted son may react disastrously upon one another, not only on account of clash of temperaments, bu also on account of what is really unknown in the situation.

There are two extreme types of parents and teachers-those who avoid the obvious errors of their own upbringing by falling into the opposite ones; and those who hold by everything that has gone to make them, under the impression of the excellence of the results achieved. An extreme attitude is to be avoided. The solution of the immediate problem is not in the mind of the parent or teacher ; it is to be found in the mind of the child. A fundamental axiom in analytical psychology is: Follow the mind of the child; let it direct the path of the conscious endeavour. The child's dreams and phantasies give a clue to his behaviour, and afford a hint as to the right line of his future endeavour. Often they hit the mark in a plain and direct manner, and clear up puzzles which are otherwise insoluble. I have an idea of the way in which what is valuable in psycho-analysis will reach the child, and that is through the teacher. I entertain a phantasy of $\mathrm{my}$ own, that in no very distant future parents and teachers will themselves seek to be analysed, not because they are ill or neurotic, but because they desire to take into account, in a practical and understanding way, the subconscious mind of their children and pupils which hitherto has had far too little attention. 


\section{III}

\section{FEAR IN THE CHILD AND THE AUTHORITY COMPLEX ${ }^{1}$}

There are two demons that haunt the life of the typical child. They are not very obvious at first sight, because they belong to the unconscious processes of the mind, they depend in a very large degree upon the child's phantasies. They are Fear, and a Sense of Inferiority.

I speak of the typical child in a typical environment. We may leave for the moment all consideration of the abnormal child, or child with an abnormal environment, because my aim is to prove if possible that the most ordinary individual is liable to be hag-ridden, and almost certain to be hampered in development by the above-mentioned demons.

Fear itself has two functions. It either warns and teaches foresight, or else it paralyses and produces panic. Normal fear is up to a point a serviceable teacher, for the child is in the presence of a Universe to whose laws he must learn to submit. If he does not fear the fire, it will burn him; let him therefore experience the fire, within limits, so that he may adapt himself to its prohibitions.

Fear of disaster promotes wise caution. We do not launch our new inventions regardless of risk, but only when we believe all the dangerous possibilities have been taken into consideration. In spite of our care, some of the gravest dangers are those which are not, and possibly cannot, be foreseen, for new conditions bring into experience natural laws which have not as yet been reckoned with.

It is our aim in the training of children to save them from needless or useless fear. 'There are things we cannot control,

1 Lecture delivered at tho Summer School of Civics and Eugenics, Cambridge, 1919. 
such as thunderstorms, absence of loved ones, birth and death, accident, illnesses, growth, development, and old age. With our best endeavours to soften the asperity of life for children, there still remain endless sources of fear, since humanity is heir to all those of a universal and collective character.

For the child each unknown event as it comes along is a source either of curiosity or suspicion, of attraction or repulsion. The inner or psychical life of which we take so little direct heed, has at least as great a validity as that of the material world. We cannot even begin to study the question of fear without having to convince ourselves of the extreme importance of the inner life, and we must look to the mind of the child to find the source of the most alarming of his distresses. The reaction of fear is often quite out of proportion to the object of fear. The emotional tone belongs to the phentasy that merges with the object, and is a contribution from the child's unconscious mind. It belongs to the myth he weaves round his experience. The exercise of phantasy has a beneficial as well as a harmful side. We must not lose sight of this while we lay stress on the other side, namely, the relation between fear and phantasy. By means of phantasy bridges are built from the known to the unknown. It is the function which operates normally between the conscious and unconscious sides of the mind. In the effort to understand life, subconscious images which have lain dormant in the primordial mind-stuff spring into existence. The child projects these images and their combinations on to the objects of his environment. Before he is aware he has become a devoted slave to his own imaginings, nor does he foresee that some of these which have a merely transitory meaning, will become crystallised into morbid forms which may haunt his path for years, it may even be throughout life.

In this connection autobiographical records are of great value, and I should like to quote those of Edmund Gosse. ${ }^{1}$ His childhood was extraordinarily repressed on its emotional side, and much over-stimulated on its mental side. Writing of his sixth year he says: "Being so restricted, and yet

1 "Father and Son." Edmund Gosse. Heinemann. 
so active, my mind took refuge in an infantile species of natural magic. This contended with the definite ideas of religion which $\mathrm{my}$ parents were continuing, with too mechanical a persistency, to force into my nature, and it ran parallel with them. I formed strange superstitions, which I can only render intelligible by naming some concrete examples. I persuaded myself that if I could only discover the proper words to say, or the proper passes to make, I could induce the gorgeous birds and butterflies in my father's illustrated manuals to come to life, and fly out of the book, leaving holes behind them.... During morning prayers, which were extremely lengthy and fatiguing, I fancied that one of $\mathrm{my}$ two selves could flit up, and sit clinging to the cornice, and look down on my other self and the rest of us, if I could only find the key. I laboured for hours in search of these formulas, thinking to compass my ends by means absolutely irrational. For example, I was convinced if I could only count consecutive numbers long enough, without losing one, I should suddenly, on reaching some far-distant figure, find myself in possession of the great secret. I feel quite sure that nothing external suggested these ideas of magic, and I think it probable that they approaclied the ideas of savages at a very early stage of development. ${ }^{1}$

"All this ferment was completely unobserved by my parents. But when I formed the belief that it was necessary, for the success of my practical magic, that I should hurt myself, and when, as a matter of fact, I began in extreme secrecy, to run pins into my flesh and bang my joints with books, no one will be surprised to hear that my mother's attention was drawn to the fact that I was looking 'delicate.' ... As I became very pale and nervous and slept badly at nights, with visions and loud screams in my sleep, I was taken to a physician who stripped me and tapped me all over (this gave me some valuable hints for my magical practices), but could find nothing the matter. . . . It culminated in a sort of fit of hysterics when I lost all self-control, and sobbed with tears, and banged my head on the table. While this was proceeding,

1 The italics are mine. 
I was conscious of that dual individuality of which I have already spoken, since while one part of me gave way, and could not resist, the other part in some extraordinary sense seemed standing aloof, much impressed. I was alone with my father when this crisis suddenly occurred, and I was interested to see that he was greatly alarmed."

The first objects round which imagination centres are the parents. Speaking generally, the nearest object of love is the mother, and the first of awe is the father. No matter how loving the father may be in actual life, for the infant he becomes the first disciplinary force that causes a separation between him and his mother. What is the daily experience? 'The mother's pre-occupation with the child, ordinarily takes a second place in the presence of the father; hence the child begins to place the parents in his compelling phantasy in two categories, by the one there is represented Love, by the other Law. Typically, "mother" stands for tenderness and submission, and "father" for authority and aggression.

These ideas of the parents are summed up under the psycho-analytic concept of the father and mother imago. The imago is a complex of associated thoughts and feelings about a real or imaginary relationship having a special emotional tone. This fact is of fundamental importance in a child's psychology. The necessity felt by primitive people and children to make images or imaginations, is, as Gosse suggests, an inner one. In this way a sum of emotion is ejected on to an external object. The Primitive does this when he takes stones and trees as fetishes, and credits them with magic powers. In the Mosaic law we have the prohibition against making "images or likenesses of anything that is in the heaven above, or in the earth beneath, or in the waters under the earth." While this law, as well as St. John's warning to the Early Christians to "keep themselves from idols," was doubtless partly designed to keep them from being drawn into the idolatrous religions and social customs surrounding them, it has a deeper origin and a more universal application on account of the innate dispositions of the human mind to project its own images, and then to fear them. 
The idea of the father-imago is universally prevalent. Many of the notions connected with it are absent from consciousness, but they lie waiting in the unconscious, and belong to the historic inheritance. The father is the head of the family, the leader of the tribe (the chief), the first man in the country (the King), the highest moral ideal, and the last court of appeal (the God). The most worshipped idol to-day is, as ever, the Authority Idol, which as in old times we take for God Himself.

The threat to a small child, "I shall tell your father," or the policeman, or the sweep, or the bogey man, gains its significance from these unconscious ideas. Honour and hatred given to the father find their motives in the image that is involuntarily formed. This image is a resultant of emotions from various mental systems set in vibration. While it has a certain foundation in experience, it is in the main far from being the correct likeness of a particular parent, either of an approving and beneficent one, or a disapproving and punishing one.

Thus, it appears, it is not necessarily the actual father, but the added phantasies that make the imago. If we look into ethnological records we find the primitive imagination creates for itself gods and demons which are projections of these terrors, they are so anti-human as only to be approached with placation. Deep in the subconscious of the most highly civilised person these phantasies exist and actuate conduct.

The childish experiences of Edmund Gosse, which incidentally show us hysteria in the making, find a parallel in some phantasies and symptoms of neurosis which occurred in a small patient of mine.

A little boy of seven was brought to me because he had taken to thieving, he also suffered from night terrors and nervous tics. He had attacks of almost frenzied behaviour. For some months past at intervals he had taken money from his mother's purse, which he subsequently spent on presents of fruit and flowers to take to his teachers.

When I questioned him he told me he was afraid to go to sleep because he thought something might be under his bed. 
One of his secret troubles was that his younger sister was in his class, and as she was much cleverer than he, he was always being surpassed by her. This disappointed his mother, who hoped for learning in her only son, to keep up the high intellectual traditions of a distinguished family. The little boy felt depreciated, and to reinstate himself in his own opinion and increase his importance, he gave his teachers fine presents bought with stolen money, and in this primitive way attempted to enhance his personality. A dream pictures the dragon as "stealing my sister." She, it appeared, was his nearest and dearest friend, though he was unconsciously jealous of her and wanted her out of the way (out of his class). If he was to beat her in class and take his proper place, it would mean hard work and effort, and perhaps he could not do it after all.

In such a case the child does not know why he steals. $\mathrm{He}$ is completely puzzled when you say to him: "As you stole the money, why did you not eat the grapes you bought with it? Why did you give them to Miss X.?" In a vague way he feels he has done far less wrong than if he ate them himself, and yet he is confronted with the fact of the theft. Without knowing it he has been following the irrational way of the unconscious mind. He was under a compulsion to overcome his feelings of inferiority. Thieving in this case was just as much a symptom of neurosis as were the night terrors, and the tics. The thefts were genuine, but must not be regarded as showing a particularly dishonest character. Nor is the case one of kleptomania, where the stealing is an unconscious act. In this instance the child is morally responsible, that is, he steals consciously, but is unconscious of the motives. His thieving is on a par with any other sort of naughtiness, but less guilty in proportion to the neurotic element. Thieving of this kind is fairly common in children and young adults, and is often punished with disproportionate severity. This nervous symptom is the result of myth making; it is an over-compensation for self-deprecation. What the child wants is to be noticed and loved. He does something to attract attention to himself. His mother's purse is 
lying about. It prompts him to action and links the idea with the emotions seething in the unconscious. He takes the money, and buys the presents, the giving of them seems to work delightfully at first, and this goes on until the whole thing comes to the knowledge of the Powers that Be.

It was evident to my mind that this child was highly imaginative, and very timid, so I questioned him about his dreams, and asked him to draw something for me; whereupon he drew a dragon. He did not seem to be perfectly sure such creatures did not exist.

On his second visit, he told me the following dream: "Annie and I were playing in the nursery. There was an awful rumbling, and the floor split open. A big dragon came out and stole my sister, and swallowed her up. I was very frightened and ran to my father, who came and killed the dragon, and my sister got out."

I talked to him about the story his own mind had produced. "Did I really make the dream?" he said, and began to be greatly interested. Then he told me what came into his mind about dragons, and what he felt about losing his sister, and her rescue by her father. Any points that arose had due attention, the child being left to lead the way so far as possible. The dream, regarded as a parable, made a profound impression on him.

The symbols worked out much in this way. The sister is the symbol for the child's treasure, his other self, his soul one may say. The dragon stands for an evil principle, and is clearly linked up with the theft, for "it stole my sister" said the dream. It represents the evil or devil principle, with its method of sloth and grab.

The father represents the good, or the God-principle, or the principle of knowledge ("father knows such a lot").

'The dream exactly shows the conflict of the child. It occurred at a time when he was in great trouble, and a large part of his psychic energy was introverted. $\mathrm{He}$ had done wrong, and did not know how to leave off doing it; all his schemes seemed to carry him deeper and deeper into disgrace. The interpretation of the dream is very obvious when all the 
facts are known and understood. But the meaning of his troubles is not clear to the child. It is most important to get his free associations, which are just those one might expect in this particular case. The dream, when interpreted, points out his mistake. He needs to understand that he has been seeking a self-indulgent, self-destructive way of gaining love and notice. What he must do is to work to overcome his sloth and laziness, as the father worked, by fighting and killing the dragon. By following the higher law in himself, he must do battle to get what he now wants to have without deserving it.

The dreams of children have a very mythological character. In them the racial memory is preponderant; they have as yet acquired little individual memory. Wordsworth tells us that-

\footnotetext{
"Our birth is but a sleep and a forgetting;

The soul that riseth with us, our life's star,

Hath had elsewhere its setting,

And cometh from afar:

Not in entire forgetfulness,

And not in utter nakedness,

But trailing clouds of glory do we come

From God, Who is our home."
}

The clouds of glory are associated with the cosmic thunders too, for the more the child is under the influence of the unconscious, the more he suffers from fear, and the more, in a specific case, is he afraid of going to sleep, lest some monster should catch him. The way to free him from these terrors is to build up his conscious knowledge, so that he is able to correct imagination with reality.

The child's fear centres round the dragon, which is an archetype of common occurrence in the mind. The dream is based on the "incest motive," and is capable of a completely Freudian interpretation dealing with a concrete wish for incest. In the view of the Swiss school, this is to be interpreted psychologically as adaptation to the mother, a regressive longing for the soft delights of a former day. Our little dreamer is only seven, but his problem is one that begins even earlier than this, and besets man again and again in the course of 
life. ${ }^{1}$ The tendencies to regress and progress are portrayed in the dream in the conscious ego of the dream, viz. the boy, and the little sister. The little sister represents that amount of the libido that strives backwards to the unconscious. The boy runs to the father, representing that portion of libido that strives to consciousness. The mother becomes destructive and terrible ${ }^{2}$ because she attracts the unconscious libido; the father becomes the symbol of the right way, because he leads to reality. The need for the dreamer is to be re-born ${ }^{3}$ from the mother, which is equivalent to saying he must find energy and vitality for a new life out of that libido which his trouble had introverted. A new attitude must be released.

Both the children quoted suffered from a sense of inferiority. This feeling is an enormous factor in the psychical life. It arises quite as much from within as from without. It is based on a comparison between the immense size and power of the parents and the smallness and ineffectiveness of the child.

Thoughtful adults are much more often guilty of reinforcing this sense of inferiority than of implanting fear. The child naturally feels weak and small. He has little power over his surroundings. There are only three ways in

1 The Dragon is not killed once for all and done with :-

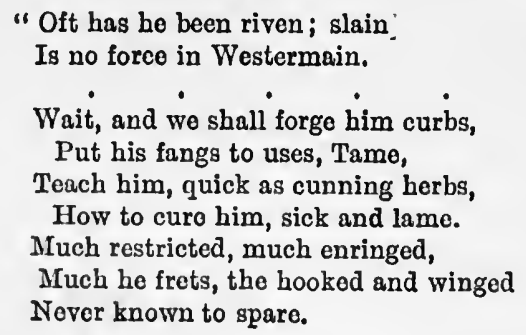

Self, his name declaro."

2 Dr. G. Elliot Smith, in his fascinating book, "The Evolution of the Dragon," tells us it "was primarily a personification of the lifo-giving and tho life-destroying powers of water," which later becamo the Great Mother. The symbol has two maternal aspects, on the one side it is a beneficent and fructifying power, on the other it is a destroying demon, who does not hesitate to devour her own childron.

3 The "Psychology of the Unconscious" is taken up with the elaboration of this universal problem. 
which he can influence them, and these are only relative. He can make himself a great nuisance, or, on the other hand, so endearing, that he temporarily manages his milieu. Or he can make himself more or less almighty within himself by the phantasies he creates. By this means he can escape from a world of reality into a world of fiction. The earlier ways, as we know, do not always succeed; nor does the way of imagination. When once the door to the unconscious creative realm is open, it admits terrors as well as delights, so that if the imaginative child knows joy, he also knows fear. If he creates a magic world on the one hand, he is tortured by his imagination on the other. $\mathrm{He}$ has yet to learn that things of the unconscious world are distinct from the objects of his thought or feeling.

This is a fact that we are late in learning. Some of us never achieve more than a dim recognition that it is through our own coloured spectacles that we see the world. One can get an acquaintance with the mind of the child as much by contact with the unchanged childish mind in man or woman as by contact with actual children. We carry with us certain unconscious tendencies or complexes, which have remained in an elementary state of development, and which have become isolated in a special compartment where they carry on an automatic life of their own.

There is a similar phenomenon in the physical world. Little remnants of embryonic tissue, instead of developing, become caught and isolated in the growing tissues, and remaining idle, as it were, may do no harm. Under certain conditions, however, they break unexpectedly into active life, and take on a growth that, being inappropriate and out of date, has a malignant effect.

I met a striking case of such arrested thinking in a neurotic teacher of forty-three. She thought, up to the day she spoke to me, that the child was born from the navel. This is an interesting remnant of childish phantasy which has many counterparts in myth and religion. The navel is a birthplace of note. Brahma is frequently represented as seated on a lotus which has its long root in the navel of the mother, 
or in the equivalent ilus or slime which is the feminine originating cause of all the elements. To the Braluman this is a symbol, but by the teacher of forty-three this phantasy had been taken concretely, and the effect of such belief can only tend to isolate the individual from a world so inadequately apprehended. The retention of such a phantasy always goes with an emotionally childish psychology. Phantasies of this kind should not persist into mature life. They serve very admirably as infantile theories, but when they become stabilised something is lacking in consciousness that ought to be there. There has been a turning away from facts which should be interesting to the normal individual, sometimes under the prudish idea that ignorance is innocence, sometimes from a dislike of the responsibility entailed by knowledge.

A few years ago a nervous young woman of twenty came to me. She was full of childish romance. Life presented her with many difficulties because she was either excitable or dreamy, and generally unpractical by nature. She was training to be a secretary. She had about a year previously very nearly become the victim of a serious mental breakdown. In her extremity she had found a way to help herself. When she was rebuked, as she often was, she would weave a phantasy that she was a martyr tied to a stake. Under the sway of this idea she could be brave, and bear everything that came in her way, and could tide herself over her feelings of levity or deep discouragement. Or when she had a difficult task she imagined herself a knight rescuing a maiden or going on a crusade. Phantasy of this kind served her for a short time only. It had pulled her through a nervous phase at a time when no other help was forthcoming, and nothing more robust would have served her so well. By the time she came under my care, however, this saving mental coustruction was already threatening to sap her sense of reality, and plunge her again into the abyss of mental confusion she had barely escaped. It is just in this way that the child uses phantasy to explain the universe or to surmount it. What is helpful and appropriate at one stage of 
development, or in states of weakness, is pathological and a serious menace at other times.

If the foregoing considerations have brought us to the point of understanding the compelling power of phantasy, we are in a better position to estimate the energic value of the authority complex.

By the term "complex" one means the systems or ramifications of ideas associated with a given object of interest. Favourite examples are religious or political complexes. Complexes have a definite emotional tone, and with some people we cannot get near the complex because the connections run so far and wide. When a person is perpetually having his corns trodden on, it is because his complexes extend to his very toes!

The authority complex is based upon the unconscious ideas connected with the father, or rather with the dominant parent, for it may happen that the mother is the greater disciplinary force, and the father the more loving and indulgent one.

At school the master or mistress replaces the authority in the home, and thus becomes a surrogate for the parents. The child tends to react to the new authority in the old manner. Where the change from home to school life is easily made, the complex does not turn up in any disturbing way, either consciously or unconsciously. But more enterprising children, or those who are described as difficult, sooner or later come in conflict with the powers that be. If a child be unusually difficult to manage even though in expert hands, we must expect to find something in.his home life, or in his phantasy, that explains what is exceptional in his conduct.

The teacher becomes the substitute for the parent, but with this great difference. At home as a rule the emotional life is more prominent. At school the intellectual life is more in evidence. So that it sometimes happens that children who were always in trouble in the nursery behave admirably in the schoolroom. They are cleverer with their heads than with their hearts. The opposite is the case with those whose strong point is their power of affection or their practical abilities. 
This accounts for some surprising differences between parents and teachers in the estimation of a child's character.

Some cases of stubbornness and hostility to the teacher are mainly explained by unconscious complexes. I came across an instance of a girl of seventeen who had become a torment in class, particularly with one teacher. The result was that whenever she went into a class there was an expectation of mischief. Not only did the scholars show some excitement in her presence, and laugh and giggle, but the teachers would instinctively look first in her direction whenever anything went wrong. Consequently, though not necessarily worse than others, she was always caught or suspected. Thus she became a scapegoat, that is, she served for the projection of naughtiness and guilt. There was a partial compulsion to play the rôle expected of her, as well as some taste for doing so.

She had been devoted to her aunt, who had brought her up from infancy. Being the only girl, for her cousins were all boys, she had been greatly indulged. The aunt had died a few months before, after a short illness. In her half-delirious state she had said many things to her niece which had served to frighten the girl badly, and the fatal event emphasised the fears aroused. On her deathbed the aunt had an access of religious feeling, and a sense of responsibility towards the adolescent girl whom she foresaw she was leaving. She made appeals to her and spoke warningly of the future. It is probable she was not in a state to weigh her words, but the effect on the girl's mind was one of worry and confusion.

During her aunt's life the niece had always identified their interests. She had cared specially for drawing and literature (for the aunt was an artist and writer) and excelled in them to the depreciation of those subjects which had a direct bearing on her uncle's profession, viz. physics and mathematics. She had been jealous of her uncle, and also of a little boy cousin, several years younger than herself. Owing to her exclusive devotion to her aunt, her affections had been narrowed down, and without her, she lost her own sense of importance and became disorientated. Only after her aunt's death 
did her indiscipline break out at school. As a matter of fact, she had buried her love with her aunt, and her deep hostility to her uncle reflected itself in relation to every one who was in authority over her. First of all, to God who "took her aunt" and with whom she would have no more to do ; then to her teachers who wished to control her. Hurt by the loss of love, she was determined not to love again. The result was deplorable, her manner was extremely hard and repelling, and though needing more understanding and help than most children, she actually gained less, owing to her demeanour. She was threatened with removal from school, and general shipwreck. But for the insight of one mistress, on whose suggestion the Principal sent her for psychological examination, she would have been expelled. These intractable children must not be judged as if they were mature. This child was full of phantasy and at the mercy of her panicstricken feelings. She was in a vicious circle of bad behaviour, and unable to free herself. Naughty as she was she did not seem so to herself, but rather she felt injured and misunderstood. She was full of a sense of bitter injustice, and unconsciously interpreted everything in school life in the light of this feeling.

Expulsion from school for conduct of this sort I am inclined to think should almost never take place. A child whose hand is persistently against his teacher's is a victim of neurosis, or fear, or misunderstanding. Sometimes the teacher's complexes are accountable for the trouble. Change of form or teacher at times works a miracle, so may a change of attitude on the part of the teacher. The child's behaviour is sometimes a half-crazy reaction to things blindly misinterpreted. Teachers will have to become wise enough to realise that there is a psychic conflict at the back of persistent naughtiness.

This girl had a dream of striking significance. It was as follows: "I was alone in the house and some one rang at the door. I opened it and my aunt walked in, looking as usual. In a minute or two her face fell off, and an ugly face with a devilish expression took its place." Interpreted analogically the dream had the following meaning. She wanted above all 
other things to have her dead aunt back. Alone in her home, that is, in the depth of hor nature, she opened the door to the mother-imago, that is, to the seductive phantasies of her aunt, seeking indulgence and tenderness instead of progress. She turned her longing to the past. She was preserving in her memory all idea of her aunt which was having a derastating influence upon her life and character. It produced a wrong attitude to life. In the dream the mask of the phantasies fell off, showing her aunt in a terrible aspect. This was revealing, for this aspect was really the effect of the girl's own devilish attitude to life, in which her hatred was projected on to everything and everybody by way of revenge against a fate she took as a personal injury. In the girl's phantasy the aunt played the rôle of an indulgent parent. By comparison with this tender imago all discipline seemed harsh. In the grip of phantasy the girl turned away from the difficult path wherever it was found. She did not do noble things but dreamt them all day long.

Another marked case of the effect of a mother-imago occurred in a man of fifty, a civil servant, whose mother died when he was a month old. He attributed every misfortune that befell him in life to the loss of his mother, and in the rôle of a poor orphan of fifty was still looking for the indulgent treatment he missed in infancy. Without wishing to minimise the serious effect the loss of a mother is to a child, or the added risks of misunderstanding and mismanagement, from the point of view of individual development it is the defects of sloth and self-indulgence which form yet more serious factors in life's handicap. This case displayed persistent evasions of discipline, not by way of active rebellion, for the man was religious in temperament, but by a general shirking of the growing pains that belong to self-development. Scrupulous and sensitive to an extreme degree he could find no conscious means of evasion, and the conflict being pushed into the subconscious he was provided with the materials for a neurosis which effectually prevented him from taking his proper part in life. A smallish income, which gave him "neither poverty nor riches," kept him free from want 
and without opportunities for rash enterprises, but permitted indulgence in a chronic neurosis.

What this type of neurotic craves for is safety, the negation of life. This craving is opposite to that of the naughty girl previously referred to. She desires sensation, to give her the life she lacks in herself. She unconsciously aims at making things happen, the other unconsciously aims at preventing things from happening. Both these persons are in bondago to the mother-imago.

Which reaction takes place in a given case will differ according to whether the individual in question puts a higher value on the inner or the outer world; or, stated in another way, whether the natural tendency of the individual's libido is to introversion or extraversion. This tendency is an innate disposition to adapt by one function in preference to others. If this more highly endowed function is too exclusively used, it produces one-sidedness, which education should endeavour to modify.

The introverted type tends to undervalue the external world in favour of the inner world, and his own ego. He likes to think about life and its problems but not to be actively involved in the business of living it; he lives in himself. The extravert, on the other hand, loves the object and the objective world; he throws himself into active life, and lives mainly in experiences. He undervalues the power of the inner thoughts and feelings, and tends to leave them undeveloped and unconscious, and lays greatest stress on exterior happenings. Another way of fitting into life is by means of intuition; the libido of this type turns to the unconscious. The intuitive seems to arrive at a rapid understanding of any situation in life by a method which is largely subconscious. His individuality is apt to be submerged, and he easily identifies himself with any impressive or striking personality or event. Chameleon-like, the personality takes colour from its surroundings, and in its mutability barely arrives at any essential differentiation. People of this intuitive type are universally charming from their ready flow of sympathy, but in their unredeemed state are little. to be relied upon, for they might aptly be described as 
"side-slippers." Many people of the so-called "artistic temperament" belong to this category. In schools it is to be recognised in those bright-eyed children who are so interested and quick in the up-take, who, when their intake is tested, have already lost the impressions made upon their minds. They have the impressionability of water. ${ }^{1}$

These classifications are useful so far as they go, but we should apply them tentatively. We should try to help children to develop along the line of their strength, and at the same time we should pay attention to what is weak in their character. Thus the inner thoughts and feelings of the introvert show him the path he must take, and encouragement must be given when he tries to exteriorise them, because his feelings and actions, possibly rather inferior when judged abstractly, are the best he can provide at present. Impatient parents or teachers say, "It is so much easier to do this myself than to teach So-and-so to do it." This is, however, just what we must school ourselves to do, that is, give the child the necessity to act, and encourage the effort, even if for the present the result is poor. The introvert child shrinks from action, and is very self-critical. It is so much easier for him to think about a thing or feel a thing interiorly than live it, and it often ends there.

It is difficult for the competent adult to stand aside and allow the inefficient child to make mistakes, so that something may develop out of them, in fact to permit evil that good may come.

And in regard to extravert children we must not neglect the further development of their actions and feelings, but we must also be specially tender to their repressed inner life and thinking. They are easily discouraged in this matter, and prefer to take refuge in the borrowed thoughts of others, for since their critical faculty is weak, their own serve them but poorly. How often the trouble into which a child falls is excused by the words, "I didn't think," and how often the answer given is, "But you should have thought," whereas

1 For a detailed description of the introverted and extraverted types, see Jung's "Analytical Psychology," 2nd edition, chap. xi. ; xiv. (sect. x.)." 
perhaps we have given them far too little opportunity for thinking, by planning to perfection multitudes of things they should have been allowed to think out for themselves.

In so far as they belong to the intuitive type we must develop them by converting their excellent intuitions into conscious reasoning and understanding, and into action based on these. It is one thing to know what is best, it is quite another thing to be able to execute it. The intuitive type is impatient of those practical things that do not keep pace with his quick perceptions. He has difficulty in adapting himself to life, and his thoughts and feelings in their nascent state are too unsubstantial to bear the stress of reality. To establish permanent and reliable characteristics of real worth is, in this type, the special difficulty.

In consideration that life is one whole, and that childhood is but a preparation for maturity, I would submit that we should allow children to handle fear. What is bad for them is that fear should handle them. True education consists, not in the removal of all sources of fear, even were that possible-for, as we have seen, if all conscious causes are removed it will spring up from the unconscious-but in learning to replace fear with courage. The perfect love that casts out fear is a love developed from within, having an expulsive power of its own, the product of slow growing and well-applied energy.

Curious cases of panic and courage were witnessed in the war. Though discipline must be maintained in an army, and under the military standard the deserter must be shot, it is acknowledged that the bravest man is not he who does not feel fear, but he who overcomes it. That man is least likely to run away who knows himself capable of doing so ; and who allows himself to fear cowardice in his thoughts, and guards against it in his acts. "That man is most likely to run away who will not let himself even dream of such a possibility, and who represses into the unconscious a thought so foreign to his ideals. This latter man will not allow himself to have fear, and it is just such a noble personality who may one day find himself fleeing in the grip of fear. The attitude is too herolike. We must learn to face in thought our instinctive 
tendencies, lest they break out from the unconscious, liberated under the dissociating effect of acute emotional strain.

How can educationalists tackle this problem of fear? They must pay greater attention to the unseen causes of fear, and learn to credit to the proper account reactions that are otherwise interpreted.

Few persons, on first thought, would attribute the reaction of pugnacity and aggressiveness to fear, and yet nine times out of ten this explains it. Aggressiveness is an over-compensation, and pugnacity a desire to strike first for fear of being struck. In the case of the naughty schoolgirl cited, her exaggerated swagger covered a sense of terrible inferiority brought to light through the death of the aunt and the consequent breaking up of the mother identification.

The reaction of lying is a very common result of fear, and is an attempt to evade punishment, partly because it is feared on its own account, and partly because punishment brings about a sense of inferiority. Lies, as we have already seen, are often told to inflate the personality, because it is felt to be inadequate. The following case is another example of this. A small boy was left at home one Sunday evening in charge of the housemaid. When she went, accompanied by the little fellow, to the bedrooms to prepare them for the night, he got hold of some tooth-powder from his mother's washstand, and rubbed it into his hair. This passed unnoticed by the absent-minded maid. Enamoured of this new game he repeated the process in the visitor's room. Later his parents returned from church and found our little hero still bearing very peculiar traces on his head. Naturally he was questioned, and their critical looks evoked an immediate sense of guilt in the child, who said the powder "must have come from the ceiling." This lie was not believed, and a whipping was threatened if he did not speak the truth. In the first instance he dared not confess his fault, because he liked to stand well with the grown-ups; in the second place he dared not confess his lie, so he took the whipping.

$\Lambda$ fter what was considered a judicious interval for repentance, the child was again asked to tell the history of the 
powdered hair. By this time he was still further depreciated, for the whipping had added humiliation to fear. Now he could not confess, and got a second whipping. He was given a third chance by the righteous but nonplussed parents. This time he made a compromise and confessed to using the toothpowder in his mother's room. At that point the confession stopped. By this time the parents, feeling themselves to be on the wrong tack, jumped at the partial confession, to let the culprit off, and the matter was never referred to again.

But it did not end here for the child. A day or two later he went to a picnic. His little soul was full of selfdepreciation. He simply could not join in the play of the other children, but clung to the neighbourhood of the adults. They doubtless thought him a sickly child. The other children thought him a mug. The day passed slowly, until late afternoon, when in some mysterious way the clouds of despair dissolved, and he joined in the play.

To this day - a half-century later-he remembers the poignant humiliation that followed this and other whippings; not that the whippings hurt, for they rarely drew a tear. The shrinking from his little companions was due to his sense of shame-"suppose they knew." - as for all he could tell they might, he would lose their good opinion, it seemed better not to tempt a fall, so he kept out of their way.

Surely the aim in such a case should be, not to punish, but to find out what the child is afraid of. After the first delinquency everything that happened in this series of silly errors was brought about by fear on the child's side, and stupidity on the parents' part.

It is clear that this child was very sensitive to the good opinion of others. What he needed to learn was self-respect. There was no harm in his play, but he intuitively felt the criticism of the adults. As a matter of fact, what they were troubled about in this case was the lying, not the childish nonsense, and they did not see how the matter was working in his mind. He lied because he judged himself according to his understanding of their adult standards. He could not 
bear himself without their approval also, and that was the unconscious cause of his fear.

Before we can consistently teach the child to respect himself we must ourselves learn to respect his individuality. That loes not mean we must come down to the level of his conduct. We must remain adults and let him remain a child for the appropriate number of years. But we must teach him to accept the responsibility for his acts on his own basis. Our part consists not in smoothing away all the external difficulties, nor in repressing ourselves and allowing children to exploit us, but in helping with kindness the tracking down of the hidden cause of the trouble. This teaches the child to educate himself in thinking, and feeling, and understanding. It leads to real courage. The tracking down must be done with insight. Any harshness in this quest will defeat its own ends, for fear will immediately provide a defence against an inquisitorial method. It would be well to work the matter out first upon ourselves, and apply very tentative methods to the child, or an even worse evil may befall him, for he has a right to his own privacy. Occasions of real courage are rarely wanting in life, though they may all lie practically in the moral sphere. No occurrences can be considered trivial where fear is concerned. If we wish to understand we must estimate the difficulties as the child estimates them. Because we see no humiliation in such and such a thing it is not so with him. We must penetrate his mind, and help him with his peculiar problems regardless of our adult sense of proportion. In every case the best antidote to self-depreciation is found in working for the thing we are envious of in others, or that we have so far acquired only in phantasy from the magic of the fairies. 


\section{IV}

\section{UNCONSCIOUS FACTORS AFFECTING DISCIPLINE 1}

Is a recent lecture, Mr. Homer Lane told his audience that on one occasion there was an epidemic of window smashing at the Little Commonwealth; he wished to stop it, and to do so joined the children in window smashing. He did this in the belief that if he took part in the performance it would lose its charm. He claimed to have achieved his aim.

This bold educationalist had no misgivings about his methods; they were offered as effective examples for social education, and the criticism evoked in my mind is embodied in what follows.

It is rather the fashion to decry discipline to-day, and to talk as if freedom were a purely external thing. Even the very freest of schools or institutions will not exist long before rigidity appears. Rules may be absent from the constitution, but they will soon arise from sheer necessity.

Discipline seems to me an essential in education. The question is, how much shall be evolved from within, and how much imposed from without? In the absence of discipline tyranny arises. If the disposal of power were to be put indiscriminately in the hands of young children, or in those of an under-developed nation, the result would be chaos and disorder alternating with tyranny, a state in which there is no possibility of education, in the true sense of the word. When children are left to govern themselves, the "natural leaders" tyrannise over the rest, who are only too ready to be slaves. Bullying results. The weaker children grumble at their grievances, but are not ready or able to take the initiative against them. Cruelty forms a part of the childish

1 Lecture delivered at the Summer School of Civics and Eugenics, Cam. bridge, 1919. 
or primitive character, and belongs necessarily to the as yet undeveloped moral judgment.

Love of power is innate in humanity. In a crude, childish state, this love of power is exercised over other persons, or over animals, and displays itself in acts of cruelty. The same instincts are seen in primitive communities in rites of torture. We call such practices sadistic, and a large element of sexual gratification mingles in them. Masochism in which there is a love of being made to suffer, is the counterpart of sadism. It is seen in certain children, who noticeably repeat acts of insubordination over. and over again, until they bring punishment upon themselves from some one whom they love. This is also connected with sexual pleasure. The sexual element is unconscious, both in the child and adult; only in relatively few cases does it become conscious as an inexplicable impulse, and it is generally an accompaniment of other nervous or mental symptoms.

These opposite tendencies can be seen even in religions which are highly developed. On the one side we have zealous persecutions; on the other, martyrdom and the hair shirt. Both tendencies are present in some degree in normal persons, one or other predominating, and in matters of education contribute unconscious factors to the question of discipline.

In the highly-developed individual, love of power is sublimated into power over the self. The multiplicity of good and evil tendencies provides each person with a private hierarchy. This power over the self is a spiritual achievement, slowly acquired. It is, moreover, a late achievement, which follows upon coming to grips with the problems of life. These problems are commonly met in every stage of life, and education should provide the right training, and take no account of the final outcome. Power in the self gives power over others, which arrives without striving, and without doing violence to human relations. In early life, development is helped by love, provided it is not of too indulgent a character. The passion that the child has to ally himself with a parent, or some older person, has a great value. If he had no instinct 
of love and fear, he would be constantly exposed to danger, and the need of coercion. He looks for and needs guidance.

In an interesting report of the Caldecott Community for 1916-1917, the question of the child's responsibility is discussed. A boy complained it was not fair to expect them always to be responsible for their own conduct, for, he said, "after all, we are only little." Another child confessed she did not like her history lesson, but added, "but I like to be made to learn it." Not only the child, but nearly every one of us would like to go in the direction of least resistance. Perhaps many of us are not a little thankful that stern necessity bids us work, for we dare not claim superiority over the idle rich, and idle poor, who do not mean to work so long as they are otherwise provided for.

There is a great deal of wisdom in the child's plea, "after all, we are only very little." In following the mind of the child we shall get hints not only where to confer freedom, but where to draw the line and impose directions. I think we are in danger to-day of making a god of liberty, and of thinking liberty exists where it has as yet had no chance of developing. This adoration of liberty is the effect of a reaction from the old bad way of a too rigid external rule. It is, however, a mechanical and undiscriminating swing of the pendulum from one extreme to the other. What has proved bad is condemned, and without due consideration the polar opposite is put in its place. Liberty in school life is not to be aimed at as an end in itself, but as a means towards self-government, which is the only liberty that can be gained by education direct. Discipline is something that is learnt, not taught, and every exercise of it should stimulate the learning.

$A$ large number of my neurotic patients come from the class of spoilt children. Many of them complain bitterly of having been over-indulged. They regret they were not taught to obey, or regret that in some directions there were too few restrictions or too many. They complain of their education, and blame it, probably more or less unfairly, as well as their parents, for their failures in life; at least, they "studied the wrong subjects," or the right ones " in the wrong way." Other 
neurotics keep a romantic attachment to everything that happened to them in childhood. They assure me they never had any troubles at that time, and were perfectly happy on account of their indulgent treatment. They find themselves unable to fit into life because this paradise is now closed to them. This rosy report is, of course, to a large extent due to an imperfect memory, and is no more accurate than the strictures of the previous group.

Some people claim that their schooldays were the happiest of their lives. This is a pathetic admission. It betokens a character that has not fulfilled its promise, and is far from being a tribute to the real success of their school discipline. Such people do well only as long as they work according to a plan, and in a community. They accept responsibility and fulfil all the conditions within the school, but never learn initiative, and are completely lost when they have to run themselves.

All kinds of illusions about the home of childhood, of every conceivable mistake or every possible good, attach to the images of the parents or their substitutes. The fanciful pictures of the father and mother, the schoolmaster and schoolmistress, as portraits of the actual people, are just about as inaccurate as are the characters in a historical romance. They are persons "seen through a temperament."

In considering the child's problem, whether of delinquency or neurosis, we must always distribute the blame for the breakdown in two directions, viz. the present and the past.

When a naughty or neurotic child is brought to me part of my inquiry is directed towards its immediate emotional environment. Sometimes the noxious conditions are so obvious that they can be attacked direct. This is by no means a generally popular method; for usually one or two persons are involved in the breakdown, most commonly one or both parents. Analytical psychology shows us every time that the psychic life is a continuity, a fact upon which Freud lays such great stress. Former impressions are never lost, but are carried along unconsciously in the personality. Whenever an obstacle occurs in the present there is always something 
enclosed in the past-that is, in the unconscious-to which the psychic energy can regress, from which conduct can be reprinted. The psycho-analytic theories press certain very important problems on parents, one being that they are much more responsible for their children's breakdowns than was formerly supposed. What parents are, counts for so much more than what they do or say. It may be that they have difficulties in their mutual relations, and show lore of power, or foolish identifications with one another; or are self-indulgent, and resistant to all changes of habit or idea. These things are the result of complexes which should be taken up lest they are left over for the children, for if they are not consciously known they are unconsciously apperceived by the younger generation, and are quite fatefully imitated; not only in childhood, but later in married or business life; the special unconscious tendency crops up with the special occasion. A man said to me recently, "Both my father and grandfather took to drink at about forty-five, and our family for generations has been notorious for disastrous love affairs round about that age." He followed this up with an excuse for his owm drinking habits, saying, "I suppose one can't help heredity." There is, of course, a great deal in heredity, but in such a case the psychical inheritance means much more than the physical inheritance. It acts like an infection rather than a transmission. The hereditary character might be broken in any generation by taking a new attitude, but it is so much more easy to imitate than to take a new path. Adaptation to parents who have neglected to work out their own problems forms a large part of the spell-if I may speak of the unconscious compulsion in this way-that has never been broken. So long as this continues to operate, it disturbs conduct in innumerable ways in childhood and youth, and brings about inferior and unstable reactions in thought and feeling in later life.

In spite of the foregoing it is clear all the blame does not belong to the past, for we are not only victims of determinism but subjects of free will.

We must not attribute every disaster that happens to us to the unhappy events or training of childhood, because there 
comes a time when we grow up. Every one theoretically is designed to become a mature, independent, free, self-regulating individual. Self-development demands courage. Most of us deserve a good share of blame for our cowardice in ridding ourselves of our deeply rooted childish tendencies. We must learn to discriminate with fairness between what blame belongs to ourselves, and what belongs to others. We have a natural tendency to project our failures on to others and our environment, and in so doing we continue to employ the very mechanism that has kept us irresponsible, and consequently undeveloped hitherto.

From time to time a good deal of misunderstanding has arisen around the psychological idea of the father-complex, and this misunderstanding will crop up whenever the question is considered from the point of view of consciousness only. The phantasies which made the "imago" belong to the unconscious, and the emotions attached to the complex are harmful on account of their unrealised and unrecognised character. It sounds sometimes as though psycho-analysts threw all the blame on the parents. This is not in reality the case. What is necessary is to call attention to the less recognised difficulties and dangers incidental to the relation of child and parent. No human relationship that is valuable can escape having its dangerous as well as its beneficent side, and least of all can this, which is the first and most important, both to the individual and the race.

But fathers and mothers are only human after all, and as a parent afflicted with a very tiresome daughter said to me not long ago: "Even a father needs some encouragement, you know." In our excess of zeal for the child, we are apt to forget the feelings of the parents. They do not commit all the errors attributed to them any more than the child does. Nor in relation to the child should they sink their own individuality. If they have learnt proper respect for the individuality in themselves they will respect it in the child.

In training the child of to-day we are working at a new generation of future parents: it will have a fresh set of virtues and vices, which will be a special edition of the old. 
It should be an improved edition, however, since we have become so very analytical and experimental. In pressing these views upon teachers I am asking the thoughtful attention of parents, or parent-deputies. I would appeal to the parental instincts in you, and not regard teachers as excluded from family life. You are essentially parents who specialise in education. Very small families, and still more, only children, are a mistake, and $\mathrm{I}$ am inclined to think that a child with only one or two parents is also a mistake. One of the advantages of school life depends upon the fact that the exclusive influence of the parents is modified by that of teachers and school-fellows, and other points of view are introduced. The influence of one parent modifies that of the other; the schoolmaster's influence modifies that of the parents, the teachers' that of the head, the schoolfellows' that of the teachers, and so forth. I would have the parents remember that they are teachers, and the teachers remember that they are parent-deputies. This way of taking up their respective problems adds understanding and promotes sympathy in aim and purpose.

The greatest importance attaches to early impressions, since they serve as patterns for subsequent ones. It is for this reason that the parents have a psychical precedence over all later comers, and it is why they often block the way to a fresh mental attitude.

As a physician I have repeatedly observed what a disastrous effect incompatibility between the parents provokes in the child. Children brought up in a stormy home atmosphere, or one in which the parents are themselves repressed, carry the traces for life. A want of harmony, short of actual scenes, has a bad effect on children if for no other reason than that too much of the parents' interest is occupied in their own inner emotional conflict, and too little is free for the concerns of the child. On the other hand, a blind uncritical attitude of the parents to each other in their rule of the children may be bad, because if one be wrong-headed there is no court of appeal, and no re-consideration of discipline. 
The most unfortunate children of all are those who are played off by one parent against another. I recall the case of a man of extraordinary gifts, and a highly neurotic temperament, whose greatest remembered happiness in childhood was of those times when his mother, having quarrelled with his father, whom she alternately loved and hated, treated her little son as a temporary lover in order to rouse her husband's jealousy. The moment the conjugal quarrels were made up the child was comparatively forgotten and even neglected. This way of treating him established in the son an inner bondage to his mother, that later on had disastrous effects and interfered with his own happiness in married life, almost to the point of wrecking it, as well as causing a severe neurosis. In this case the son came to identify himself with his father, and in later years he unconsciously imitated his father's way of managing or mismanaging his own wife and children.

It is on a basis of past experience that the teacher's work on the child begins. Each one comes to school with what is for him a typical experience. He unconsciously fits the teacher into one or other of the parent-types. If his father is unjust he will suspect injustice in his teacher. If his mother deceives him, he will expect the same treatment at the hands of the schoolmistress. Serious misconceptions may arise because he is already biassed in his interpretations, and more than a little insight is necessary before the effect of his subjective feelings is recognised. $\mathrm{He}$ has to gain his fresh experience, and differentiate his feelings further before he can do justice to the new types of adult people he meets.

If we turn from the child to the teacher we note that he, too, brings an unconscious mind to the business of education. His is more complex than the child's because it has more in it, the result of years of experience, accumulated memories and rationalisations. There are two main types of teacher, the "bound" and the "free"; or those who with regard to their work are " under the law," and those who are "under grace." If we look round this room we could roughly classify the audience into bound and free. Some are very markedly repressed. The manner of life among women teachers does not 
promote freedom. This is especially the case with girls who go straight from school to college, and leave college for posts which tax them to the uttermost, in those years when they are acquiring practice in the art of teaching. By the time they have acquired facility they find themselves caught in the machinery of some educational system. As each day ends it finds them often with piles of exercises to correct. ${ }^{1}$ After these are done they are too tired for enjoyment, or it is too late to do much, and in order to be fit for to-morrow's work they go to bed. I doubt if the life of the average assistant master is very much better, though he is apt to take his duties less seriously, for which under the circumstances we cannot blame him. Also his physique is generally better, partly because he has more outdoor games at school and college, and also during his professional life.

Only a very genuine sense of what belongs by right to their own natures enables teachers to stand up against the deadening influences of a life of crowded routine. But if they have sufficient values in themselves they will escape from what is deleterious in the life, and sooner or later, change and adapt it to suit their freedom-loving natures.

As in the case of the child what we should lay stress upon is the fact that freedom should be possible. Hence we must not ignore or neglect the outward circumstances either in the case of teacher or child, because life can be made too hard to bear, and many sensitive persons are crushed and sacrificed to the machinery.

I have spoken of the evil effects of a stormy homelife on the minds of children. An opposite evil can be seen to its highest degree in rigid institutional life, in the absence of normal emotions. This colourless life is

1 Among my patients I have a woman teacher who tells me she has 153 essays to correct weekly. This takes her at least twelve hours, in only threo of which can she correct in class. This heary out-of-school work, which is usual in secondary schools, robs teachers of their freshness, and their ability to "play." It reacts unfavourably on their scholars. They are often obliged, though unconsciously,' to maintain the most rigid discipline to protect their frayed nerves. The more sensitive ones cannot allow a wholesome amount of freedom in class on account of their own irritability. 
extremely harmful; children particularly need help towards the expression of their love, which pre-supposes a person or persons to expend it upon. In normal school or home-life unusual things happen frequently. Unusual circumstances provoke new thoughts and new feelings, and pliability of character is demanded. Think, for instance, of the effect which getting up a piece of acting has, on the social life in a school or college. It uncovers a number of unsuspected qualities, and establishes a host of new relationships within the walls. While constant domestic scenes are bad, change is good, and institutional life lends itself too little to change. Useless routine is bad for teachers and scholars. That symptom which teachers have expressed to me as "terminess" would not so often be experienced if there were more variety. Perpetual change, however, is no more to be recommended than dullness ; we do not want to bring about restlessness, but rather stability in movement. I suppose we all suspect that routine is established more on the teacher's behalf than on the child's. Greater liberty is dreaded in school because it is believed to entail harder work on the teacher. But I submit this should not be so. If it is so, it is because the teacher is divided in his own mind, and has not fully worked out the problem of personal freedom. If he is afraid, it is because he is still dominated by his unconscious childish fears, and so is in a manner a child in charge of children, without the courage and self-confidence necessary to outlive the experience of the new order of things, and the criticism which innovations in methods of discipline are likely to entail. A new method may mean a less orderly, or at least a noisier class, and so evoke adverse criticism from the Head. Here, too, is a conflict with the authority-complex. Assistant teachers must learn to be free, to take up an independent mental attitude towards the beliefs and sentiments of their own generation as epitomised in the Head of the school, for these are largely "collective sentiments," i.e. the uncriticised inheritance of former generations.

In Samuel Butler's novel, "The Way of All Flesh," he deals with this conflict between the generations. He depicts four generations, and shows the relation in each case between 
established authority and innovation. The analysis is made with wit and remarkable insight as one would expect, but it has a note of tragic bitterness, betraying that the conflict was a personal one for Butler. In "Life and Habit"1 he says: "It is one against a legion when a creature tries to differ from his own past selves. He must yield or die if he wants to differ widely. . . . His past selves are living in him at this moment with the accumulated life of centuries. 'Do this, this, this, which we too have done and found our profit in it,' cry the souls of his forefathers within him. Faint are the far ones, coming and going as the sound of bells wafted on to a high mountain; loud and clear are the near ones, urgent as an alarm of fire. 'Withhold,' cry some. 'Go on boldly,' cry others. . . . Our former selves fight within us and wrangle for our possession."

The poignancy of Butler's personal conflict has been revealed to us recently in Festing Jones' admirable biography, ${ }^{2}$ which is well worth study from the standpoint of analytical psychology. He shows how crippling is the effect of submission to outworn conventions, and proves it is only by courage to break away that the young generation obtains the freedom that allows their characters to expand and that makes individuals of them.

Individuation, as must be emphasised again and again, is the supreme task to which a person is called. What is of fundamental importance is that the parent or teacher shall himself have achieved an individual character, in fact have found himself, and become at one with himself. In education you may give a very large degree of liberty, you may place a child in the most favourable conditions imaginable, but you cannot do this work of differentiation for him. Just what liberation and differentiation he himself achieves is his own peculiar work. Education should aim at seeing that the problems he is presented with are suitable to his age and understanding and at fitting him to take up his responsibilities as they come along. Even the most carefully planned system will

1 "Life and Habit." Fifield.

2"Lifo of Samuel Butler." 
fail if this is not done; and without any system at all, and under the least farourable external conditions, true education may be achieved if the right spirit is present. I have heard apostles of MLontessori, and apostles of other educational systems claim that they are supported by psycho-analysis. Such a claim in my opinion shows an imperfect understanding. If there is one thing psycho-analysis has-taught, it is that the human mind and soul is in each case "individual and unique," and that no conditions can be made that will exactly suit all persons. Consequently what is one child's food is another child's poison; and while some children develop best under rigid external discipline and constant attention, others are demoralised by it, and thrive best under wholesome neglect. Analytical psychology lays stress on the point that the child is hindered by his own particular complexes, and these are apt to lead to a misunderstanding of the meaning of discipline. Unhappily a great deal of so-called discipline is applied to the child in an unreasonable way, a way which he is as little capable of understanding as a savage of understanding the reason of a volcanic eruption or of a tidal wave.

Discipline so applied must appear to be something devastating that sweeps all before it, especially those young and tender growths that have as yet been rooted but lightly in the developing mind. Children do not really resent restrictions which they understand, even though they refuse them lip service. They very shrewdly sum up the people who cannot keep them in order, and those who make them obey. They keep their private opinions about the grown-ups. They respect adults not because they are like themselves, but because they are different. They are models to which they hope vaguely to attain one day, and it is well for them when the models are really superior. They do not like to see their models playing the fool.

It is for this reason I find myself at issue with Mr. Homer Lane. Because children smash windows that does not in my opinion justify him in joining them, even though his motive is above suspicion. In matters where the adult is ahead of the child, more developed, and wiser, he must expect the 
child to come over to him, he must not identify himself with the child by identical behaviour. Can an adult acting in such a way feel he is behaving sincerely? Is he not behaving in a way that from the standpoint of his greater development cannot be justified? He is adopting a pose, and is doing violence to his own ideals. Suppose instead of windowsmashing the epidemic of naughtiness took the form of torturing cats or robbing a barrow. Is the Head to join them also in these things in order that they may come to see there is no fun in it? Where is the line to be drawn? The epidemic might equally be one of showing too demonstrative affection, or of silly love-making. Does it not come to this, that we must first be fundamentally true to ourselves, and in so being we have a stable position from which to take action.

How are we to obtain this stability, for there is nothing harder to come by than satisfactory actuating principles? We are greatly assisted by making a practice of looking below the threshold of consciousness as well as above it. A study of our own unconscious gives us the means of deeper insight, although it does not necessarily make teachers of us, nor even free men and women. Perhaps the first step to stability lies in accepting discipline because we need it.

It is well that each one of us should learn at some point in his life to submit his will to that of another person. In the last resort the submission of the soul is made to God, no matter under what concept we think of God. But we learn to submit to God through submission to some human being. In childhood we submit to our parents, not by individual choice, but by circumstances already determined for us. In school the child submits to his teacher. In analysis submission is transferred for a season to the analyst. Not to the analyst qua individual, but to the analyst qua representative or interpreter of the inner law that exists for each one of us in his own unconscious mind. The effect of psychological analysis is to bring from the unconscious, out into the light of day, just what is the "ruling idea" in a life. This ruling idea is the authority to which in nine cases out of ten submission has been made unconsciously, that is, under 
compulsion. This one-sided submission tends to bring about a conflict.

The great value of analysis lies in changing the unconscious authority into a conscious one in accordance with the law of the whole personality. The process is a liberating one, for we often find that the ruling idea, once it is abstracted from the phantasies that are attached to it, is no longer a bogey. We often find that it is after all no longer an authority, and that its long unconscious reign is over. The overthrown authority must now be succeeded by another, this time one of conscious making, and no longer to be regarded as permanent or sacrosanct, but as necessarily to be constantly transformed into one commensurate with our growing and liberated life. But "an idol overthrown is still a god." We have great difficulty both in recognising the power of such gods, and in freeing ourselves from them. The authority of the educator or analyst should prove a stepping-stone from compulsion to freedom.

An intensive study of the self quickly teaches us that in many respects we are other than we thought ourselves. We are constantly deceived about ourselves and our motives, and just where we are self-deceived we tend to be deceived about others. For what exists unconsciously in ourselves tends to be projected on to others; we see the beam in our brother's eye and neglect the effect produced by the mote in our own.

Especially when we have to deal with children our vision should be clear, and our feelings just and free, and when we act as parents, teachers, doctors, or priests, our personal bias should bo as much in abeyance as possible. We may no longer think of the world as being what we would like it to be. We must take the responsibility of regarding the world as it $i$, and deal with human nature on the basis of its fundamental instincts and tendencies, good and bad, animal and divine.

Why do so many valuable educational experiments and hopeful schemes come to grief? Chiefly because we are idealists who will not accept the conditions, and the limitations, and work in accordance with the laws of life. We must do better than pursue impossible ideals. We must learn to 
appreciate not only material reality, but psychic reality, and "idealise our reals" by making use of what material we have at our disposal, including the instincts which are our heritage, and which contain the motive springs of life.

It is useless to think the solution of educational problems lies in such devices as co-education or segregation of the sexes. It is not in schools, or nunneries and monasteries, or nature cults, in special clothing or in nakedness, in regetarianism or prohibition, in Anglicanism or Spiritualism or Nonconformity, nor in any "ism" under the sun, but in the further development of our humanity. Let us develop the individual; as Pindar says, "let us find out what we are and become it."

Systems fail, especially in education, where children are the subjects of experiment, because not enough allowance is made for human nature itself. When we expect too much we over-strain the children and discourage ourselves. Not only the intellect if too fiercely forced, but the virtues also, become attenuated. Human nature is both better and worse than we think it. If we make a new Eden the serpent will again enter it. The history of the Garden of Eden will be repeated inevitably in each individual soul, until man, arriving at responsibility, learns how to fit himself into life in a way that does justice to all sides of his human nature.

There is one scholar upon whom we may legitimately practise every method of discipline or indiscipline, and that is the self. We must find out what we are. Where do our wishes lie? What do we think when we allow ourselves to think without reservation? What do we feel when we remove from ourselves the restraints of will and habit? How much of all this that seems new or dangerous to us can and should be lived? What would its personal effect be, what its general effect? What is the meaning of the wealth of phantasy that exists in the psyche?

In my experience few are able to make a personal study of the unconscious mind without some disturbances in equilibrium, and perhaps a temporary disorientation. For this reason a superficial approach to the subject is to be deplored. 
The first effect of contact with the unconscious is often one of fear and dislike, this is especially the case with neurotic people who suffer from unwelcome intrusions of the unconscious mind into consciousness.

When a healthy person takes up this study of his own free will, he should remember he is destined to dive into that very region whence neurotic fears issue. Things will have to be considered that have hitherto been ignored. Repression, even if mistaken, is incidental to man's mental progress, and the releasing of repression liberates not only valuable and much needed energy, but it also allows skeletons to start into activity which display extraordinary animation, showing that they were not put into cupboards for nothing.

But for those who can face these things without doubt new values will be found, and an enrichment of life should ensue. In any case, the unconscious is a fact of our psychical life, and whether we like it or not, we are up against it in education as elsewhere. 


\section{THE USE OF SUBLIMINAL MATERIAL IN} ANALYTICAL PSYCHOLOGY ${ }^{1}$

I HAVE chosen for the subject of my paper the analytic use of subliminal material, believing this to be something of interest to all of us. The Society for Psychical Research has made intimate studies of various subconscious phenomena, in a manner quite unfamiliar to me. I, on the other hand, have been acquiring a practical knowledge of the working of the unconscious part of the mind in particular ways which are probably unfamiliar to many of my readers. There should be here a promising field for discussion, and I welcome the opportunity now given me of opening it.

I shall use the word "unconscious" in the sense introduced by Freud. In a paper published by this Society he said, "Let us call 'conscious' the conception which is present to our consciousness and of which we are aware, and let this be the only meaning of the word 'conscious'; as for latent conceptions, if we have any reason to believe they exist in the mind - as we have in the case of memory - let them be denoted by the term "unconscious." "Freud's "unconscious" corresponds in part to the "subliminal" of Myers, viz. "those thoughts and feelings lying beneath the ordinary threshold of consciousness, as opposed to the supraliminal lying above the threshold." Freud distinguishes between the preconscious and the completely unconscious layers of the unconscious mind. The contents of the preconscious have once been conscious and they can fairly easily become conscious again, if suitable stimuli occur. The completely unconscious part of

1 This paper was read at a General Meeting of the Society for Psychical Research, January 31, 1917. Proceedings, vol. xxx. Reprinted by kind permission. 
the mind has contents which have never yet reached consciousness at all. According to Freud, this material remains unconscious because of a powerful resistance against its admission into consciousness. It is connected with infantile wish-tendencies which are incompatible with the adult thinking or feeling. It is kept unconscious by a mechanism which he calls "repression." The barrier produced by repression can only be surmounted with great difficulty. It may be psychologically "rushed," so to speak, as in an attack of mania, where the unconscious material breaks through into consciousness and holds the field in a disastrous manner; or it may be systematically brought up, as in psychoanalysis.

For Freud the unconscious mind exists as the result of repression. Jones says, "The splitting of the mind into conscious and unconscious processes represents an acquired state of affairs, and not a primary situation." This acquired unconscious mind Jung calls the personal unconscious, and adds the concept of the impersonal unconscious, which is the historic mind, containing the instincts and primordial forms of later psychological functions.

The personal elements of the unconscious mind have been acquired in the attempt of the individual to adapt to society. This is a task which presents special difficulties to people who deviate from the normal. To lead a satisfactory life one must develop as an individual and also as a member of a group, and growth in the one direction should be complementary, not antagonistic to growth in the other. In analysis of the unconscious mind we soon find how great is the conflict between these two sets of claims. The strife is not only due to repression, but is also a result of the need for further self-expression. The unconscious mind should not be regarded merely as infantile and primitive. It is the creative mind and contains all the possibilities of future development. Moral instincts ${ }^{2}$ are as much an essential content of the unconscious mind as are the sexual instincts upon which Freud has laid such exclusive

1 "Papers on Psycho-Analysis," p. 624.

- Trotter calls these gregarious instincts, see "Instincts of the Herd in Peace and War." 
stress. Primitive man, our common ancestor, made taboos and imposed barriers upon what he unconsciously felt to be his more dangerous instincts. This fact is of great significance, and justifies belief in man's innate tendency to surpass himself.

To advert from the origin of subconscious phenomena to their actual characteristics, we observe that the unconscious mind expresses itself in curiously veiled symbols. Freud attributes this veiling mainly to the activity of a hypothetical "censor," who cannot allow a more direct expression of unconscious infantile wishes, because they are distasteful and unwelcome to the conscious personality. Jung gives little credit to the censor, and sees in the veiled symbolism the primitive human mode of thinking, of which the dream is a survival, and which is shown also in the construction of myths and in folk-lore. This difference in emphasis between Jung and Freud leads to widely different results. The Freudian interpretation of symbols is monotonous and stultifying. Jung's interpretation reveals a richness in the content of dreams which is fully in accordance with the creative and evolutional character of the human mind.

Let me now turn to psychoanalysis. Psychoanalysis is a technique for discovering and analysing the contents of the unconscious mind. It is a therapy, specially beneficial in illnesses caused by disturbances in the unconscious region of the mind, functional diseases such as hysteria, and other psychoneuroses. Historically, it may be regarded as an offspring of hypnotism, as chemistry is an offspring of alchemy. In each case the offspring differs widely from the parent. In hypnotism unconscious mental processes are covered up from the patient; in analysis they are laid bare. The history of hypnotism is too well known to need comment here, save to say that most psychoanalysts of repute have hitherto come to the newer therapy via the old. Thus psychoanalysis owes a debt to hypnotism, and to those pioneers who initiated the use of a psychic remedy for psychic disease.

Hysteria and hypnotism show us the mind in dissection or dissociation. Analysis deliberately seeks to resolve the mind, even the morbid and distraught mind, into its elements. 
It brings repressed material with its attached emotions to view. This naturally has a somewhat disturbing effect on the individual, for it involves a kind of operation on the mind. But as with surgical operations, its aim is not only to disturb and dissect, but to resect and heal, leaving the condition healthy, with the function restored. The physical healing and renewal correspond with the synthetic or reconstructive side of analysis.

In hypnosis an apparent synthesis is obtained. This acts effectively for a time, and may suffice. There is, however, considerable risk that under a severe accidental emotional strain dissociation will recur. The process of synthesis in hypnotism is not a conscious one. It is inexplicable to the patient, who accepts it gratefully as something akin to the miraculous. In psychoanalysis the cause of the dissociation and the means of the synthesis are made apparent to the patient. The resulting cure should theoretically withstand all the events of life. Of course this is not always so. We have to acknowledge our share of failures. Analysis is not a panacea. Failure is not always due to the method however: there are patients who do not wish to be cured at the cost entailed, for we are concerned here with other wishes than those which are conscious. It must be remembered that much of the work is done on very nervous people, and that these very sufferers are asked to contribute a great amount of effort. They must be people of good will, capable of co-operation. At first sight this demand on the neurotic, though wholesome, seems very hard. He is extra sensitive and painfully self-conscious. He unconsciously protects himself from the mental sufferings to which his peculiar make of mind renders him susceptible, in one of two ways: either he shuts himself up within himself and develops symptoms such as phobias, which tend to deliver him from his environment; or else he develops hysterical symptoms, such as blindness, or paralysis, which tend to throw him on the sympathy of people around him. In the first case he turns his psychic energy inwards by a process of introversion; in the second he turns it outwards by a process of extraversion. In each case the same purpose 
is served-a modification of the individual's actual relation to the world, and to the demands made upon him by daily life. Either reaction is the outcome of an unconscious childish attitude of mind. Psychoanalysis aims at helping the patient to find the unknown causes of this attitude, and his understanding must accompany the analytical process at every step. The origin of the first mental dissociation was in the unconscious, and it is there we must ultimately find the means for the desired synthesis. Whatever in the morbid symptoms is not understood-not merely intellectually but emotionally too-contains a possibility of present failure and future breakdown. Jung says, "In psychoanalysis the infantile personality must be set free from the unconscious hindrances to its development in a rational manner. The energy which is thus freed serves for the building up of a personality matured and adapted to reality, who does willingly and without compulsion everything required of him by reality." " The Scotch have a way of describing a man by saying "there's not much to him." In analysis we find there is much more to a man than he was aware of, and this applies generally to the healthy and to the morbid. It is not merely a question of resources-it is one of energy. It is useless for a country at war to contain rich coalfields if there is no one to work them. The nervous invalid is in a similar position. He has large resources which he cannot develop and which are an actual encumbrance to him, because they offer a temptation to the enemy, and use up his own energy in an unproductive way in guarding them.

This brings us to an important psychoanalytic concept, called the libido theory. It was first introduced by Freud, but greatly extended by Jung, and I shall explain it entirely from the standpoint of the Swiss school. The term libido is used by Jung as equivalent to psychic energy, which is the central impulsive or propulsive force in human nature and human actions. It may also be described as passionate interest, desire, inclination, or striving. It may be applied to one object or another, from which follows the shifting of 1 "Psychology of the Unconscious," p. 479. 
interest from one thing to another. Like physical energy it may be kinetic or potential, i.e. active or latent.

Miss Maria Moltzer ${ }^{1}$ says: "Libido can perhaps best be described as effect or capacity for effect. It is capable of transformation from one form to another. The metamorphosis can be a sudden one, as, for instance, when one function replaces another in a moment of danger; or it can be a gradual one, as in sublimation, where the libido is led over a long and difficult path, through a variety of forms into a different function." Thus the combative instinct which makes war between nations may be directed to the struggle for international peace. One has only to think of a life's progress to realise that the energy which was once applied to activities infantile in character, and appropriate during infancy, has to take other forms at later stages of growth. The libido once given automatically to sucking is later devoted to eating, which is a conscious process. The love which was originally given solely to the mother, that is to an undifferentiated object within a group standing in the mother relationship, is gradually applied to the differentiated mother, to the nurse, father, other members of the family, and later to companions, teachers, lovers, and causes. We should expect that where development is normal, the libido would be differently applied at six, sixteen, and sixty, and, to judge by external behaviour, this is generally the case. But the libido must be looked for on both sides of the threshold of consciousness; not the whole of it is in the conscious life. Some is with our subliminal memories and imaginations. There is a tendency for too much of it to be applied below the threshold of cousciousness. This is particularly the case with neurotic people, for the reason that those who cannot live agreeably to themselves in the real world are led to create a world of phantasy to live in. This produces a thinning of the forceful currents of life, and in some subjects the thinning is so extreme as to result in complete dissociation of the personality - a fact illustrated by the classical cases frequently

1 "A Conception of the Libido." Paper read before the Zürich Society for Analytical Psychology, 1916. 
referred to in the literature of the Society for Psychical Research. Absent-minded acts show a temporary and partial dissociation; we are not "on the spot," as we say; that is, the libido has momentarily dipped into the subconscious.

In the analytic work we strive to find where this missing energy is located. We actually find that much of it is applied to phantasy building. We all know what it is to day-dream; but what we do not know so well is that day-dreams occur without our being even aware of them -they may be entirely subliminal.

A person may be said to be approximately normal when the libido is well applied, and flows easily from point to point, as required in thought, feeling, and action. A person is neurotic when the stream tends to stagnate and remain in lacunae, or to run in too many directions at once. He is then like the owner of treasure who has no means of realising it. There are people of many talents whose energy is lacking, and people of small talents whose energy is all available, and it is adapted energy, after all, that tends to make one individual more effective than another. There are some who have ample energy, but who are so desirous that they expend it extravagantly in overwork, so that their resources are always at a low ebb. The unconscious is the conserver of our memories, and among these our libido should be able to move freely, selecting one or another and inserting them into consciousness at the right moment. In the psychic sense our well-being may be said to depend upon a good rapport with the unconscious mind.

A neurotic person is deficient in control of his psychic energy. In a severe case he either cannot direct it to the useful end he desires, or else he uses it in an exaggerated manner. He is a victim to the phantasies formed in his own unconscious mind. In order to cure him, the analyst has recourse to dream or phantasy material, which arises from the same source as the hysterical symptoms and is of a similar nature. The symptoms are phantasy formations created by a displacement of energy from the psychical to the physical realm, consequent on the fact that to some natures physical 
suffering is easier to bear than mental suffering, and offers an escape from it. The neurotic person is not to be regarded as inferior to other people; he is very often superior, but more sensitive, and far too thin-skinned. $\mathrm{He}$ is not alone in making phantasies; phantasy formation is a perfectly normal mechanism; it is a function few of us would wish to be without. Every inventor makes phantasies before he makes his invention; the philosopher does the same in the process of arriving at his new concepts. The business man and the lover equally pave the way for their ventures with daydreams; the mother plans for the Christmas holidays in her phantasies. With the poet and artist their poems and paintings are more or less direct expressions of the unconscious mind. They may in a very special sense be called mediums of the subconscious. Shakespeare says :

\footnotetext{
Lovers and madmen have such seething brains, Such shaping fantasies that apprehend More than cool reason over comprehends. The lunatic, the lover, and the poet, Are of imagination all compact:

One sees more devils than vast bell can hold; That is the madman: the lover all as frantic, Sees Helen's beauty in a brow of Egypt : The poet's eye, in a fine frenzy rolling, Doth glance from heaven to earth, from earth to hoaven; And, as imagination bodies forth The forms of things unknown, the poet's pen Turns them to shapes, and gives to airy nothing A local habitation and a name. Such tricks hath strong imagination, That, if it would but apprehend some joy, It comprehends some bringer of that joy : Or in the night, imagining some fear, How easy is a bush supposed a bear ! 2
}

"The unconscious holds the germs of future conscious contents," 2 dreams and phantasies help us to arrive at new ideas. It also is compensatory to consciousness in its effect ; its normal tendency is to produce a balance in the personality, to tone down and soften extreme tendencies, and supply a point of view missing from consciousness. A person who pays

1 "Midsummer-Night's Dream," Act $\nabla_{\text {., Sc. i. }}$

"Jung's "Conception of the Unconscious. Collected Papers," chap. xv. 
too little attention to imagination is apt to be sterile. When we say he is without it, we recognise a defect in his character.

A case which illustrates the effects of subconscious phantasy is that of a Miss A., a young woman of thirty. She was brought to me because she had violent attacks of hiccoughs lasting from one hour to a whole day. She had an innocent mindless expression, and a high childish voice. She had at one time been clever and capable, for at serenteen she was forewoman of a room in a blouse factory, where she showed originality in designing and eutting out. She exhibited the usual belle indifference to her symptom so characteristic of the hysteric, for though the hiccoughs were of such violence as almost to jerk her off the couch on which she was lying for my examination, she yet wore the placid expression of an infant suffering from painless eructations of wind. Her guileless baby-talk was equally remarkable. I was obliged to send this patient into a nursing home, much against her will; and without giving her any other treatment I began an analysis, which was at first carried on every day for one hour. One of her early dreams was the following :-

Something was wrong with me, but what, I did not know. I was having advice from a gentleman who seemed to be a surgeon. He did a lot of talking with mother. He then lifted a little girl on to a wooden horse and pushed the horse and child into a pond. The ehild was wearing one of my dresses. We all stood and watched her sail away. After that the doctor went into a shop, still talking. My sister Maggie said, "That's the worst of Dr. Long."

Here the dream amusingly hits off the exact situation. Without giving details I will just say that my patient identified herself with the little girl on the horse by the dress she was wearing; the surgeon was identified with myself as the "doctor who talked so much." The "pond" brought up as a free association a previous dream. In this dream she was reluctantly coming to my consulting room for the first time, and as she crossed the street to my house a great pond spread out before her into which she fell; this she had called the Slough of Despond, for the 
thought of being treated medically filled her with despair. She did not want to go to a doctor; that is, unconsciously she did not want to get well. My talkativeness was a witty and revengeful criticism by her unconscious, of my persuasiveness in making her come, against her wish, for a second visit, and finally talking her into a nursing home. The pond, then, was a symbol for this terrible adventure of treatment. She is accompanied in the dream by her mother, and indeed by her whole family, for this grown-up baby is never far, psychologically at least, from her mother's apron strings and her childhood's companions.

The dream gives a picture of the childishness of her attitude. The little wooden horse was understood to be her psychic energy, which was a feeble affair-as unsuitable to her present age of thirty as a child's toy would be as a steed. The argument between the mother and the surgeon represented the tempest of emotions roused by making her conflict conscious. The conflict was between her childish adaptation to her mother, and the new demands made upon her that she should sacrifice the shelter which her symptoms had hitherto procured for her, and follow the analytical push out into life.

The make-up of this dream seems very like the story one tells children when one wants to point a moral. The unconscious is not a moralist by intention, but it is a picture maker, a weaver of parables. The meaning of the dream is arrived at, not from the manifest content (that is, the part of the dream which is remembered, and which probably is only a fragment of the whole), but from the latent content. This latent content is to be gathered from the free associations, which it is the analyst's business to stimulate and discuss in the time devoted to the analysis of the dream. The meaning of the dream lies on both sides of the threshold of consciousness. It is the analyst's art to bring the two into juxtaposition, so that understanding penetrates to the patient.

Earlier in Miss A.'s case there had been an attack of blindness of hysterical nature. It had occurred at the age of seventeen in this way. She travelled backwards and forwards 
daily between home and factory in the city. One evening, on her way home, she was alone in the carriage. As the train left the station a working man swung himself into the carriage, sat opposite to her and suddenly exhibited himself in an alarming and indecent way. She was rooted to her seat, unable to move or speak. A minute or two later he swung himself out as the train slowed up to enter the next station, which was Miss A.'s destination. She ran the three-quarters of a mile between the station and her home, arriving breathless and almost beside herself with terror and excitement. The only account she gave to her parents was "that a man had followed her from whom she ran." Three weeks later, as she was examining the work one of her girls brought for inspection, darkness fell upon her. She asked, "What has happened to the light?" Nothing had happened, but she had suddenly become blind, and had to be led home. This blindness passed away in the course of a few weeks, although her sight remained inadequate, and rendered her comparatively helpless for some years. She was no longer able to go out to work, and lost all her initiative, and though she became helpful in her mother's house, could take no responsibility. She constantly had hallucinations of being pursued; and once, like Luther, who threw an inkstand at the devil, she threw everything she had in her hands at an equally visionary figure which came in at her door. Her second severe psychical illness was that accompanied by the violent hiccoughs described. Sheiwas permanently cured of these within a week, and her cure has been lasting.

Several months ago she came to me again, looking anxious, and told me that no less than five times in the previous few weeks the kettle and saucepans had fallen out of her hands, the contents being spilled. The last incident of this kind was that she had washed up the tea-cups and absent-mindedly put them into a large enamel jug to carry to the dresser - "a stupid thing," she said, which she "had never done before." Five minutes later she emptied the jug into the sink, smashing all the crockery thereby! She also said that for several nights she had been wakened from sleep hearing her name called, and had gone to her friend, who was ill at the time 
and who was to her an adopted mother, saying, "What did you call me for?" But, like the infant Samuel, she found the voice was a subjective one. These acts are what is called "symptomatic," and result from a splitting of consciousness. They show the tricky behaviour of the unconscious, and their counterpart is sometimes experienced at séances. My patient had been neglecting to pay proper attention to the workings of her unconscious mind, and her phantasies had once more got her partially in their grip. They were a signal from her unconscious that she was in some danger of a fresh breakdown. Analysis of a few dreams soon brought to light the new problems which were disturbing her, and helped her to get her energy on the right track again. Miss $A$. has acquired insight enough into the analytic method to realise that she must be on her guard, and take preventive measures to avoid a breakdown, whenever she is disturbed by symptomatic acts of the kind described. In such symptoms one is able to recognise the beginnings of a psychic illness, a type of suffering upon which the use of a thermometer and the counting of a pulse can throw little light.

I now propose to give the analysis of a dream in some detail. A dream may be interpreted on its objective or on its subjective aspect, or from both points of view, supplementing each other. The line to be followed is indicated by the remarks of the dreamer. On the subjective side, all the personages that occur in the dream are dramatisations of the dreamer himself under various aspects, more or less disguised, and all the things they do and say represent different conflicting feelings or ideas of his. The dream characters are of the same nature as the different characters that appear in cases of multiple personality, or the personifications of automatic phenomena. To demonstrate this in the interpretation of dreams is generally enlightening to the person under analysis, because few people realise the simultaneous. existence of opposite feelings in themselves. In making the following analysis I asked my patient to give her free associations, taking the various dream-parts as texts. In order to arrive at these, the dreamer should be as passive as 
possible in regard to the ideas which come into the mind, should repeat them without self-criticism, and should reject nothing, no matter how far-fetched or irrelevant it may seem. This, though it sounds easy, is exceedingly difficult.

Miss B., the dreamer, is of the intellectual type. She is aged forty-five and has been engaged in teaching and literary work. She is suffering from inability to walk any distance, and has vague abdominal pains. She can walk about in the house and in her own room with a firm elastic step, but out of doors she is assailed by fears, and has to lean against supports. A distance of fifty yards seems well-nigh impossible to her. She has to come to my house in a cab, a walk of some four minutes. She once took this walk at my suggestion, and as a consequence had a collapse. She has been ill for seven years. Up to that time she earned her living, and led a most praiseworthy life. She was the youngest child of an unhappy marriage. Her father was a heedless spendthrift, her mother a patient Griselda, of almost saintly forbearance. The two were incompatible, and this youngest daughter, clever and sensitive, gradually sided with the mother, though undoubtedly most of her love was given to her father. As she grew up she soon put her talents to use, and earned an income, which later on she devoted largely to her parents' support and succour. Her holidays were almost exclusively spent in the family home, from a sense of duty. Here she underwent constant anxieties, and to a certain extent stood between the parents. It seemed to her in reviewing her life that it was one of perpetual sacrifice and self-less devotion.

In appearance the lady is quiet and self-respecting. She has a clear skin and well-cut features. She looks healthy, though at times she is very pale and worn, and she very soon tires. Her animation springs up quickly in response to intellectual or ideal subjects. Her expression is lively. If anything offends her she compresses her lips, and very angry looks sometimes dart from her eyes. This clange of expression indicates unconscious feelings and gives one the impression of slumbering fires.

She brought the following dream for analysis:- 
Dream.-I see myself in a strange room, there are people in it, but I do not know any of them. A gentleman of the company, who seemed to know me and to have some interest in me, asked me to come with him, as he wanted to show me a school building. I took my house shoes off and put them somewhere behind the leg of a piano, and put a blanket round my shoulders to go out, as it appeared to be raining.

When we reached the road outside, I saw on the left a cluster of beautiful blue-bells; farther down the road, on the same side, hung a great clump of wild broom in full flower. The road and the flowers were bathed in a beautiful clear light. The school building was some distance beyond the flowers, but we did not get to it, nor did I see it. I knew it was there.

While we stood for a moment on the road, I saw an animal glide out suddenly from among the blue-bells; in shape and size and in its sinuous movement, though not in colour, it looked at first like a weasel. A beautiful phosphorescent light shone right down its back. It glided swiftly across the road, and as it went it became much larger, and now the light on its back was no longer to be seen. It settled itself down on a low bank on the opposite side of the road with its back to us, and I now saw its coat was spotted greyish black and white and that it was quite a large animal. I asked what animal it was, as I did not recognise it, and was told it was a wolf, and I wondered if we had not better move away from its neighbourhood when I heard that.

There was something very sinister in the appearance of the creature, as it very quietly stretched itself out, apparently quite oblivious of our presence, but one felt in it a certain indefinable something that rather expressed or betokened extreme watchfulness, power, and knowledge. Then it rose up slowly, crossed the road back to the blue-bell clump and stood among the flowers; but now it was no longer a wolf, but a low-type woman with coarse, hard features, a hooked nose and unpleasant aspect. Her clothes were not ragged, but plain and tidy, and she wore a bonnet. She was talking to some one who stood near her. The dream ended there. 
The following are some of the dreamer's free associations:

School.-I have been associated with schools practically all my life and am interested in them. In Sweden I visited several and taught in some there. The schools in Sweden for the people are infinitely better equipped than ours. I have visited schools in Sivitzerland and in Paris, and have been present at language lessons given in schools in France and Switzerland. I have tanght in schools in Wales and England.

Blanket.-Suggests bed and warmth; one would not use a blanket as covering for the body except in a case of great urgency, and where it was the only covering available, such as in shipwreck, or fire, etc.

House Shoes suggest my present pair, which are of velvet and very comfortable, but nearly worn out. I always like to wear house shoes in the house.

Piano.-Calls up the pleasure I have in being able to play a little; but I like a good piano and sweet and rather muffled tone. Playing gives my fingers something to do and in this way is a satisfaction and pleasure, apart from the much deeper enjoyment of the music.

Blue-bells. - A stretch of blue-bells in spring gives me infinite pleasure. I don't like spring to pass without having this pleasure; I have missed something very helpful and beautiful if it does. I know of many blue-bell woods, all very beautiful, in Wales and also in Somersetshire.

Broom.-Grows more gracefully than gorse, without prickles, is less common, is very beautiful in a mass, although you seldom see it so. White broom is more beautiful than yellow. I can think of three gardens where there is some very lovely white broom.

Phosphorescent light.-Recalls glow-worms and fire-flies. I have seen the former in Ireland. This particular light strikes you as different from any light you have ever seen. I have noticed it on old tree stumps. I have translated a fairy story from the Swedish in which hobgoblins used rotten tree stumps for lights.

Wolf--Hungry, fierce, cruel. I have seen wolves only in 
Zoos; have translated stories from the Swedish in which wolves figure largely; belong to cold northern climates now.

Browning has written a striking poem, "Ivan Ivanovitch," in which a mother throws her children one by one out of a sledge to the wolres, so that she may escape herself.

Greyish black and white coloured coat.-Does not suggest a wolf; colours out of place; I like a decided black and white.

Woman low-type.-I saw a woman of this type at a railway station in London some months ago; such a face repels and saddens me.

The telling of this dream with its free associations occupied the first part of the analytical hour, which I am briefly describing. The latter part of the time was taken up in weaving the dream parts and their associations into one fabric in order to obtain the interpretation.

As this proceeding goes along, fresh-springing associations are added by the dreamer, and some analogies may be introduced by the analyst (the hermeneutic method) ${ }^{1}$ from history, mythology, or experience.

'The dream related gives, through its analysis, the patient's subconscious view of the present situation, and of her immediate problems and her own psychological attitude. It exhibited her orientation, for hitherto we only knew she was ill and in need of treatment, other treatments having failed to cure her. We knew that her illness was more psychical than physical; we could see she was a conscientious person, with a somewhat saint-like character; but without such a dream one would hardly know where to begin to work.

She is in a strange room, ${ }^{2}$ as indeed she is here in London ; there are other people in it; she knows none, that is, she does not personally know any one who has been analysed; she would "like to know what effect it has on others."

A gentleman who seemed to have some interest in her shows her the school building. The analyst is interested to

1 See Jung's "Collected Papers on Analytical Psychology," 2nd edition, p. 468.

2 The italics here refer to items in the dream, the inverted commas to items of the associations. 
show her something she has never seen before, that is, her unconscious ; analysis is a "new school."

She makes her preparations; she takes off her soft house shoes; they are indeed nearly worn out. This tendency of hers to keep indoors is hard on her slippers, which are so comfortable. She finds she ought to put off these comfortable outworn habits to go outside to the road. This brings an association with the command to Moses, "Put off thy shoes from off thy feet, for the place whereon thou standest is holy ground," and gives a religious aspect to the visit to the school building, that is, she must take her new effort at analytical understanding seriously. She puts the shoes behind a leg of the piano. The piano is an apt symbol of expression ; she prefers her sweet sounds "muffled."

She "plays a little." The piano at her lodging is poor and jangling and out of tune, so that the music she can produce just now is not satisfying. The "finger exercise" represents extraversion; the "deeper enjoyment" introversion. All the harmonies of her life are muftled. The putting of the shoes behind the piano is a makeshift affair. Things are not in their right proportion; how could a piano leg hide a pair of shoes? It is easier to live a half-invalided life than to take up a drastic new attitude. Like her slippers, she feels "worn out"; but this is equivalent to shipwreck, and that she thinks it so (subconsciously), is shown by her use of a blanket as covering; it is an occasion of "great urgency." This adds to the notion of a religious call, a sense of desperate personal need. The blanket has the significauce of something comfortable taken from her bed; she "loves warmth"; her ill-health has made her spend much time in bed, and value her comforts. She feels now like one who has lost her all in storm or fire. She is indeed an invalid and might expect shelter, and yet she has to go out in the rain to see a new school building. The demand of analysis is that she should take up life again. She consciously acquiesces up to a point, but the dream shows her to be wearing the blanket, a symbol of her invalid life, which she carries with her on her new venture. 
The school building was at some distance beyond the flowers. Much had to be seen, experienced and understood before it was reached. The flowers were interpreted as phantasies; the school is "beyond." Will the goal be reached? That is always the problem; has one enough patience and perseverance to get beyond the phantasies to the real working place? The dream puts the question but does not answer it. The school building had come up in former dreams as a place where she had done educational work, which had been rebuilt, and which she was re-visiting. It is something new on an old foundation. Perhaps what analysis requires of her is not altogether new, only a reconstruction and a fresh attitude to life. The new building is an improvement on the old; that much is clear. She knows that we must assimilate the new by means of the old, for until we can do this, we cannot accept the new, although the old no longer serves us. Until we can accept the new emotionally, our thoughts carry no conviction and supply no power. Thus she must bring over into the new life the blanliet that is so ill adapted to her new purposes. She will throw it away only when she is able to face the new requirements.

The road outside goes through beautiful blue-bells and is bathed in beautiful clear light. The flowers are the pretty phantasies about herself and life she loves so much. They are "beautiful," but danger lurks in them too. These spring flowers suggest new springing hope.

Broom was there, too, and the rarest kind, white broom. She "prefers it to gorse." It is typical that what is beautiful in her eyes is "rarer, more graceful and without prickles." This sensitive soul would like her roses without spines. Be it noted that broom suggests gorse in the associations. That is, a contrast of smooth and prickly. There is the idea of opposites in the associations with the colour of the wolf's coat, which was spotted greyish black and white. The dreamer likes "a decided black and white." Black and white represent evil and good. She has always wanted to separate the one from the other. Indeed, has she not done this in following the path of sacrifice? What else could she have done? This 
clear-cut attitude has repeatedly made her turn away from anything that is dubious and dangerous in life and revert to the known and approved. It has led her to adopt the path of sacrifice as "white," and reject all that is unknown, all her natural desires for herself, as "black." This attitude has always led her back to the parental home, no matter how unhappy that return made her. She had never risked spending on herself, or living her own life, because who could tell where it might lead? Suppose there was "a hungry wolf" inside one, how dangerous that might be!. We may call to mind here the legend of St. Francis and the wolf of Agobio. This hungry wolf was causing grief in the little town, robbing and killing. The saint went out to it, struck a bargain with it, tamed it, converted and led it home, turned it into a friend of the poor, and it became a guardian of the town. There is a kind of goodness that tames the animal nature by accepting it, and dealing with it; by uniting with it in friendship. This surely is the meaning of this legend.

But for our dreamer "white" is the safe colour. It is the colour of etherialised saints, of brides, and little children. She can keep herșelf pure and uninitiated and infantile by an invariable choice of white. But it does not really succeed. To remain spotless means to cut oneself off from real life and live in phantasies. Phantasies, however, have a way of running off with one, of suddenly becoming dangerous, that is, if one begins to live in them; and the sufferings (incidental to life in the real world), which one avoids, may push surrogates of themselves into consciousness in the form of neurotic symptoms, such as disability to walk, or vague abdominal aches and pains, which are alarming and penalising.

Miss B., whenever a choice is presented, decides to live for her parents. She identifies herself with her suffering mother, and bears the burden of her father's vices as though she were herself his wife. In thinking thus of others, she avoids thinking of herself, and evades that greatest of all problems in life-the acceptance of personal freedom and the necessity of learning to use it. This, in other words, is the task of dereloping her individuality. 
Timid natures, such as hers, unconsciously refuse individual thinking and feeling, and shirk the problems of love; which naturally arise and require enterprise and responsibility for their full acceptance. Miss B. thinks she is freely selecting a path of self-sacrifice. Her unconscious motive is that she prefers to remain a child; she cannot accept the temptations of freedom. She would ever remain with the "white," which she believes to be the good.

But the dream tells us the reason for this. Unknown there is an animal lurking. Out of the bed of the shelter of blue-bells darts a stealthy creature in the form of a weasel with a beautiful phosphorescent light down its back. It crosses from one side of the road to the other. It turns its back to her, as though disregarding the conventions, or so that it may be seen in all aspects. It increases in size as it mores, and becomes a wolf, and finally returns to the blue-bell clump; and behold it has now turned into a woman of low type. It is a kind of werewolf.

In looking at the woman the dreamer knows she is looking at a representation of herself. Her clothes are plain and tidy, she wore a bonnet. She herself is extremely neat and plainly dressed. The bonnet is a sign of middle age. The unpleasant aspect explains these darting expressions of illfeeling and malice that rise up so unexpectedly from her unconscious from time to time.

The beautiful phosphorescent light has the effect of a magic illumination. It reminds her of the torches used by fairies which are symbolic of the light of the phantasies; it reminds her of the inexplicable, baffling, insect light shown by the glow-worm and fire-fly-these humble things which are so wonderful and illuminating. This is the light that belongs to the subconscious view of things. It is "different from any other light." It is not the light of the intellect, but non-rational rather than rational in character. It is the light of intuition.

This analysis by no means exhausts the dream and its associations, but it must serve as an example of the way the work proceeds. It is carried on by means of a conversation 
between analyst and patient, which follows the patient's lead as closely as possible.

What is most remarkable in the dream and analogous material is its character as compensatory to the conscious thinking.1 This of necessity throws light on the daily problems. One is working in what Gilbert Murray calls "the uncharted region of the mind," ${ }^{2}$ which contains all the germinal material that may ultimately become conscious, and from which art and religion emanate.

The dream itself may in a sense be regarded as a primitive form of art, sometimes crude, sometimes lovely. The instance just given is clear and bold allegory, provocative of deep emotion in the dreamer and, when understood, capable of giving rise to a new set of values, and by the release of libido, providing some motive force towards a reconstruction of life. But though the dream is valuable as a stimulus, this is not all that is wanted It supplies only part of the motive for conduct, the other part must come from the conscious reason and the will. The patient in this case had been overthrown by her unconscious, and had taken her phantastic view of life for reality. Now in analysis we go to the very source of her overthrow and learn wisdom from it; we now use the phantasies that formerly made use of her.

The patient whose dream I have given is not unique in her breakdown. She represents complexes and conflicts to which all are subject. How to effect a compromise with life in its two aspects is a common human difficulty, but we do not all break down over it. Perhaps a temporary experience of neuroses would have a beneficial effect on many of us. It would teach us to sympathise with others, and help us to realise there is no precisely normal reaction, no exactly right path.

Our dreamer's "high has proved too high," her " heroic for earth too hard." The lowering of her standard would increase the possibilities of life. It is better to solve all the problems we can here and now, rather than postpone them for a future

1 Nicoll, "Dream Psychology," chap. vi.

2 Gilbert Murray, "Four Stages of Greek Religion." 
life. In order to maintain her one-sided attitude, she has pushed all she takes to be evil into the unconscious and disguised it with phantasies; and in doing this she has sacrificed her own development. Her ideal of perfection has kept her childish. The animal has magic in it; that is the strange light it carries. This power (for good or ill) is at present too much in the unconscious; and her emotional life is limited because of its repression. Her symptoms represent her repressed feelings.

Primitive man embodies the idea which I wish to convey in his attitude to his totem animal. His desire is to obtain its " mana" or virtue, its force or magic, and thereby enhance his own personality. His rituals, whether of participation or abstention, are directed to that end. The dream is on the level of "totemistic thinking," and expresses the notion of vital force under the symbol of the wolf, which later becomes incorporated in the woman. So Miss B.'s next step must be to obtain the "mana" from her animal nature. She must recognise that side of herself, pay attention to it, and consciously abstract from it what is useful to herself and to humanity. She will thus acquire forcefulness and an extension of her personality, and bring about that co-operation between good and evil, spiritual and animal, white and black, without which no life can be lived satisfactorily.

To act "nobly," according to a standard of virtue which she has not independently thought out and adopted for herself, is useless for one who has already broken down under such an attempt ; it does not work. What we want is to be as effective as possible on a level suitable to our capacity, and to live as free from neurosis or any other hampering manifestation as may be. The difficulty for each is to cut his coat according to his cloth, to find out what suits his special nature, to make a harmonious compromise. It does not do to be a saint or martyr in the conscious, and a werewolf in the unconscious. Such an attitude is bound sooner or later to be no longer supportable. The more sensitive and valuable the character, the graver the conflict.

Dreams have been denied a moral meaning; I cannot but 
think this is an error. In no department of human activity can an ethical bearing be excluded. The moral meaning is not, however, to be found in the dream alone. It would be dangerous to take a dream too literally or concretely; but it supplies the view missing to consciousness-missing because in some way painful to consciousness. The meaning is to be found only through the work of the conscious upon the unconscious.

I cannot agree with Miss Bradby's view that the unconscious is educable. ${ }^{1}$ On the contrary, it is always the primordial material of instincts and intuitions of ideas (archetypes), capable of endless new combinations, and charged with libido. The unconscious has the appearance of being educable because it reflects progress, or the reverse, in consciousness. Analysis by revealing the meaning of the symbols in the dream provides a view which is compensatory to the conscious one. This is enlightening, and when assimilated brings about a change in consciousness which leads to an improved situation. This improvement is in turn reflected in subsequent dreams which represent the new psychological state. The real work is done in consciousness, and is the effect of effort directed to a new understanding of life through assimilation of the unconscious. Intuition is an unconscious process. It gives a kind of uncanny wisdom to the dream; but its tricky character makes it an unsafe guide by itself. Nevertheless, intuition will often find a way where reason fails, but we must bring the weight of judgment to bear upon it. Freud says: "Nothing can be brought to an end in the unconscious; nothing can cease or be forgotten." 2 For such reasons the conflicts must be worked out in the conscious.

The dream just analysed was chosen on account of its general character. A trained analyst will find other meanings than those given; the patient herself as time went on found other important meanings and associations. It has been said that the whole of a life might be revealed from one dream

1 "Psycho-analysis and its Place in Life," p. 36. Bradby. Oxford Medical Publication, 1919.

2 "Dream Interpretation." Freud. Page 456. 
if the associations were followed sufficiently freely and far; but no dream can be exhaustively analysed, especially in public.

Before I myself had analysed dreams and become familiar with some aspects of the subconscious mind, I found examples of dream analysis very unconvincing, and I cannot hope that my own attempt will prove less so. One cannot recapture all the delicate threads of the conversation, and portray the subtle reactions that made it possible to bring the material above the threshold of consciousness; and when once the material is in consciousness and is so obvious, it seems as if it must have been there all the time. The dream gives a concrete picture of an incident that at first sight may not be interesting even to the dreamer. It seems meaningless till the free associations show it to have a symbolical meaning. The emotions attached to it belong to the psychological problems which also occupy the dreamer in the day, and the symbols selected are singularly apt, and often witty. An example of a witty dream, is the following. It ran: "Some people travel by boat, some by rail, but I always travel by Virginia creeper." We can all make a guess at the meaning of this dream, and in so doing we shall all interpret it differently. What it actually meant to the dreamer can only be known when the free associations are forthcoming.

The next instance of phantasy production is one which credulous people might be inclined to attribute to appearance of a spirit, but which to a student of analytical psychology has quite another interpretation.

A certain Mrs. C. had a hypnagogic vision. It was the head of a young woman with a peculiar and striking face. The keynote of the expression was sad. The face appeared on a grey misty background. Mrs. C. woke from this vision with a feeling of sorrow. On going to sleep again she saw the same head in a dream. This time it was a dead face. As the dreamer gazed at it, the eyes opened and looked levelly forward. Mrs. C. woke up weeping, and the memory of the hypnagogic vision and the dream caused her acute distress when she recalled 
it during the following day. Unknown to Mrs. C., then or since, the woman whom she recognised in the dream had committed suicide a few days previously in tragic circumstances, and her body was still unburied. Mrs. C. had seen her only threo times, then not to speak to and only for a moment. She had consciously thought her ill and sad-looking, and her striking appearance had roused a passing curiosity. One association with the dead face in the dream was of a thorn-crowned head of Christ painted or printed on linen, known as St. Veronica's handkerchief, in which the eyes appear to open as the gazer approaches the picture. Another association was of a so-called mystical painting, in which a cross appeared, which it was claimed had never been put there by the painter. Thus the head in the dream represented sorrow, despair and death, and also sacrifice and crucifixion.

All these emotions belonged to the immediate life problem of the dreamer, and her unconscious mind with remarkable sureness had selected, out of hundreds of indifferent faces seen in the previous few days, just the very one that poignantly symbolised her own particular sufferings. This appearance of the dead in the dream is a coincidence that we must necessarily come across when we observe unconscious phenomena, just as we find it in any group of conscious phenomena. It is obvious that the dream must be attributed to a reminiscence of the dreamer's, rather than to any supposed action of the dead person. What analysis adds to the view of its subjective origin is that it has a meaning discoverable by the dreamer, as representative of certain unconscious thoughts or wishes.

Those who have read reports of séances are often struck with the frequent banalities of the so-called controls. They serve to strengthen the supposition that the phenomena in question are emanations from the unconscious mind of the medium, and of the collective unconscious of the sitters through the medium. The material of dreams is often quite as trivial, but we recognise that it has no concrete value-only a symbolical one. In analysis the conscious mind is brought to bear upon it critically. This critical estimation is generally lacking in the evaluation of material produced at séances. 
During analysis the work done on the unconscious by the conscious mind continues to force fresh material above the threshold. Examples may be given which treat of the relation between the analyst and the analysed person. Incidentally they show how humorous the unconscious is. E.g. a lady expressed feelings of parsimony in the following way: She dreamed that she was being fitted by a Bond Street tailor for a coat and skirt; she regretted she had not bought it before the tailor had removed to this expensive address, as he had made them just as well at half the cost when he lived at Surbiton. This actually refers to the recent removal of the physician from a suburb into the area of consulting practice. She could have paid smaller fees if she had consulted him before his removal.

Another patient ended a spell of analysis with a wish to establish friendly relations with the doctor. This did not seem possible. She dreamed that she was on an island. A beautiful dolphin visits her on Government business. As he swims away she feels very sad, and notices that his tail is studded with yellow discs. They are of shining metal, and strengthen the tail as a band of metal strengthens the blade of an oar. The analysis showed the metal discs to represent golden guineas, symbolic of the cash nexus which she now feels to be the sole bond between her and the doctor, and which she tries to rejoice over, on the ground of cash being necessary to his well-being.

The analyst often turns up in his patient's dream under any guise that fits the situation of the moment. In a single day the dreams of various patients might depict him as: (1) a policeman, representing a guardian of law or a helper; (2) a siren, one who draws into danger; (3) a ship's stoker, one who attends to the invisible sources of energy ; (4) a gardener, one who cultivates growing thoughts and feelings, or who prunes bushes, and nurtures seeds ; (5) a piece of jewellery, which may be either precious or a sham; (6) the Kaiser, one who makes bombastic assertions; (7) a bull with a swollen head who obstructs the only gap in the hedge. Every symbol would have its special meaning for the moment, and would be 
changed in the course of analysis as rapidly as the mental attitude changes. Though in each case the analyst is meant objectively by these characters, they have a subjective meaning as well, standing for some attitude or feeling in the dreamer which is projected on to the analyst.

The analysed person appears to himself under innumerable guises. His ambition may be symbolised by Alexander, his power by Jore, his patience by Job, his piety or sexuality by monk or nun, his self-depreciation by a cringing dog, his temper by Xantippe, his greed by a ravening wolf, his childishness and greed by a sucking pig, and so forth. The problems with which the dream is concerned are curiously veiled, not for purposes of concealment merely, but because the subconscious naturally thinks in terms different from the conscious, and is trying to solve problems by seeking analogies. The dream is a means of expression. It is, according to Jung, "the subliminal picture of the psychological condition of the individual in his waking state." It is also a fact that the subconscious view of a problem is often different from the conscious one. Just as the day-dream offers a relief from the hard facts of reality, so the night-dream refreshes us with the opposite point of view, or points out our error or reassures us in a picture. The dream is a source of wisdom, as we all unconsciously admit when we leave some knotty problem overnight with the words, "let us sleep upon it."

Sometimes we find that the psychological problems are brought up under a recurring dream character. This personification persists until the problems connected with it disappear -till "the ghost is laid," in fact, not by magic but by development, by assimilating into consciousness the repressed elements which the dream-character in question represents. Let me illustrate. Miss X., a kind-hearted woman of forty, with the benevolent feelings of a social worker, was generous-minded and affectionate, but she was also slangy and aggressive, and unconsciously inconsiderate of the feelings of persons with a different outlook on life. In some respects she had the psychology of an open-hearted public schoolboy of sixteen who is well-intentioned, but careless and regardless of the 
feelings of others. In her dreams the following character appears again and again under slightly different guises; each guise embodying some special point $a$ propos of the occasion of the dream. The character is a youth-like a Greek youth, and rather like the Faun of Praxiteles. He is more like a natural and kindly animal than a man. He might be mentally or morally defective, but is quite amiable and gay. He has a romantic appreciation of feminine charm. He appears under the following circumstances:-

(1) A policeman comes to arrest him good-temperedly and put him where he can do no harm.

(2) He had been sent up to Cambridge, but only wasted his time. Now he is going to have another try.

(3) Miss X.'s father helps her to capture him when he "runs amok" in the house and is a danger. Once caught, he can be "put on his honour."

(4) He comes home as a semi-prodigal and joins family prayers, but is allowed to look at a picture book.

(5) Returned from the hunt, he sticks his legs up on an inn table, whereupon the company, shocked at his manners, proceed to hunt him.

(6) He wakes up and is terribly frightened to find himself alone.

(7) As "Sir Pompey Briseas"-Breezy Ass-he is required to enter into an estate and manage a property. He hates having to do it.

This character reappeared until the unconscious trends symbolised were fully acknowledged, and the attitude abandoned-at least in intention, for it takes time to work the change. Such an unconscious attitude creates many difficulties in life, puzzling the patient, who is apt to think these difficulties are owing to faults of others. Her conduct is influenced, none the less that the irresponsible side is under repression, and in this case concealed by enthusiastic interests in life. Here $I$ may add that the sex of a dream personification matters little-male may stand for female and vice versa. The symbol most appropriate will be selected, regardless of sex, or because of it, as the case may be. This should not 
surprise us, because every normal human being contains elements of both sexes, not only biologically, but also psychologically.

The next example is a cryptic word which occurred in a dream, in the making of which a great condensation of dream ideas has taken place. Here I must again remind you that the remembered dream is the manifest content only. As Freud says, "The first thing that becomes clear to the investigator in the comparison of the dream content with the dream thoughts is that a tremendous work of condensation has taken place. The dream is reserved, paltry, and laconic, when compared with the range and copiousness of the dream thoughts." 1 I do not propose to relate the dream, but will merely give the word and the associations attached to it, supplied by the dreamer, who was Welsh, and a speaker of Welsh. She saw on a doorplate the word: "Anwlwimdwy."

The immediate associations were as follows:

Anwl-was a Welsh word meaning "dear."

Dwy-means "two," and is the feminine form of the numeral adjective.

$\mathrm{Wy}$-(1) a common ending for names of places; it means a current of water.

(2) the last syllable in her mother's name:

(3) the first syllable in her sister's name:

(4) a word meaning "egg."

Lwm = "lum," part of the names of two people of whom she thought, giving associations.

Wlwin $=$ cwlwin $=$ " knot."

$\mathrm{Nwl}=$ niwl $=$ "fog."

Mdwy = modrwy = "wedding ring."

English words gave the following associations:

Anwl = annul, null and void.

Wmdwy-Humpty Dumpty, the Liberal Party, Antisuffrage.

Lum $=$ Lump.

Following these items back to early reminiscences, she recollects that at the age of nine she associated with three 
children whose names all began with $\mathrm{W}$, and now noticed that in Anwl, Wm, Dwy, there are three W's, and Wy suggests the name of two of them, but the third has no letter beyond the W. Every one of the foregoing associations led to important dream thoughts. Anwlwimdwy, like a word-salad, is merely the form that conceals the latent content. It is a symbol, embodying psychological problems, a language of signs which has the significance of shorthand. Analysis finds the associations, showing subtle connections between the form and its contents; these connections represent the dream thoughts.

Another short dream showing similar mechanisms occurred to a middle-aged man, who was thinking of proposing to a lady who lived in Highgate. He was feeling dashed by recent experiences, and was inclined to give up his quest. As he woke one morning he caught this fleeting dream: "Archie Hemel Hempsted." The associations with Archie were: an ingenuous youth; the railway arch: Archway Tavern; Highgate Archway; the way to Highgate-this was the way to the lady of course! Hemel-Himmel = Heaven. "What is the German for saddle (he continued in associating), and for a camel's hump, which is not a defect, but is useful to ride on?" Hempsted was a combination of Hampstead and Hemel Hempsted-two places associated in the dreamer's mind with successfully wedded couples who are free and natural people. His mixed attitude to this problem of marriage, needing such courage on the part of our timid dreamer, is well shown in the camel's hump - " having the hump." The question about the German for saddle means: won't he be saddled? but will it not be Himmel? etc., etc. I need not elaborate further.

When dreams and phantasies fail, as they occasionally do in analysis, there is either conscious material to work upon, or other subconscious produets, such as verses, drawings, paintings, or models. All is grist that comes to the analytical mill. A certain patient brings me a kind of shorthand drawings, which analyse out very usefully. They are extremely abstract-looking forms, sometimes mere lines or curves, 
symbolising repressed feelings; they are not unlike some scribblings I have seen in Miss Johnson's accounts of Mrs. Holland's scripts.

One comes to believe that nearly everybody is capable of some form of primitive art, and that it, like the façade of the dream, is a fruit of the symbolic function of the unconscious mind. Some patients bring models done in plasticine. These are executed as unconsciously as possible; others bring verses, or automatic script. These things are appraised analytically, not from the artistic standpoint, though occasionally evidences of real art appear in a latent or nascent state.

Any effort to force an interpretation of subliminal material falls flat. The intelligent patient will have none of it. When the material is rightly handled, the more obvious and simple truths go home at once, for the reason, as Jung says, that the analyst "has a confederate in the patient's unconscious." The interpretation of the symbols wakens the most vivid interest at once, and carries conviction. It is this vivid interest that helps the patient over many difficult places in analysis. Analytical work follows laws and demands a technique. The training which analysis gives in the observation of unconscious phenomena greatly deepens the individual's rapport with his own unconscious and so brings his other side into closer union with his consciousness. The Swiss school advises that after an analysis, the patient should remain in touch with his unconscious, that is, by paying attention to it and carrying on his own analysis to the best of his ability. "The real end of analysis is reached when the patient has attained adequate knowledge of the methods by which he can remain in such contact, and apply its results to his life." 1 The problem is how to adapt oneself to the necessity that life lays on one. This can only be done satisfactorily by paying sufficient attention to the inner demands as well as to those of the external world. It is natural to make efforts to overcome the obstacles in life to a certain degree. When the obstacles are too great, and the man gives up trying to overcome them, the energy that should have " Analytical Psychology," p. 471. 
been thus used turns instead to producing emotional disturbances, physical and mental. It is imperative that a solution for the patient's conflicts should be-found, and it should be found by the patient himself. For the aim of analysis is to leave him morally responsible. It helps him to discover where his libido flows most freely, and to find the path in life where he can be most truly at one with himself. When he has learnt to find the latent values in himself, he should be more tolerant and harmonious in his relations with other people and more satisfied in himself. It is with this important aim of helping to unify the personality that we make analytical use of subliminal material. 


\section{THE CENSOR AND UNCONSCIOUS SYMBOLISM IN DREAMS ${ }^{1}$}

THE importance of dream and phantasy can scarcely be overestimated. They spring from the basic foundations of life, and unfold to us the origin of thoughts, feelings and intuitions. The unconscious, which is the dream-originating mind, is in ceaseless activity, moving beneath and around consciousness which it is perpetually influencing. It sends signals of various sorts to it. 'The dream is one sort of signal, the neurotic symptom is another. Others are unreasoning fear, prejudice, trivial mannerisms, ready wit, slips of the tongue, intuitions, as well as the phenomena of neurosis, delirium, and madness.

It is clear that what we know of ourselves leaves very much unexplained, and we are forced to the conclusion that "self-consciousness does not exhaust the ego." 2 We might almost conceive of the ego as surrounded by the personal unconscious, which is itself suspended or imbedded in the universal unconscious. There is one way in which we have access to any part of this mental territory, and that is ria the dream and phantasy.

Even a superficial examination of the dream shows it to be a dramatisation of which the individual dreamer is the author. We can no longer retain the idea that the dream is sent by an external divine power, or share the primitive's notion that a spirit has entered the dreamer, or that he has gone out of bis body in spirit-form to hunt or fight with another being.

In the dream the ego is split into several characters, which occupy the stage. The conversations carried on have the

1 Lecture delivered before the Quest Society, January, 1919.

2 Du Prel, "Philosophy of Mysticism," vol. ii., p. 13. 
significance of monologues in which the conflicting ideas are represented. For example, Dr. Johnson had a dream in which he was in argument with another man. He came off badly in the argument which his friend sustained with wit and reason. When the good doctor awoke he was puzzled as to why the word of wisdom had not been with him. Here we can easily see that both arguments in the dream were sustained by Dr. Johnson. The reason why the conscious " I" of the dream came off second best we cannot now fathom, because the explanation belongs to the psychological situation of the dreamer, a matter to which we shall refer later.

An intensive study of the dream seems to reveal a thread on which the successive epochs of mental development are strung. This should not surprise us, for we have looked too long for a unifying principle in the conscious life only. One third of our lives is spent in sleep, a state in which man is obviously plunged into a different sort of consciousness from that of his waking life. As Du Prel says, "sleep and waking are of equal importance for the solution of the human enigma." In sleep we borrow from consciousness much of the material for our dream, just as in waking life we unceasingly borrow from the unconscious, ideas which present and insert themselves in the mental stream. The idea may be a right or a wrong one for the purpose in hand. A good rapport with the unconscious predisposes to the selection of the right idea. Common sense might be defined as a sense that is common to both sides of the mind; it implies a rapid presentation of suitable ideas on the part of the subconscious, and a right selection of ideas on the part of the consciousness. Such equal working of the two sides of the mind, the creative and the critical, the emotional and the rational, constitutes mental harmony. The appearance of duality in the mind lies in the fact of a threshold of consciousness. Although there is no real duality, there is a qualitative difference in the mental functioning above or below the threshold. Just as we explain man biologically by the present and the past, so we can explain him psychically. Man as a species is now performing automatically and involuntarily bodily processes that occupied 
the total life energy of former species in his own line of descent. He is no longer engrossed in the activity of digestion, and only when ill is he reminded of his organs. The "consciousness" of the amoeba, like the consciousness of the early primitive, becomes subconscious in civilised man. The shifting forward of the threshold of consciousness approximates to the growth of a new sense. The threshold, as we know it, may be said to have its origin at that epoch of evolution when a distinction is realised between what is objective and what is subjective. This progress in human thought is the result of natural evolutionary strife. Man is required to adapt himself both to the inner (subjective) and to the outer (objective) world. The battle, so to speak, takes place at the threshold of consciousness; this is where man lost his Eden, when he had already very far adranced beyond the time when "mind was mud" as Meredith puts it."

Frend does not speak of the threshold of consciousness, but of a "preconscious" area between the conscious and unconscious. In this area he has postulated a Censor of Resistance. He says that two psychic streams are represented in the dream. First, there is the wish tendency always striving for the expression of some repressed desire; and secondly, there is the censor always striving to prevent this tendency from gaining expression.

These two psychic streams are always in opposition to one another. The unconscious wish is too primitive in character to be acceptable to consciousness, so that the censoring of the wish produces the distortion in the dream. The censor as a concept embodies all the repressive forces acting on behalf of the civilised personality. In waking life the censor is in control, except in moments of mental aberration or relative dissociation.

The dream, according to Freud, is " the disguised fulfilment of a suppressed wish." ${ }^{2}$ It is, he says, in every instance a wish realisation, "because it is the product of the unconscious mind which knows no other aim, and which has no other

2 "Woods of Westermain."

2 "Dream Interpretation," p. 136. 
forces at its disposal but wish feelings." 1 The wish referred to is not necessarily shown in the manifest content, that is, the remembered dream. It is indeed very rarely seen there except in children's dreams.

Du Prel, writing before the date at which Freud published his "Dream Interpretation," said, "The content of our dreams is difficult to catch, and more difficult still is it to understand this content, since the dream is a cluster of intimate problems. This intricacy explains the two extreme modes of regarding the dream-that of the old philosophers and that of the modern dream-contemner. The one who thought that highly important phenomena are to be discovered in dreams, if only in fragmentary form, is disposed to the superlative view by the very difficulty of understanding them. Thus the ancient Greeks. Others, again, take the disorder of the presentment for mere presentation of disorder, and deny to the dream any scientific significance whatever. Thus the moderns. Extreme opinions are never true. We have to hit the mean . . between over-estimation and under-estimation." 2

That writing about dream and phantasy has a sort of vogue to-day, we see from the great interest aroused by such books as A. E.'s "Candle of Vision," and Algernon Blackwood's phantastic novels. Productions of this sort may be overestimated. Dreams arise involuntarily in all sorts of people. Quite illiterate persons, and even mentally deranged people at times produce dreams of exquisite beauty. The unconscious mind is the artist who produces the dream. The aforementioned writers differ from ordinary dreamers in possessing the ability to write their dreams in good literary form. What we do with our dreams expresses our personal work. The dreamer who can learn to detach himself from his daydreams and his night-dreams, so as to abstract thoughts and ideas from them, or who can turn his gift to creative purposes, has acquired in this way a new range of perception and new faculties. It is through the possession of a marked ability

1 "Dream Interpretation," p. 448.

a "Philosophy of Mysticism." Du Prel. Vol. i., p. 52. Translated by C. C. Massey. 
of this kind that the poet or man of genius is distinguished from the average dreamer. There is a special temptation to give a false value to the dream at a time like the present, because dreaming or phantasy-making offers a relief from the painful realities of a world in disintegration. Many persons are killing time, "and incidentally killing eternity," by dreaming of what they will do when we return to the delights of pre-war days-days that can never come back to us save in anodyne dreams.

A short analysis of a dream follows which will serve to illustrate points as they arise. The remembered dream is but a fragment of the whole. In this case the manifest content is very brief. What we discover by analysis is not the lost dream, but the thoughts of the dream.

A young woman woke with the memory of the following dream sentence : "Follow the grave-diggers," and at the same time she saw a piece of ground with three marks something like footprints upon it.

The associations which follow were entirely supplied by the dreamer, as they arose in consciousness. The facts were originally quite unknown to the analyst, and are not, as critics so often believe, the result of suggestion.

The dreamer had the impression that the three footprints indicated progress to something which lay beyond, at least that was the emotion evoked when she looked at them. They were square and cut in the ground, and suggested half-dug graves.

The number three brought up memories of three funerals. The first was that of the head mistress of her early school and recalled the unintelligent way in which the dreamer had been taught, the bad tone of the school, and the bullying of the tiny children that went on. She was a very shy and awkward child and suffered because she was badly dressed; she seemed to have nothing in common with her little companions and could not join in their games. She attributed her solitariness to her home life, for her mother (who later on went out of her mind) was very untidy and peculiar, so that the child's life was full of care and anxiety. She had to be nurse and 
helper to her mother at an age when most children are playing with dolls. As she was very sensitive, she was sadly depreciated in her own estimation by all these things.

The second funeral was an aunt's. It took place in Rome. She spoke of her uncle's grief and her wish to comfort him. This she dared not do, because she was very conscious of the fact that she was not in mourning, although she felt she could have said much more comforting things than the other relatives who offered consolation.

The funeral brought up memories of a former visit to Rome, and a stay with a rich aunt, with whom she had nothing in common. At the time of her visit she was going through a phase of religious conviction, with rigid observances. This irritated the aunt, who was agnostic. Moreover, she was badly dressed and awkward, whereas her aunt was fashionable. She thought also of the relations between this aunt, and the one whose funeral was under discussion; the latter was very bourgeoise, and the two were mutually antagonistic. The dreamer hated convention, but was always feeling uncomfortable because of her external lack of it.

Lastly, she thought of the third funeral, which for her was the most important of the three-that of her mother. The mother's death could only be regarded as a relief, and yet it called up much sadness. She thought of her father's grief, and of her own unbecoming mourning. She "hated black." At that time her feeling about death was that it was a "retribution." Indeed, punishment seemed the keynote of the whole ceremony. She spoke of all the things of which her mother's illness had robbed her. She feared to marry; she even feared to make an intimate friend lest she should become a burden to others as her mother had become to her. Even during her holidays she had never had pleasure like other girls, on account of perpetual nursing and housekeeping. She had never been to a dance. When she was in society she did not know how to be frivolous or merry like other young women, and she was always under a sense of guilt.

A notable feature in this dream is the recurrence of similar emotions at each funeral-one may call it an identity 
of emotion; in each case she revives the memories of poignant sorrows of early childhood and youth. They are all associated with fears about her mother's mental state. A sense of inferiority is always present on account of her disorderly home, her poor education, and because she was badly dressed, and awkward in society, and unable to express her feelings with the ease of most people.

In all these ways she identifies her fate with her mother's, and fear of insanity is at the back of her mind.

Now as regards the actual situation: this lady is in many ways well equipped. She is highly educated, and trustworthy; she occupies a responsible position, and is eligible for a better one. She has a thoroughly reliable character, but she keeps a childish attitude to life in her sense of inferiority and self-distrust. This debars her from a happy life. As the result of her mental idiosyncrasies, she is easily wounded by her friends-life seems all retribution. Her own feeling is projected on to the world.

The dream, when analysed, tells her that she is unconsciously tied to her mother's fate because she has identified herself with her mother. So long as this mental attitude persists, she will inevitably and logically adopt a suffering rôle in life, because she experiences the emotions belonging to her mother's fate, not to her own. Her mentality exposes her to martyrdom, and invites suffering.

The associations connected with the dream-sentence, "Follow the grave-diggers," ran somewhat as follows : Gravediggers are those who in burying the dead do a public service. They do not feel their work personally-that is, with any sense of personal loss - and when it is done they go back to ordinary homes and share the same kind of rest and comfort as other workers. The dreamer feels she, too, must get rid of her symbolical corpses, these dismal emotions that she drags about with her. For it is these persistent emotions which depreciate her and make her unable to share the common joys and sorrows of life.

A treble emphasis is put on the necessity to make stepping stones of her "dead self" by the three half-dug graves. It 
means a sacrifice of the childish personality, which is the cause of the neurotic attitude in life, and which prevents her from adjusting herself in a healthy way to her environment. The grave for the childish personality has been half dug several times.

It is highly probable that the emotional attitude engendered by clinging morbidly to the past actually predisposes to mental disease. The person who is over anxious about insanity invites the very fate he fears. Probably in the course of time this factor of an unconscious bondage to the hereditary fate will be seen to have a greater bearing than even the physical inheritance in determining the outbreak of a psychosis.

One may ask, "What good can the analysis of such a dream do?" It can do much good. It makes things conscious that have been unconscious and yet dynamically active. It brings about a better understanding of the dreamer's difficulties. In this particular case, instead of being made to feel inferior by others, the dreamer was making-herself miserable and inferior by her subjective view of life. She was projecting what was missing in herself and her own attitude on to others and on to her environment. The dream indicates a new direction. It is one of those dreams which is like a prophecy, in the sense of an inspired utterance, not a forecast of the future. It was just in this sense that certain of the Delphic Oracles were uttered. The ordinances were cryptic in character. Inspired by the subconscious, they were also elaborately worked at by a priesthood in possession of a well-organised intelligence department. When given to an intelligent inquirer anxious about the next thing, they were productive of "furious thinking "; since they were open to various interpretations, every possibility had to be taken into consideration. The general effect of the oracular saying was to get the best possible wisdom out of the votary. It was the business of the oracle to be wise in itself.

The method of dream analysis, as my example shows, consists in taking every part of the manifest dream-content and examining it separately. We try to find how it has been 
formed, what events and impressions of the day have entered into its composition. We instruct the patient to speak of everything that comes into the mind, following a process of free-association of ideas. This brings out a multitude of thoughts which are connected with the dream, in fact everything that passes in the analytical hour bears upon the dream. There is nothing unimportant or insignificant in the dream or in the thoughts that are contained in the dream. The dream is a "momentous psychic act" (Freud). Every symbol has a meaning and one or more determinants. The symbols are not related to one another directly, but indirectly through the dream thoughts which are only shown to be relevant during the analysis. The dreamer himself may be represented by similarity or identification with a person in the dream. There are certain limitations in the dream. Negatives are generally, but not always, indicated by failure to accomplish, such as, "I cannot move"; and by obstacles which cannot be overcome. Criticism is generally expressed indirectly by presenting situations which are absurd, or equivocal in character. Hence in place of judgments alternatives are put, or a composite symbol condenses into one form several situations or tendencies. Judgment is left to consciousness.

The emotional values of the symbols and situations depend much more on the dream thoughts and the dream identifications than on the manifest content. All the material introduced into the dream is psychologically significant.

It is notable that there is no sense of proportion or sequence between the dream experience and the dream emotions. This displacement is necessitated by the choice of material, and the dream's "regard for presentability." Freud points out that the unconscious can only represent abstract thought by a recasting of the ideas into figurative language, ${ }^{2}$ in which cross references and identities play an important part, bringing about a condensation of many thoughts into one symbol, and great alterations in psychic intensities. One would suppose that in this factor we had reason enough for

1 “Dream Interpretation," p. 422,

Ibid., p. 314. 
the symbolism in dreams; but this is not Frend's view, for he expressly says that "he regards the disfigurement of the dream owing to the act of the Censor of Resistance as the essence of his dream theory." The censor is able to force the wish system to disguise itself. This disguising process in his view forces symbolism on the dream, and the choice of the symbols is the result of some necessity to form thought connections in particular directions. ${ }^{1}$ Memories and phantasies dating from childhood are very generally introduced. These memories may not appear in the manifest content, but they are at once aroused by looking for ideas associated with it, and are often only discovered by allusion. Freud holds that the sexual factor is always present in dreams, and "as a motive for the exercise of the censor receives striking prominence." 2 In sleep the censor is in a measure overpowered. Should the dream wish come through in an extremely crude form it is because the censor is completely hoodwinked. In this connection Freud gives what seems to be a very specious bit of reasoning when he says that sometimes the dream wish reaches such a depth of depravity (e.g. a death-wish towards the father) that it completely escapes the censor and is transferred to the dream without alteration, because we could never have dreamed of anything so wicked, therefore the censor is not prepared for this monstrosity, "just as the legislation of Solon was incapable of establishing a punishment for parricide. ${ }^{3}$

The dream censor is a necessary postulate of Freud's view of the unconscious, which, according to him, "knows no other aim than the fulfilment of wishes," and exhibits only primitive tendencies. That this is an important aspect of the unconscious cannot be denied. But there is another view of unconscious processes which, as we shall see, seems to make the censor superfluous.

The censor has nevertheless been an extremely useful concept, and one that should not be undervalued. The word itsclf is a good instance of symbolism, and has been of great service in the formulation of the Freudian theories. It served

4 "Dream Interpretation," chap. iv.

2 Ibid., p. 157.

${ }^{3}$ Ibid., p. 226. 
as a bridge to more discriminated ideas, and we may be quite sure that Freud's lasting fame will not rest either on the retention or overthrow of his censor. His discovery of a scientific method of dream interpretation is sufficient to put him among the Immortals.

The adherents of the Swiss school of analytical psychology interpret dreams both objectively and subjectively. When the dream symbols represent real objects of love or hate or interest in the outer world and are so understood, and so referred to in the associations of the dreamer, we call the interpretation objective, a term akin to the "material category" of Silberer. ${ }^{1}$ This kind of analysis dissects the dream into its memory elements, and relates them to matters of fact. This is causal interpretation.

Subjective interpretation relates the dream elements to the feelings of the dreamer. In this all the rôles played by the people or things in the dream are regarded as expressions of tendencies or attitudes or views of the dreamer. This approximates to Silberer's "functional symbolism." Subjective interpretation is extremely important from the teleological standpoint, for it points to the solution of the individual problem, the dream as a rule constellates round the most difficult and painful problem of the moment. Both kinds of interpretation are valid. The one is analytic, and leads down into the depths of the impulsive life. The other is synthetic, and brings back from the depths the raw materials for the purposes of constructive life.

This twofold interpretation fits into the general scheme of life because adaptation is itself twofold, viz. to the inner subjective world of psychic reality, and to the outer objective world of material reality.

Jung's view of the unconscious does not require the retention of the censor. In his idea all psychic phenomena, including the dream and the neurosis, are manifestations of psychic energy. This energy "is subjectively and psychologically conceived as desire or 'libido,' or vital energy in

2 "Problems of Mysticism and its Symbolism." Silberer-MIoffat, Yard $\&$ Co. 
general." While "the dream, for Freud, is in its essence a veil for repressed desires which are in conflict with the ideals of the personality," for Jung it is "in the first instance the subliminal picture of the psychological waking state of the individual." 2 Instead of being only the fulfilment of a disguised wish, it is also a means of expression of things necessary to be understood or considered. The dream pictures individually have a concrete value, "they do not intentionally conceal ; they teach and help to reveal." For the Swiss School, the meaning of the dream symbols is individual and manifold. There are no symbols with absolutely fixed meanings, ${ }^{3}$ though there are many "typical" ones, which appear everywhere. These form the constantly occurring images and motives of mythology. They are indigenous, and present in the legends as well as in the rites of primitive people all the world over.

Dr. Ernest Jones" says : "A given symbol may have two, or occasionally even more meanings; for instance, in dreams a room may symbolise either a woman or a womb. In that case the interpretation will depend on the context, the associations and other material available." This admission should open the way to more liberal views; but for the Freudian, all the symbols seem to work out on one basis.

As an example of a symbol with a fixed meaning, we may cite the well-known Freudian interpretation of stairs, steps, or ladders, ${ }^{5}$ as coitus symbols. I admit readily this meaning

1 "Dream Interpretation."

" "Analytical Psychology," p. 222.

4 "Psycho-Analysis," 2nd edition, p. 139.

s Stairs, steps, or ladders often appear where a change to some other level or state is indicated: as from death to life, from a higher to a lower moral status, from affluence to penury, and so forth. The going up, or climbing, may symbolise strenuous effort; the coming down may mean relaxation of effort, or possibly descent into the unconscious. Jacob's ladder is familiar to us; and Frazer tells us in his "Folklore in the Old Testament" that, "Some peoples both in ancient and modern times have imagined that the souls of the dead pass up from earth to heaven by means of a ladder, and they have even placed miniature ladders in the graves in order to enable the ghosts to swarm up them to the abode of bliss. Thus in the Pyramid Texts, which are amongst the oldest literature of the world, mention is often made of the ladder up which dead Egyptian Kings climbed to the sky" (vol, ii. p. 56).

"It ls, or used to be, a popular belief in Russia, that the soul had to rise from the grave, and therefore certain alds to climbing were buried with the 
is sometimes present, but $I$ have looked for it in vain in scores of dreams where the free associations of the dreamer pointed to quite other interpretations. It is a misappropriation of symbols always to interpret them in the same way. When the attention is over-concentrated on any one idea (as, for instance, that all symbols have a sexual significance), it is possible to miss quite obvious meanings of another kind. Students of psycho-analysis will in the course of time have to adopt a broader basis for the interpretation of symbols than the exclusively sexual one. Freud has protested that he is "not responsible for the monotony of his interpretations." But if it is decided a priori that practically all ideas symbolised are sexual, no other ideas will be sought or tolerated; and of course their number will seem few.

"But $O$ the truth, the truth, the many eyes That look on it! the diverse things they see According to their thirst for fruit or flowers!" 1

Jung points out that primitive man was enabled to advance beyond his original state by the aid of the symbol. ${ }^{2}$ $\mathrm{He}$ had resistances against sexuality, and tendencies to improve his state. The imposition of tabu is the half-conscious legislation of the primitive against himself. This resistance against sexuality formed a block for the flowing libido, which then betook itself to another stratum of consciousness and, unable to realise its wishes wholly, fell back upon phantasy and the formation of symbols. Thus the energy was transferred again to the unconscious sphere, as a result of "the

corpse. Among these were plaited thongs of leather and small ladders. One of the most interesting specimens of survival to be found among the customs of the Russian peasantry is connected with this idea. Even at the present day, when many of them have forgotten the origin of the custom, they still, in some districts, make little ladders of dough, and have them baked for the benefit of the dead. In the Government of Voroneje a ladder of this sort, about three feet high, is set up at the time when a coffin is being carried to the grave" (Ibid., p. 57).

"By such stairs ... must we depart from so much ill." Dante's "Inferno," Canto xxxiv. lines 82-4.

1 "Ballad of Fair Ladies in Revolt." Meredith.

2 "Psychology of the Unconscious," pp. 171 et seq. 
urge for sublimation," that is, the tendency in man which converts a lower aim into a higher.

"The functional importance of the symbol is clearly shown in the history of civilisation. For thousands of years the religious symbol proved a most efficacious means in the moral education of mankind. . . . Concrete values cannot take the place of the symbol; only new and more efficient ones can be substituted for those that are outworn, such, for instance, as those which have lost their efficacy through the progress of intellectual analysis and understanding. The further development of mankind can only be brought about by means of symbols which represent something far in advance of himself, and whose intellectual meanings cannot yet be grasped entirely. The individual consciousness produces such symbols, and they are of the greatest possible value in the moral development of the personality." 1

We find that the formation of symbols arises from an inner necessity quite other than that imposed by the censor. A censor, if it exists, would seem to me to act in the conscious as the expression of any inhibitive force operative at the moment which prevents us from understanding what we have dreamed. It would be shown in the case of any emotion which prevents clear thinking, or any confusion of thought which interferes with feelings adapted to the occasion. It might be due either to immoral or moral motives. The good is inhibited as well as the bad. If the symbols appear to disguise, it is due, less to their inherent imperfections and the limitations of unconscious representations, than to the limitation of rational understanding. It is chiefly due, however, to the reluctance of the conscious mind to admit the existence of unrealised tendencies, whether creditable or discreditable. What is really unwelcome to consciousness is the repressed function. Not only the libertine, but also the rationalist, has great difficulty in admitting ideal or superstitious quasireligious motives; but the unconscious finds symbolic means of representing these tendencies in each case. The unconscious view of any problem is compensatory to the

$$
1 \text { “Collected Papers," p. xvi. }
$$


conscious. ${ }^{1}$ It tones down and supplements the harshness and insufficiency of pure reason.

There is a propensity in the unconscious to feel any inadequacy of conduct as guilt. In the dream of the gravediggers, the dreamer had to see herself as the cause of her own depressing fate; she had a persistent sense of guilt.

By a gathering together of appropriate symbols, which lie ready in the unconscious, the dream-mind produces a myth or parable which, when understood, is full of penetrating wisdom.

The thoroughgoing determinist is committed to explain the dream on causal principles only. In the dream analysed above, the causal meanings, as revealed by the free associations, are very obvious. The self-depreciation is based on a mother-identification which has its roots in infantile sexual phantasies. But under-expressed ideas are also contained in the dream-thoughts, and point most clearly to a new way of solving the problem.

We can agree with Freud's idea of the dream as a wish fulfilment only, with the added interpretation that it "wishes" to give also a psychological view that is compensatory to consciousness. It reveals emotional tendencies and hidden thoughts that should modify conduct, with which they formerly interfered subconsciously in a disastrous manner.

As the flower holds nectar, so the unconscious contains wisdom. But we must go to it, garnering it in obedience to its own laws, and by work and effort making it into the honey of life. Not without labour shall we gather our store. If in the course of psycho-analytic treatment the dream interpretation indicates a new understanding of life, and a different view of duty, the patient must take the new path, or a still more unfavourable sitnation is brought about. We cannot with impunity ignore what we know, for that leads to further repression, and deeper neurosis.

Traffic with the unconscious is not free from danger. It either contracts or enlarges the personality. It never leaves it unchanged. This is one of the grave perils of mediumship, occultism, and mysticism. The phenomena that come 1 "Analytical Psychology," p. 307. "Dream Psychology," chap. iv. Nicoll. 
under these headings can only be safely studied in their proper sphere, namely, that of psychology. The symbolical dress of the unconscious makes it something of a trickster, as those who handle it unconditionally may discover, even to the extent of losing their orieutation.

A case in point occurred in my practice. Miss $\mathrm{P}$. had always been interested in psychic phenomena, but had a shrinking from "spiritualism." She heard addresses from two well-known divines of the Church of England in 1915 and 1916 , in which they urged their hearers to study psychic matters more thoroughly. This coincided with her wishes, and when the head of her Government Department incidentally gave similar advice, she consulted a woman psychometrist, and a male clairvoyant. The former gave some correct facts, the latter, who struck her unpleasantly, complimented her on the remarkable results obtained by a novice. Miss $P$. proved, in fact, to be a good medium. She next had sittings with a professional, and received "messages" from a dead relative.

She then joined a circle of educated persons for purposes of experimentation and used a planchette, which quickly wrote the name of the dead relative. Numerous sittings took place with and without a professional medium. She herself sometimes took the place of the medium. At two of these sittings she went into a trance, which she disliked very much.

Every day during her summer holidays she did some automatic writing, in which messages came apparently from dead friends. The automatic writing did not enchant her particularly, but the holiday passed pleasantly until one morning an accident happened.

One of the house party was gardening and standing on a high step-ladder. In passing, Miss $P$. called out to her, "Don't stretch up to that ivy, Muriel, you will fall." Muriel answered that she was quite safe, and Miss P. passed on but with a slight feeling of uneasiness. On returning a little later she saw her friend lying on the ground in what she subsequently learned was an epileptic fit. It looked as if she 
had fallen from the ladder, aud Miss P. blamed herself greatly that she had not stayed to hold it.

As she looked at her convulsed and unconscious friend she was terribly repelled, and thought of her as being possessed by an evil spirit. That night she could not sleep. She began to think she too might have a fit. During the following four weeks she appeared to be outwardly well and calm, but was inwardly assailed by horrible fears, of which she was terribly ashamed.

She was just beginning to feel better when a neighbour's wife, long ill with tuberculosis, suddenly went out of her mind and had to be remored to an asylum. Miss P. could not bear to hear this woman talked about, and thoughts of her were accompanied by fear that she herself might become insane.

In the middle of her holiday another disturbing thing happened. News came that a younger brother was "missing." Presently messages were written from him automatically, as though he were dead. Six weeks later news came that he was a prisoner in Germany. This gave her a terrible moral shock. That this mistake could have occurred seemed to invalidate all the other messages purporting to come from the dead.

In the autumn she returned to her professional work, but was constantly troubled with fears of epilepsy and insanity. These fears were increased when a month later news came that the insane woman had escaped from the asylum and had committed suicide. This brought back the old feelings of horror and apprehension, and she became so weak that in alarm she consulted me. At this time she looked very frail and ill, and was subject to extreme fear, so much so that the opening up of the unconscious analytically was a matter of some anxiety to me. After a certain amount of dream analysis, however, her fear diminished and her symptoms subsided.

Her former unconditioned entrance into the subconscious realm had paved the way for her subsequent identification with her unconscious epileptic friend, and with the woman who became insane and suicidal. The mediumistic state is one of identification with the unconscious psyche itself, and few can 
stand it without moral or physical deterioration. The unconscious stages of epilepsy, and the state of insanity (and indeed the resulting suicide), are instances of the overwhelming pathological effects of falling into the unconscious. By a process of introjection Miss $P$. participated in both states, and was threatened with a very serious nervous collapse.

The tendency to unconscious identifications forms one reason why psycho-analysts of experience always urge upon those who desire to practise psycho-analysis, a thorough course of personal analysis at the hands of an expert. It is essential, so far as is humanly possible, to eliminate the errors we are bound to fall into until we recognise our own unconscious complexes and predispositions. No uniformity of opinion need be feared, but until we are familiar with our own unconscious minds we cannot justly estimate the general phenomena of the unconscious. No genuine student can now afford to ignore the new way of scientific approach to a study of the mind. Before man had science to aid his mental apprehension he was right to approach the unknown by intuition.

Philosophers have long known intuitively many things which we now know scientifically, but to rely too exclusively upon intuition, is to travel upon a regressive, more primitive path. To-day we need to correct intuition by science, and enrich science by intuition. The student of the occult would be wise first to know himself, and find out in what way he is liable to be biased in judgment through unconscious complexes, and to realise in his observations those phenomena which merely express his own unconscious.

As long as we are identified with the unconscious, no matter how splendid a visionary world we inhabit, we are out of adequate contact with life itself.

The crippling kind of mysticism leads man away from earth to regions of the imagination, whereupon common. life loses its interest and intensity. Enlightened mysticism leads us to develop the precious faculties lying dormant in the unconscious, and to enrich our mundane existence by using those psychic powers of vision and perception which carry the profound conviction that the "kingdom of heaven is within." 


\section{VII}

\section{SEX AS A BASIS OF CHARACTER ${ }^{1}$}

I AM not proposing to take up the subject of character as a general question, but to limit myself to a certain narrow analytic view of it on the basis of sex.

We are at an epoch in history when there is a crying need for good citizens. By good citizens we mean people of valuable character; we cannot change the human material at our disposal, but we can make the most of the least of it. It is quite certain that we have within us all that we need for the well-being of ourselves and the world at large, but it is not all come-at-able. It is of deep concern that the character of the rising generation should be developed to its full measure, to meet the demands of the problems of reconstruction. New times demand new characters in a sense. This is possible because character is the perpetual acquisition of something that is at all times incomplete. Its first requisite is that it should be capable of growth. Like a tree it must bend in response to external storms while at the same time it strikes its roots deeper into the soil.

The effect of character is seen in reaction to life. It is of the essence of character that one may calculate more or less certainly on the way a given man will respond to life's demands. But we are subject to surprise, we find action sometimes exceeds our expectations, and quite as often disappoints them. If we look for a moment at the outside world we get a hint of these surprises. The war has demonstrated a great amount of heroism, of patient self-sacrifice, of endurance, of

1 Paper read at the International Congress of Women Physicians, New York, October 3, 1919. Reprinted from the Psychoanalytic Review, vol. vii. January 1, 1920, by kind permission. 
tireless discipline and derotion to duty. There is also witness to love of home, pity for comrades and enemies, sometimes orgies of vice, complete indiscipline, total disregard of loved ones, and violent expressions of vindictiveness and revenge.

Any emergency in life may call out such passionate feelings. The making of war or peace are only examples of special emergency, where rapid changes of thought and habits are involved. Of all the factors that give rise to unexpectedness none are so influential as unconscious sex-motives. National action is individual action multiplied a thousandfold. If we concentrate on the intensive study of one man only we come to understand the general springs of conduct. But to understand this one man we must study not only his conscious, but his unconscious mind.

The psychological view forces us to realise that the unconscious side of the mind plays a far larger part in our actions than is generally supposed. The unconscious elements of the man's mind may be antagonistic to the conscious elements, and the inner conflict, though altogether unknown, may be so severe as to frustrate the best intentions. St. Paul exclaims poignantly: "I find a law then that when I would do good evil is present with me." It is the examination of this law of the unconscious that has led meto think that the sex basis of character I am about to put before you is of vast importance.

I am taking it for granted that the outline of the theory of the unconscious mind is known to you. But for the sake of clearness permit me to give a very brief résumé of some conceptions regarding it.

It comprises the general mental dispositions which are not only a personal inheritance but an inheritance of all the ages. It becomes the receptacle of all the memories of experiences in an individual's life that are no longer wanted in consciousness, and also of the memories of phantasies and dreams, and of abortive or full-grown thoughts and feelings. Not only does it belong to the past, but to the future, for it contains all that germinal material which will later on exhibit itself in consciousness. 
Dr. Ernest Jones, summarising Freud, describes the unconscious mind as having six characteristics. ${ }^{\text {" }}$ "Firstly, it is the result of repression. This repression occurs because the unconscious mental processes are of a character that is incompatible with the civilised conscious personality. Secondly, the unconscious is dynamic in its nature, the processes are conative in type, conveniently described as wishes. 'Thirdly, it is the home of the crude instincts. Fourthly, it is infantile in character, and persists in an unchanged manner throughout life. Fifthly, it ignores moral standards and is illogical. Sixthly, it is sexual in character, and the sexuality is of a crude and infantile type."

This description of the unconscious, though true so far as it goes, is to my thinking a depreciative and partial one. Nor am I fully in accord with Dr. Lay's view of it when he portrays it as a mighty Titan whose demon forces we can and must harness to our uses, but whose tendencies are mainly mischievous. ${ }^{2}$ But while the worst that has been said of the unconscious represents some of its aspects, it has many others. It is the source of intuitive knowledge, and origins of religions. It is the germinal place of mental and emotional forces, it is a chaos of infinite resources, it is the home of all that afterwards through elaboration finds itself in consciousness. It is in the conscious that the moral judgments are formed, but it is from the unconscious that the representing dreams and phantasies are produced, and these, when interpreted and understood, are of a nature that reveal rather than obscure the harmonies of life. They reflect, as Jung has pointed out, the psychological state of the dreamer. The character of these phantasies is so discriminating that we are forced to concede to the unconscious a morality and logic of its own. The same psychological functions of thought and feeling work, but in a different medium. Seeing that the unconscious mind is one with the conscious it is unlikely that its attributes are wholly different.

With this view we are encouraged to steer past " the rocks of asceticism and the whirlpools of sense" to the very sources

1 "Papers on Psychoanalysis," 2nd edition, chap. vi.

" "Man's Unconscious Conflict." Wilfred Lay, Ph.D. 
of our being. 'The question is, can we find our true orientation in the midst of the phenomena of the uuconscious, and, accepting our relative ignorance, shoulder the responsibility this new line of research imposes upon us? Through the study of the unconscious mind we have a new approach to the universal storehouse of wisdom. We penetrate the depths that existed before all philosophy or science. Perhaps the discovery of the technique of the unconscious, that is, dream analysis, is the greatest discovery of our time. It is, however, a very young science, and born with all the possibilities of growth and also of error. It has been claimed as a merit that Freud's theories were launched in an almost perfect state, and that practically nothing of importance has been added to them since. While doing homage to the master mind of Freud, I see neither merit nor truth in this claim to perfection. Whilst, as far as I know, Freud has said little that cannot be scientifically maintained, he has said far less than the whole truth. Contributions of great importance have been added by other schools. But when all is said, it is Freud's genius that has given us the key to the unconscious, and a method of highest value. He has not given us the unconscious, except in the sense that Christopher Columbus gave us the New World. What we have already found there bids us be humble about the whole contents. It also bids us remodel certain of our ideas in accordance with our findings. We may not ignore what we know from fear of what we may yet have to know. Psychoanalysis, as all the portents show, is destined to permeate medical practice and educational systems, and it is in recognition of this fact that I ask your attention while I put before you some of the fundamental bases of character that lie in the elemental constituents of sex.

I must ask your consideration for a moment of an analytic concept of libido. Freud used the term libido to indicate sexual desire and longings under wide aspect. Its connotation corresponds with that of the word "hunger." 1 The American psychiatrist, Putnam, uses the word "craving" as the nearest

1 Prof. J. W. Scott, of Cardiff University, has suggested the word conatus in the sense in which Spinoza uses it. 
English equivalent. Claparède calls it "intérêt"; others have tried "psychic energy," but all these terms lack something. I once thought when I heard Professor Murray lecture on the Stoic Philosophy that the missing word was "phusis," but even that does not altogether fit. Libido may be applied to destructive striving, as well as to struggle towards growth. Hence one comes back to the word libido, using it in Jung's sense, as applying to any passionate interest, or form of life-force.

$\mathrm{His}$ is an energic conception, which supposes a hypothetical stream of force that accompanies the individual throughout life. It is essentially vital impulse, dynamic in character, and capable of endless transformations. In the course of life there is a determination of libido to any point of need. It is available for every purpose of growth and development and repair. It can penetrate every recess of man's being. It can be in the conscious or unconscious. Like physical energy it is incapable of becoming more or less, hence the question of its application and availability is of utmost importance.

One may think of libido in terms of man-power. Au attack is going on at the Western front ; it is to that point the manpower is sent, representing the available libido. More and more may be required, and as long as more is available the front is held, but not without weakening and risks at some other spot. Hence there is need for adaptability. Very much depends not only on the quantity of man-power but on its mobility. So it is in the psychic realm. There is plenty of libido if only we can make it available for our purposes. We might think of directed libido as "will," and yet it is not only will, for libido is mainly undifferentiated desire and creativeness. The desire and will elements of libido are often in opposition. When such a conflict takes place in consciousness it leads to mental change, to education. When the stream of libido is applied mainly to the unconscious, phantasy-weaving gains too great a relative value.

Such deflection of the libido streams brings about partial or complete splitting of consciousness. Minutes or hours pass by without leaving proper traces in consciousness. When our pupils or patients are full of day-dreams, we may be sure their 
interest is not with their work, and that their libido is flowing in regressive channels. They are mis-using imagination and its fictions to compensate for the present difficulties of life. Such a regression of libido most often occurs when new responsibilities have to be assumed or when special new adaptation is required, as when there is a change from home to school, or from college to business, corresponding with a change from peace to war in national life. Emotional problems with a loved or hated parent, or teacher or companion, are sufficient to bring about a breakdown in specially sensitive persons; this is particularly the case when the cause of the conflict is mainly unconscious.

Day-dreams have another significance, and one which must not be overlooked by the physician or teacher. They often occur when the child or adolescent wants to know something which he feels unable to ask. ${ }^{1}$ Sometimes he is hardly aware what he wants to know. The greatest problems of life at this epoch centre around sex. If from timidity or repression he is unable to satisfy his intellectual or emotional needs, he falls back upon imagination, and by this means apprehends what he can, and invents fictions where thought and feeling fail to instruct him. This is the time when regressive tendencies appear, to which I shall refer in due course.

The next step in the present study of the basis character is to be found in a consideration of the bi-sexuality or hermaphroditic character of the human being. There is no exclusively masculine man or exclusively feminine woman. Each bears traces of the other sex, not only physiologically but psychologically. The importance of this well-known fact is not sufficiently realised. For some five weeks of pre-natal life the human embryo appears to be undifferentiated as to sex. ${ }^{2}$ As far as we know it could become either male or

1 See "The Psychic Life of the Child," Jung's " Analytical Psychology."

2 Medical opinion inclines to the idea that the ondocrine glands play a considerable part in the sex characteristics of the human being, but just what part is extremely uncertain. At present there is neither consensus of opinion nor uniformity of experience. Should the matter come to be accurately determined, the special psychological content will still remain in need of explanation, for we are souls as well as bodies. 
female. A fer weeks later rudimentary organs of an unmistakable character are formed. At birth the child, whose sex organs are now fully formed for later maturity, is still psychologically undifferentiated. If the boy and girl are dressed and trained alike, several months will elapse before casual examination will inform us of the child's sex.

In mature life each sex does under certain conditions display what are somewhat arbitrarily distinguished as qualities belonging to the other sex. Under war conditions this capacity is an asset of extraordinary value. It is not only that a mixture of sex tendencies is present, but there is also an amount of available libido which gives a certain capacity, even zest, for the performance of each other's relegated task. This comes out in the play-instinct, as every one knows who has anything to do with the preparation of school and college plays. There is no lack of enthusiasm for playing the rôle of hero or heroine by a person of the opposite sex.

We have already briefly touched upon three aspects of the basis of character-

First, the existence of the unconscious mind, with its contribution of unknown motive.

Second, the presence of psychic energy designated libido.

Third, the bi-sexual predisposition of every individual.

Further light is to be obtained by a consideration of the normal components of sexuality itself. It was Freud who first described clearly to us that the normal sexual impulse has a threefold character of auto-erotism, homo-sexuality and hetero-sexuality. ${ }^{1}$

Auto-erotism is that love of self to which a portion of the libido is devoted. It is manifested in various ways ranging from the bodily instinct that expresses itself in masturbation, or the psychic equivalents of self-centredness, sexual phantasies, and Narcissism, to the sublimated purpose of selfdiscipline, self-valuation, and self-realisation involving complete autonomy.

Homo-sexuality is love for one of the same sex. Its tendencies åre manifested on different levels of development

1 "Three Contributions to the Sexual Theory." 
or mental culture. It can show itself in the instinctive animal form of mutual masturbation on the appetitive stage, or in the rational and purposive stage in conceptions of brotherhood, mutual aid and noble friendship.

Hetero-sexuality is the recognised normal sexuality, love of the other sex. It covers the phenomena of seduction and prostitution, no less than the best expression of love in mutual consideration between man and woman, family love, and it provides some of the highest motives of citizenship.

We have been accustomed to call the first two components abnormal, but when these tendencies are submitted to psychological estimation we find them to be just as essential in the make-up and development of the individual as hetero-sexuality itself.

Plotinus had the idea that the soul in its desire to develop itself, separates itself from the Divine Universal Soul, and descends into generation, in order that it may by reason of its sojourn in the inferior body individualise itself. In a similar way the process of individuation belongs to our mundane existence. At any moment the soul, or the individual, is in danger of being entangled in the web of life, and nowhere is there greater danger than from unrecognised sexuality. The more so that the way of redemption lies through sense rather than in spite of it. We should seek to make the best of both worlds, and no longer repress but rather express what belongs to our vital animal processes.

We dare not despise sense, for that of which we take too little heed has a dangerous way of tripping us up. We must bring down our too lofty ideals to fit them better to our instinctive nature, thus raising instinct to the human sphere, and make fullest use of all the powers that are ours by right. In this sense we must approach the question of sexuality, and detaching ourselves from the preconceived feelings of conventional morality, which at present are simply ours by adoption, regard the subject anew, that we may differentiate our attitude towards its components and find out what is actually going on in ourselves and those round about us.

Auto-erotism. When we turn our attention to the sexual 
trends in greater detail, the auto-erotic component is the first to attract our notice. The infant starts life as an entirely ego-centric being. For him the objective world does not exist save as an extension of his own consciousness. "With no language but a cry" he brings about changes in his environment. He apprehends the universe through his sense perceptions, and his own body is necessarily of unique importance to him. He incidentally and naturally finds certain pleasure zones in it, which again in turn quite naturally lose their interest for him in consciousness. At times his bodily functions attract his attention. His body is close to him-his nearest plaything. Therein are mysterious processes, his own creations, and objects on to which he projects his phantasies. $\mathrm{He}$ is busy constructing the beginnings of thought out of his experiences. In dreams of later life excreta not infrequently form symbolic material for dreams. This is a revival of infantile phantasies and pleasures which have a certain analogical appropriateness for the immediate problems of later life. Under analysis it is seen how these primitive nature-things have become the bridges to more developed ideas. The child no less than the adult has an implicit working theory of the universe. He evolves his thought out of his phantasies. Just as the dream or phantasy abstracts itself from the general unconsciousness, so later thought abstracts itself from phantasy, and losing its subjective character gains an objective expression. As the child grows the libido devoted to auto-erotism becomes differently directed. He strives to make himself a "little man." He goes on in the direction of the educational push, to establish himself as a person who can feed himself instead of being fed, can present a clean or a dirty face, can please or displease, and gain smile or frown from others for himself. So he obtains a certain power over his environment and realises that many an infant joy is sacrificed to maintain it. Thus the autoerotic tendency is more or less transformed into self-love and self-development. In later life this transformation is necessarily much more consciously carried out. Not all the autoeroticism, however, is sublimated. Some is repressed into the 
unconscious, whence it re-enters consciousness in various ways, supplying an emotional tone not always capable of an obvious explanation. Time forbids us to go into the subject of repression, save to say that the reason for it is to be found in the battle of the higher over the lower self, and the great difficulties life presents. Throughout life the sublimated auto-erotic tendencies are of highest value, being embodied in desires for knowledge, for excellence in sport, for work, for "creation out of the self." We could ill spare this component from the sexual trinity, even though it plunges us into many pitfalls on the path of life.

It is not uncommon to get an outbreak of auto-erotic practices at special epochs in life; as during puberty and adolescence, or when a difficult emotional problem presents itself, accompanied by repression. This is similar in appearance to, though different in meaning from, the passing infantile masturbation which usually becomes latent very soon after it appears. Whenever the tendency manifests itself later, it implies a regression of libido, that is, a return to a former and no longer appropriate mode of adaptation. These habits should not be regarded too reprehensively. They should rather serve as a sign that something of significance is going on in the psychic life of the child or youth. Now is the opportunity to find what is causing the block in the mental or emotional life. These practices are always accompanied by a sense of self-depreciation and feeling of inferiority and guilt. At such times the ready-made moralist is apt to come down upon the delinquent with crushing force, driving him further into himself, and the slough of his own despair. But what we find is after all a creative tendency that is off the lines. The practice is symptomatic, and does not always indicate a sexual need, but may be a surrogate for another need. Almost all normal persons, not only incidentally and transiently as in babyhood, indulge sporadically in autoerotic practices, or at least in auto-erotic phantasies (autistic thought) which have the same significance.

It is Nature's way to teach us from error as well as from truth, and many a neurotic fear would be avoided in later life 
if we would study this problem again from the beginning. The cruel threats that are used to stop masturbation are in themselves a cause of much needless suffering. "Shall I become insane ?" "Have I done myself irrevocable harm ?" are questions not rarely put to me in my consulting-room. As I have said before, these habits sometimes arise when the child has a personal problem for which it is desirable to find another answer.

At times masturbation acts as a safety valve for the pentup sexual forces, but it is after all " a fraud upon the natural development of things, because all the dynamic forces which can and should serve cultural development are withdrawn from it through onanism." 1 Frink considers that its occurrence is probably normal, and that its complete absence is more often found in neurotic persons. ${ }^{2}$ Tactile masturbation is less common in girls than boys, but sexual phantasies are more common. The serious effects of the habit are certainly overstated, and quite other than the orthodox opinion of the last generation led us to suppose. They belong to the injured moral feelings rather than to the habit itself. It is, however, undoubted that excessive masturbation is deleterious. It leads to isolation, egoism, and misanthropy as a defence against the feelings of inferiority. To attack the problem of autoerotism is of fundamental importance in the development of the individual, who must free himself in this matter, both from the collective prohibitions and the collective vices.

Next we pass to an even more delicate problem-that of homo-sexuality.

This subject has been brought before us in England recently by two very able novelists. Miss Clemence Dane's story of a girls' school called "The Regiment of Women," and Alec Waugh's "Loom of Youth," dealing with a boy's public school life, have given us to think furiously. It is a strange phenomenon that in the professional classes our problems often have to be brought home to us from the outside. That these books and others of like character should have

1 "Psychology of the Unconscious," p. 187.

2 F. W. Frink, " Proceedings," Int. Conf. Wom. Phys., New York. 
appeared now is a sign of the times for those who can read portents.

The European War has had the effect of separating men and women and massing together those of one sex. It has produced tremendous emotional problems of every sort. It has torn youthful civilians from home and normal conditions of life, and placed them under conditions where the ordinary moral notions are entirely reversed. Living through months of segregation as in camps, barracks, on ships, and on expeditions, is not a new thing, but it is accentuated by being experienced on such a huge scale. We have already a few obvious legacies from these cataclysmic times. There is a mass of venereal disease, a great outbreak of hysteria and other psychoneuroses among men, and not least there is a shortage of some ten million men in Europe. At such times homo-sexuality is bound to make its appearance as a problem for humanity.

Something else has been happening. Women have been obliged willy-nilly to do men's work in engine yards, in munition factories, on the land-in every field in fact of industrial and professional life. Something male in a woman's psychology has been called for, and we have seen there is a latent sex-element which enables her to respond. In fact, the regulation tasks of the sexes have been completely mixed, for in many camps and hospitals the women's work has been done exclusively by men.

If homo-sexuality crops up at such a time, as my foregoing remarks show, its existence is not new. Perhaps the necessity to accept and consider it as one of the problems of our times is new. Franker discussion of all sex problems has made it possible to consider it here to-day.

Homo-sexuality then is love for members of the same sex. It begins at home among brothers and brothers, sisters and sisters, and has always united mothers and daughters, fathers and sons in bonds of friendly love. This useful emotion is emphasised in school and college life, and not excluded from existence and importance by the fact of co-education. It has great value in promoting esprit de corps. It can act against imposed discipline, for it sometimes unites and strengthens 
the class against the teacher. Where the teacher is hated, friendly bonds between the scholars are relatively strengthened, because they aid the spirit of revolt, or render servitude less intolerable. It has been bistorically significant in times of slavery. It has a personal value. It is the beginning of lasting friendships. It is a way in which humans find some of their relations with each other and with society. A spoiled child, intractable at home, often accepts without question the discipline shared, or indeed administered, by school fellows. The education children give each other on this basis is no less important than that which they receive from their parents and teachers.

Through juxtaposition the love problems that are suitable to the age are experienced and must be solved on the basis of childhood and adolescence. The young ones must be allowed to go in the direction of their life's currents, helped, hindered, and warned, by the wisdom, not the prejudice, of the parent or teacher. It is for the seniors to study the problem in all its bearings, and take a constructive attitude towards it. "Young, all lay in dispute; I shall know, being old," says the sage. What is wanted here is understanding between the generations; more confidence and less hostility between the two. Personal friendships which are fraught with such fair promises have their dangers too. The erotic element is capable of taking concrete and undesirable forms. Here, too, the heavy hand of conventional morality comes down with excessive tyranny, and boys particularly, and more rarely girls, are sometimes summarily expelled from school for an error they but half understand. Some promising careers have been wrecked this way, and love, which is such a valuable teacher, has been tortured into a demon shape.

Such punishment either makes rebels, or it plunges the culprit into the abyss of self-depreciation. It fastens a reputation-which is apt to stick. It turns a tendency, or a partial component of the sex life, into a fixed form of a kind that does poor service to the race or individual.

Here again, error presents an opportunity to those who would teach. 
This problem cannot be considered from the standpoint of the scholar only. Teachers are concerned with it. Whether we like it or not, boys and girls pour upon teachers of the same sex an amount of such love. It is natural. It is a kind of love that has a purpose to serve at this age. By its ideal character, by its very aloofness, it tides the scholar over many a difficult place. It gives a standard to live up to ; for it is rank folly to think the young are fit to act in every emergency, or can know at all stages what is best for themselves. They need models, and good ones; otherwise they will create them out of the unconscious.

What is important is that the teacher should be sure of his own ground, and should unite in his conduct the wisdom of the serpent with the harmlessness of the dove.

If the hetero-sexual love is stimulated too early and too severely it means a cutting short of a different kind of emotional experience more suited to the age of the individual.

In the "Regiment of Women" the situation is drawn with great skill. Clare Hartill, ambitious for her class and for the success that reflects the glory of the teacher, used the devotion she had the gift to inspire, for the purpose of power. She could not live without sensation, and obtained it from the erotic love of younger teachers and scholars. One of her pupils in an access of emotionalism throws herself out of the window. The story of a young girl's suicide is rare, but it is not unsupported by fact. The love was not recognised for what it was, either by Clare Hartill, or by her admirers. She could not have faced the word homo-sexuality. Nor could the Principal and her fellow-teachers have allowed things to reach such a pass had they analysed the situation.

The picture in the "Loom of Youth" is different. There a situation of conscious homo-sexuality among schoolboys is disclosed. One of the boys who happens to be caught is expelled. Sexuality is much more conscious among boys than among girls. It is equally important and prevalent in both sexes. To ignore it among girls, and to punish it so cruelly among boys is equally unfair to the young.

Do we treat it in this way because it saves us from thinking 
about a very difficult problem? Thought requires that we should each find our orientation to the problem. To do this we must examine the content of our own sexuality, both conscious and unconscious. In this way we gain an insight that gives us understanding and wisdom in dealing with others.

How far may we use this natural tendency in education? Do we not find a good rapport between a teacher and his class of highest value? Can we not educate much more easily those who love us? If this is so, shall we close our eyes to our responsibility or, fearful of the god Eros, shall we clothe our discipline in unremitting sternness or tyranny? Must we not, on the contrary, shoulder our responsibility? The children watch us. They begin to behave to their problems as we do to ours. Where we are reverent and frank they will also be reverent and frank. If we are prudish and repressed they will imitate us. When we are carried away by undisciplined feelings of love or power, they will be only too quick to let erotic emotions and the desire to impose personality play havoc with their lives, a havoc which has more than a temporary influence.

The dangers of mishandling this problem are very grave. To class a youth as homo-sexual is to put him into a category to which in all probability he does not belong. In this way we manufacture homo-sexuals. It is even a question whether people who are exclusively homo-sexual really exist. I think they do. But the majority so-called are so because the libido which might have gone on to the further hetero-sexual stage becomes fixed in this immature and regressive form, so that the highest type of actual love in an individual case never outgrows this character; and difficulties which are estimated as "insuperable," are experienced in loving a member of the opposite sex.

The homo-sexual tendency may become "fixed," because in the absence of personal effort and development, it is the easiest sexual expression life offers to a given individual. It arises as we have seen out of unnatural conditions such as the segregation of the sexes,- - or out of the economic difficulties in the way of marriage. Among women, whose numbers 
considerably surpass those of men, there is an arithmetical reason for it in the impossibility of marriage. Less reason for it exists amongst adult men, since the whole of the sex life is more or less arranged for their convenience, except in the case of genuine homo-sexuals, who are of course very much fewer than those who indulge in homo-sexual practices. Justice demands that we should allow the genuine homo-sexual to express what is his normal sexuality in his own way. In many respects he is already heavily handicapped by nature. We make homo-sexuality a penal offence in men. It is absurd in the present state of social morality to inflict penalties upon, and expose to blackmail, men who live their sexual life privately and decently, even though they do not conform to so-called normal standards. Personally, I would recommend the removal of homo-sexuality from the penal code, but make seduction of a minor an offence, whether homo-sexual or hetero-sexual, and raise the "age of consent" considerably for both sexes.

I do not propose to discuss the hetero-sexual content of love to-day. Not that it is absent in any part of life. It is always present even in the child; it is always pushing itself towards maturity. Its first block occurs where a too passionate devotion to the parent of the opposite sex is fastened upon the father or mother by the child. This may have the effect of making him homesick and inadaptable. But the ready transference of the parent image of authority or love, to the teacher, assists in breaking up this too dependent attitude, and at the same time modifies the other elements of the emotional life. Each stage must in turn be psychologically experienced and surpassed.

I feel in introducing this subject for discussion I am voicing problems every really thoughtful physician and teacher is constantly meeting. There are no ready-made solutions. The facts already there need more open consideration. There was a time when the medical profession did not dare to face the problem of sexual disease. Bitter social experience has forced it on us. The emotional life is part of our common humanity, and "the course of true love never 
did run smooth." At any moment, thanks to the instinets, awkward sex elements may intrude themselves. My experience as a physician leads me to believe that the emotional problems of the married are no more or less severe than those of the unmarried, and that both men and women have much the same sexual problems, and are in a similar mental relation to them. Friendship which we all like to think is untroubled by sex, is often wrecked upon it, and that most often where the sex element remains unconscious. At all stages of life sense gives soul its opportunity, and soul helps sense. In every human relation there is need of sacrifice, self-control, and mutual consideration. 


\section{VIII}

\section{UNCONSCIOUS FACTORS IN SEX-EDUCATION $^{1}$}

IN approaching the subject of sex-education the point I desire to emphasise is that in the unconscious mind of the pupil we have a factor that falsifies a great deal of sex instruction. It is on account of the unconscious mind that class instruction on matters of sex is often useless, or even pernicious.

Sex-teaching, as I understand it from the pedagogic standpoint, has two sides: one deals with facts of sex, the other with moral ideas.

I submit the only side that can be taught with advantage in classes of young children deals with the facts of sex, and even here the facts are best approached through study of the development and fertilisation of plants and animals. Human physiology should be left to the senior classes. When the time is ripe the children will effect a junction of ideas themselves, intuitively.

It is better that the facts should be dealt out to them impersonally. I object to implanting in the minds of children the idea of the " sacredness of sex." It would be better to emphasise what is human in sex. The generative organs are no more or less sacred than the brain or stomach, nor are the generative processes more or less wonderful than the cerebral and assimilative functions. We are in any case "fearfully and wonderfully made," and we should give the right attention to each and every part and function.

It cannot be denied that sex assumes an enormous, even overwhelming, importance in life; but let us diverge from our main topic to discuss for a moment conditions under which the gustatory organs and functions exceed in importance,

1 Lecture delivered at University College, January 9, 1920. 
temporarily at any rate, that of sex. In infancy and old age the sex function is quite secondary to the nutritive function, and at other times in life they run in close rivalry. When famine and hunger threaten, the gustatory function at once becomes pre-eminent in importance. At such a time, the phantasies contributed by the unconscious mind, centre not around love, but around food.

As an example of this, Scott and Shackleton have told us about foods becoming the main topic of conversation and of dreams, as the Arctic explorers and their parties approached nearer and nearer to starvation. In certain dire circumstances, men who seemed far removed from the primitive, have been known to kill one another for a last bite of food, and have in extremis even become cannibals. Such incidents remind us we have a vast background of primitive and animal ancestry behind our relatively short existence as civilised man. Besides the more physical manifestations, other functions of the psyche such as thinking, feeling, intuition, or sensation, may be repressed with corresponding loss. We cannot cut off anything that is vital in any direction without the risk of becoming prey to unconscious thoughts and feelings, which, because repressed, intrude into consciousness as imperative ideas, compulsive acts, obsessions, morbid imaginations and subjective sensations.

I do not subscribe to the idea that the unconscious is composed only of repressed material of a sexual nature, although the subject under consideration demands that we dwell primarily upon that component. The unconscious is rather to be regarded as the foundation and origin of all things. It is the non-rational underlying and interpenetrating the rational, and contains the impressions which are compensatory to consciousness.

It is this compensatory and non-rational contribution that makes the unconscious mind the most important factor in the sex problem. The problems lie far less in the concrete realities of sex than in what we think or feel or imagine about it. Our thoughts and feelings are constantly made and betrayed by the compelling power of the phantasies, which 
are dynamic in character, and have an insistent tendency to push their way into consciousness.

Charles Lamb expressed this idea in another connection. He says of himself that he was "dreadfully alive to nervous terrors," 1 and spoke of the great impression a picture in Stackhouse's Bible of the Witch of Endor raising Samuel had made upon him; but he adds: "Had I never met with the picture, the fears would have come self-pictured in some shape or other: 'Headless bear, black man, or ape '-but as it was my imaginations took that form."

He goes on to say, "It is not book or picture, or the stories of foolish servants, which create these terrors in children. They can at most but give them a direction. Dear little T. H., who of all children has been brought up with the most scrupulous exclusion of every taint of superstition-who was never allowed to hear of a goblin or apparition, or scarcely to be told of bad men, or to read or hear of any distressing story, finds all this world of fear, from which he has been so rigidly excluded $a b$ extra, in his own "thick coming fancies"; and from his little midnight pillow, this nurse child of optimism will start at shapes, unborrowed of tradition, in sweats to which the reveries of the all-damned murderer are tranquility.

"Gorgons and Hydras, and Chimeras dire-stories of Celaeno and the Harpies-may reproduce themselves in the brain of superstition-but they are there before. They are transcripts - types-the archetypes are in us and eternal. . . .

"The kind of fear here treated is purely spiritual, that it is strong in proportion as it is objectless upon earth-that it predominates in the period of sinless infancy-are difficulties, the solution of which might afford some probable insight into our ante-mundane condition, and a peep at least into the shadowland of pre-existence."

Charles Lamb, as we know, was extremely sensitive and neurotic, and was subject to "intrusions into consciousness of the psychological function of intuition in the form of 'images." " 2 He speaks of the archetypes of phantasy lying in the

1 "Essays of Elia": "Witches and other Night Fears."

2 Jung, British Journal of Psychology, November, 1919. 
hinterland of the mind. Jung has recently described the collective unconscious as composed of "the sum of the instincts and their correlates the archetypes," that is, the instinct-forms of thought.

It is largely the presence of the archetypal ideas or "instinct forms" that makes the sex phantasies of the child so abundant, and his sex education so uncertain in its results. The material of fear is already in the mind. $\mathrm{He}$ adds or detracts from all the teacher says, whether the teacher is parent or pedagogue. The energic value of sex curiosity is such that the child must either get to know, or determine fiercely not to know about it. Curiosity is capable of the severest repression. The overweeningly curious child may at the critical moment violently repress into the unconscious his longing for knowledge. This results in an exaggerated attitude of innocence or prudery, which may be all that survives in consciousness to indicate the violence that has been done to a natural instinct. As a matter of fact, the young child rarely comes to an adult for answers to the seething questions about sex. Is not this largely our own fault?

What is it that disturbs the grown-ups so much when, in the pre-self-conscious age, the child blurts out some innocent question in mixed company? It cannot be the facts of sex, which are more or less known to all the adults present. What makes one person blush, another cough, another become preoccupied, another draw a red herring across the track of the question? Something in the unconscious has been touched up-connected with the sexual phantasies of each adult-whose personal emotions tend to complicate the answer. The child looking from one to another gains an impression of he knows not what. This sets going his sexual phantasies, always easily stimulated into activity, especially where a block is interposed on the path to direct knowledge.

Sexual phantasies are neither evil nor useless in themselves. They are essential and inevitable. They become destructive only when after having fulfilled their purpose they are stabilised and fixed; or when they are used in mature life as a means of "flight from reality." But in the case of the child 
the utility of the phantasies is clear. Even should we tell him the literal truth it will not be accepted as such. It is always re-interpreted into fictitious terms, and becomes something the child can think.

On one occasion when I was putting a small relative to bed a question arose as to how the baby came. I told her as best I could about the baby being nourished and developed in the mother's body. Her eyes sparkled and all her dimples appeared as she said: "Then if I die before I grow up, will the little baby go back to God inside me, and won't it ever get born?" She wasn't even concerned to get an answer to her question; her imagination bolted with an idea that delighted her; already it seemed she had a little child inside her, and it would be born some day. She did not want to know anything more just then. She turned her head and settled to sleep.

She had obtained a false impression and my words immediately evoked a phantasy in her mind. Such experiences show us that when we talk of sex education we must take into account the irrational factor. If we forget this we shall find that "the best laid schemes of mice and men gang oft agley." We mean so well, but the child's imagination baffles us every time, even if we ourselves are perfectly clear in our own minds. When we give an explanation we sometimes produce a new error, which we perhaps attempt to straighten out. In so doing we may do wrong because we force the child's mind to accept some fact in a form it cannot yet assimilate.

It is impossible to indicate all the difficulties that beset the childish mind, but I will give examples illustrating a special cause of misunderstanding. Some children have, psychologically speaking, a complete confusion of sex. It exists without any corresponding anatomical irregularities, but these children have no feelings which pronounce them as specifically male or female; or, being male, female feelings preponderate, and vice vers $\hat{a}$.

The following account is written by Miss T. I will give it in her own words. She is now thirty-six. 
"By the time I was eight years old there were three younger children, a sister and two brothers. I remember saying to my little brother that I did not believe I was a girl at all, and that it was a mistake.

"Somewhere about this time my aunts and uncles began to criticise me and said I was a rough, rude child and a tomboy. My parents were mortified, and tried to correct me. They sent me to a day-school. They tried to make me learn to sew, but I would not. They tried to make me more clean and tidy. I hated the confinement and chill of my clothes, and used to try to put on my brothers' clothes. I liked very old clothes and detested fine and smart ones, and would not put on some that were bought for me. I resisted my parents and my nurses. The more they talked of my being a girl, the less I believed I was one, because nothing they said seemed true of myself.

"When I went to school, when I was about nine, I never played with girls if I conld get boys to play with me.

"I tried to reason about myself, and about why I was so miserable, but I always said that I was not going to grow up in the way people wanted me to do. I thought all grown people told lies, and that they could not possibly believe themselves the things they expected me to believe. I thought that when I was old enough I would find a way to escape.

"From nine years old till twelve, in all my spare time, I ran wild, I never came indoors if I could help it. I associated with gardeners, navvies, workmen wherever I could find them. I learnt to use their tools. I was always laughed at by my parents when I tried to do things, but never by these workingmen, who were always kind to me.

"I had tremendous energy. I learnt nothing at school, but I devised outdoor adventures of all kinds, and always had a crowd of boys and girls willing to come and play. We built castles, and stormed forts, and so on. All these games were based on the imaginings of the ferr preceding years.

"When I was between six and eight years old, I made my father read to me. Every evening I lay in his arms in a big armchair, and followed the stories be read aloud. These were 
"Arabian Nights," fairy tales, "Ingoldsby Legends," and so on. He always fell asleep before I had had enough. During those few years I liked my father, and he fed my imagination and did not scold me. Between eight and twelve I abandoned the fairy tales and began to live them out of doors.

"Besides this kind of play, I began to keep animals. I caught pigeons, and kept a lot of them. I also had other animals, and spent all I had on them. My two young brothers helped me. We understood by observation about mating the animals, and about reproduction. We never discussed the subject with grown people. We were devoted to our animals, we took pleasure in the creation of numerous young families. We never spoke of sex in reference to human beings. I don't think we thought of it. I kept away from grown-up people as much as I could.

"When I was about twelve, my boy friends disappeared to other schools, and I was rather lonely. I used to stay out of doors, and tried to make up a kind of continuous story. It was based on the old fairy tales-of knights, dragons, princesses, and so on. I was never the princess, but always the knight or pirate, or backwoodsman. More and more I became like the man in the story, and felt like him, and believed I was he.

"My night dreams were of just the same things. No one taught me anything, and I was intimate with no one except ignorant, uneducated people. But I began to feel admiration for a few especially good-looking men and women, though $I$ never tried to make friends of them.

"For about two years people went on criticising me. I regarded my mother as an enemy. She repeatedly threatened to send me to a boarding-school, to punish and shape me. As the school was in beautiful country, I thought I might like it. But I had a bedroom to myself at home, and I heard I should have to sleep with other girls. I hated the idea because I was very shy with girls. I was not shy with boys. When the time drew near, I went in tears to my father and implored him not to send me. I said if he would have me taught the useful things that boys learnt I would work hard 
and, by and by, would earn my own living. I said I couldn't and wouldn't be turned into the kind of young lady my halfsister was.

"My father was moved by my tears, but my mother came in and sent me out of the room, and I was sent to school at thirteen and a half. I settled down into a state of hard defiance, and went away very angry and bitter, but without any more tears.

"Before I went away, my mother told me about menstruation. I connected it at once with animal reproduction. I thought the animals mated voluntarily when the female chose, and as I felt I should not choose to do so at all, I said, ' $\mathrm{Oh}$, well-that won't happen to me.' When it did, it made no change in my point of view.

"Before I was sent to school, and after I got there, I brooded continually about running away from home and school, but I could not see how I could escape being caught, or how I could live.

"At school my first feeling was not against the mistresses, who seemed kind; it was against the girls, and I felt a dreadful physical disgust for the place. This was so bad that the slightest odour, such as of dinner, or boot-blacking, or soap, gave me a feeling of nausea. I also got a feeling of nausea when I had to sit very close to other girls. The whole thing was a physical shock for me and it took about a year to get over it. I think of my life at that time as nothing short of an illness.

"In my first year at school I continually dreamt of travelling and living as a man, and it was perhaps the time of worst confusion that $I$ had. In my dreams I seemed to get back into a real world. My life at school seemed to be all acting, and only in dreams and in story books did I seem to live my real life and see the world in a real way."

I need not comment on this case-it speaks for itselfsave perhaps just to say that a child who is permanently in such a state of disbelief in regard to all she is told, is in a completely wrong attitude to life. She could not believe the elders because she had, without knowing it, given a greater 
value to the images in her own mind than to the facts of the objective world.

The next example is somewhat different. A nice-looking, well-grown girl of fourteen and a half, was brought to me because she was supposed to have a mania for boys. She picked them up on the way to her day-school, and when as a preventive measure she was sent to boarding-school, she found means of making assignations with boys and, escaping from captivity, went roaming with her young friends. Another indictment against her was that the boys were of an inferior class. She was the Squire's daughter, and would consort with sons of tradesmen.

Her father brought her to me in great distress; he was especially anxious because a maternal aunt was said to have erotomania. What was to be done with such a rebellious daughter, in whom plenty of lesser naughtiness accompanied the graver faults?

The analysis of a single dream showed her unconscious confusion of sex. She felt like a boy in most respects, she loved all their games and sports. Her collection of stamps and her breeding of rabbits was quite excellent. She showed no interest in boys as lovers, and was irritated and nonplussed when a sentimental rivalry momentarily arose between two of them for a kiss. She loathed girls and called them sneaks. She declared she was always shocking them. It soon became clear that her love for boys was a longing for their companionship because she felt more at home among them. It was not a wish for flirtation. This once understood, the problem had to be differently met. An immediate change was made in her external life. She was taken from school and given work to do that gave scope to her qualities and brought her amongst boys in a natural way.

She was also helped to see what was at work in herself, that she must accept her feminine sex if she wanted to get through life decently. She could develop her talents in work that fitted her psychology, work that could just as well be a woman's as a man's. She must learn to satisfy her male tendencies in creative work, and take up open and responsible friendships with boys, while conforming as far as possible with 
outward requirements. The new plan worked, and two years later she went back voluntarily to the girls' school into which she was now ready to fit.

If the real significance of these cases is appreciated, it will lead us to further realisation of the curious and unexpected material we have to deal with in any mass of children. To children thus orientated the instructor is apparently "talking through his hat." Such children represent many who do not correspond with the so-called normal. Yet it is exactly these children who will experience the greatest difficulties in later life, and who most need our understanding help. For such natures one needs an individual key. The general key is useless or breaks the lock. And yet what an amount of insight and study is needed before we know how to apply these individual keys. Of course we cannot discuss individual difficulties in class, but a certain amount of class instruction opens the way for these children to consult the teacher, and then sometimes a word cau be spoken in private to one scholar or another that will remove mountains of difficulty, and provide a clear channel through which the pent-up emotion may flow.

In children with sex difficulties the wisest course is to refrain as much as possible from punishment and criticism. The naughtiness and resistance often disappear when we drive them with a loose rein and cease to impose ideas of what is normal and conventional. The child is invariably depreciated by whatever in himself is unlike others. He needs more selfrespect, not less. A stolid or aggressive manner often conceals the greatest wavering and timidity. It is an over-compensation for a sense of deficiency.

Let us take an example of this mechanism of overcompensation from another sphere. In many solvent countries at the present time the exchange has moved against the British Empire. Recent figures of the Board of Trade returns showed an enormous falling off in exports. Numerous indications might suggest we are losing our first place in the markets of the world. National credit and prosperity are involved, and we suffer in our patriotic feelings. These facts 
as far as they go are extremely painful; we foresee a loss of power and prestige.

There are two ways of meeting such a situation. Either we may rationalise and explain away the facts, and at the same time compensate the disquiet and dissatisfaction we cannot altogether quell, by boasting more than usual about our conquests, our colonies, and our mercantile supremacy; we may refuse to admit the possibility that we can lose our place in the sun. Or we may take it otherwise and accept the fear, the humiliation, and the sense of loss that belongs to such a situation. We may attempt to realise the position, study the causes, search for the remedy, seek to know what our individual share of the burden should be, aim at improving industry, economise the waste, in fact put the shoulder to the wheel. We can accept the position in order to change it.

The former way is one of repression. It is accompanied by rationalisation, and over-compensated by boasting and empty vanity. The latter way is the way of acceptance, of sacrifice, and clearly the way that leads to more and fuller life. It is the way of sublimation. We must not confuse repression and sacrifice in our ideas. Any unconscious and mechanical sacrifice is a repression; being human, we are unable in the last resort to escape sacrifice; it is inevitable in the cause of adaptation. We must take care that it is consciously undertaken for a creative purpose, and that it is consciously borne, and ends as soon as it has served its purpose, never becoming automatic. There is no virtue in suffering for its own sake. In the case of the child whose naughtiness conceals a painful sense of guilt, punishment will either increase the necessity to dispose of the self-depreciation by ignoring or repressing it, to which end he may become more conceited and defiant than ever; or, on the other hand, punishment may lead him to succumb to a crushing self-disparagement. Either alternative is a failure from the educational standpoint. The chance to help him with sympathy and understanding has been missed, as well as the opportunity to lead out his libido to a more appropriate expression, through the sacrifice of its undesirable pleasure trends. 
But before the teacher can hope to help the child to solve his problems, he must have recognised and dealt with his own. Before we get very far we find we have been cherishing (as if they were virtues) habits of thought, and ways of feeling, that have prevented development. It is essential to sacrifice the childish personality in ourselves; either in its uncritical dependence, or its uncritical revolt. We have first to become aware of the existence of what is childish, for it is not necessarily obvious in the outward behaviour, except upon rare occasions.

Childish phantasies are natural in the child; it is natural, too, that he should be dependent upon others during his long immaturity. But childish phantasies in the adult have a morbid significance. They blind him to reality and so constrict the personality. The mechanism by which they are maintained is by relegation to the unconscious. We have to work hard to discover them in ourselves. When we have found them, and understood their meaning, they provide a clue to what is missing from our conscious attitude.

There is one specific direction in which we may profitably work. The commonest and the most obrious unconscious phantasies are about our parents. A certain unconscious orientation to the parents is present in everybody. I fancy I hear some one say, "My father was never any particular law to me-I did not specially love or fear him." Or, "though I feared and obeyed or loved my father as a child he is now dead and has long since ceased to influence me." To such objectors we might say, "Leave off thinking for the time being of your actual parents and take a psychological view. Think of the image of the 'ideal' father, the 'head of the house,' the 'shepherd of his flock,' the 'tyrant of the hearth,' and so on. Are you sure no such important figure exerts undue influence in your life? Is there no one to whom you refer most things in phantasy if not in fact? Do you delegate no authority that should be yours? Are you self-governing? Again, in reference to your mother: Do you not look to find an understanding mother in your wife, your head-mistress, your religion, your 
best friend, in fact in all those in emotional relations with you ? Does no infant in you cry for a tender uncritical love from others? Does the bond that is outwardly severed not operate in you unconsciously?" This is a psychological meaning of the "incest phantasies" in which the individual is never essentially separated from his parents.

The getting free from the parents has an effect of twofold value. The problems are pretty equally distributed on either side of the dividing line between parents and children. A time arrives when they must naturally separate themselves; when this happens they can also for the first time see one another as independent beings. Losing their projections and identifications, which are congenital and collective, they arrive at an independence that allows them the possibility of a just judgment.

The new attitude is effective in proportion to the inner freedom of either party, but it is an obvious fact that the inner and outer freedom by no means always progress pari passu.

Liberation of the personality is the result of conscious conflict which would be stupid and useless if it did not lead to the acquisition of new values. One can scarcely lay too much stress upon this particular problem. There is a unity in the emotional life which led Freud to include all forms of love under the term sexuality. Although the child's emotional life is not sexual in the adult and concrete manner, it forms a prototype for all the subsequent psychic content of the love life. The attitude to the parents forecasts the future unconscious attitude of the adult, and, be it one of servitude or rebellion, it must undergo change. A child who never submits to authority, who is disobedient, unloving and undisciplined, has great difficulty in finding a teacher, lover, or friend, and a marriage, an occupation, or school of thought to which he can give the necessary and prolonged allegiance. It is a fascinating, if baffling thought, that we can begin the study of the child's psychology by turning a searchlight into the neglected recesses of our own minds.

After the recital of the difficulties attendant upon sex 
education, one naturally wants to know how and when the teaching may be given with advantage.

It is very desirable that sex instruction should be given in all training colleges and universities. There is need of more education in medical schools, in order that future parents and teachers and doctors may be enabled to handle the subject wisely as it comes up in the home, or school, or clientèle. ${ }^{1}$

Opinions in matters of sex are undergoing great changes, and what is needed is an intelligent, trained leadership. At present the majority of teachers are not competent to give indiscriminate sex instruction, and parents are also much behind-hand. In fact, sex education ought to begin with the present generation of teachers and parents.

This should not, however, prevent us from answering any question a child puts to us, as truly as possible. We must note what the child does, and how he interprets our words. Where we find fear associated with the subject we should seek to remove it, but we need not trouble if the child's idea is inexact as long as it serves him as a working hypothesis which allows him to make progress in his human relations. We should not laugh at his mistakes or his phantasies, but try to get into direct contact with his emotional processes, and keep a critical eye upon our own accustomed formulas of sex. We want to keep a path open between us and the child. We often get new problems ourselves from the mouths of babes and sucklings.

Direct sex teaching in classes of small children rarely works, but whenever it comes up in the curriculum, as it does in history, scripture, botany, etc., let us teach it "in our stride." It does no harm to know that the Reformation turned on the love affair of a king, or that David had a human problem of lust and envy. The out-of-school care of animals is useful, as we saw in the case of Elsie T. Although human beings failed to teach and convince her, she learnt a great deal from the pastime of breeding rabbits and guinea pigs. She

1 This idea was embodied in a resolution passed at the International Conference of Women Physicians, New York City, 1919. 
gained an amount of information that was evidently absent in the childhood of Dr. Ethel Smyth, ${ }^{1}$ who tells us in her autobiography of an agonising memory in early life. She writes:

"When I was about eleven, one awful day, after overhearing scraps of a conversation, or perhaps enlightened in a flash by a line of poetry, I suddenly gathered that having babies and embracing were mysteriously connected ; and despair fell upon me, for shortly before I had, without enthusiasm, allowed a boy I rather hated to kiss me in the rosery! Like every child in a large family I was aware you could not tell for a long time if a baby was on the way or not, and for two or three months I would surreptitiously examine my figure in the glass and fancy the worst! What agonising suspense of after years can compare with that of a child thus tortured, unable to confide in any one, and wondering as I did, should the dreaded thing happen, whether I would drown myself in the deep water near the lock, or lay my head on the railsperhaps in the tunnel, where people would think it had been an accident!"

We must not be too shocked when children do much naughtier things than exchanging kisses. A teacher in an elementary school told me that at one time there was an epidemic among her scholars of masturbation, and of scribbling indecent things upon the walls of the school. She had noticed this going on, but felt unable to tackle it.

One day she had fallen into an absent-minded state and suddenly looking up from her desk she noticed several of the children employing their hands wrongly. She became suddenly overwhelmed and put her head on her desk and cried bitterly. Now we know this was a weak and stupid thing to do. She knew it too. The poor sensitive young teacher had become identified with the collective guilt of her class. Hence she was helpless. She became neurotic and useless-and why? Because in her own life she had an unsolved sex problem, though of a different kind from the one manifested in the class. It was a liaison with a married man, a common problem in which she drifted helplessly. When her

2 "Impressions that Remained," vol, i. p. 84. 
scholars presented her with a concrete difficulty, she had no standpoint of her own from which to tackle it. She was betrayed from within. She became a nervous invalid, and the problem was temporarily evaded by being transferred from the physical to the psychical sphere.

There is a prodigious outcry to-day that we must educate, educate, educate, not only children but the general public on matters of sex. Every one is saying (rather evasively, I think) that it is the teacher's duty. However, do not let us be hustled. The evils which have gone on so long will not be improved unless we prepare ourselves to attack them in a more understanding way.

It is in order to promote some unification in the factors of the sex life that we should devote ourselves to the study of unconscious phenomena so that we may take them into our calculations in reviewing the whole problem from childhood on. 


\section{IX}

\section{THE SIGNIFICANCE OF PHANTASY IN THE PRO- DUCTION OF THE PSYCHONEUROSES ${ }^{1}$}

For the first time in the history of medicine, we are in a favourable position to understand the problems of the neurotic. The work of the last fifty years on functional diseases, culminating in the psychoanalytic theories, has brought to light the fact of the continuity of the mental life.

The links missing from consciousness are to be found in the unconscious mind, where everything that has taken part in our experience continues to exist, and exert an influence for good or ill upon the present.

Although the function of the unconscious mind is compensatory to consciousness, it none the less contains elements which are irrational and primitive, and which are incompatible with those of the cultured, rational mind of the highlydeveloped personality.

This twofold character of the mind provides the elements for mental conflict and dissociation. When the conscious aims conflict with the unconscious tendencies to such a degree as to interfere with an individual's capacity to adapt more or less well to the demands of life, a neurosis may supervene. The symptoms of neurosis are compromise-formations, which in Freud's view represent the unconscious gratification of a repressed wish of an infantile and erotic character.

Freud has divided neurosis into the Actual, and the Psychoneuroses. ${ }^{2}$

Briefly stated, the Actual Neurosis is one in which the causation is in the present, and lies in the sexual life; the

1 Read at a meeting of the London Branch of the Federation of Medical Women, 1919.

2 Sce Dr. Ernest Jones in "Nervous and Mental Diseases." 
pathogenic agents are operative at the time the symptoms present themselves, and are predominantly physical. Whereas the Psychoneuroses have a predominantly mental basis, the causation is in the past and lies in the experiences and phantasies of childhood.

In practice there is no clear line of demarcation between the two groups. It is merely a question of accent. In every case we should look for the causation both in the present and in the past. In the actual neuroses a change in the habits of the sexual life, and the application of suitable medical measures may be sufficient to bring about a cure; but with the psychoneuroses the etiological factors are completely unconscious until revealed by analysis, and require psychological treatment.

The use of the psycho-analytic method is still relatively new, and is far from being generally understood by the bulk of consulting physicians or general practitioners. However, all have gone so far as to admit that, in spite of our best efforts, there is a large residue of nervous patients whom we have hitherto failed to cure, and we do not know why we failed. It is useless to stigmatise them as malades imaginaires. Though the blame is put upon the patient in this way the doctor is not absolved. Where we cannot effect a cure our interest is apt to flag; we even become a little annoyed, and we believe our patient to be "stupid" or "obstinate" or "hopeless." Is not this a projection of our own uninformed attitude on to the patient? Till fairly recently we knew little about "motor areas" and "nerve tracts" in the brain. Even now a great number of the patients who die in asylums show no brain changes recognisable by our present means of investigation. Therefore it behoves us to be humble about the disorders we call "functional," and recognise we have still much to learn about the working of the mind.

Speaking generally, it was the absence of organic lesions that underlay the contempt in which the neurotic was formerly held; a contempt as falsely founded as that which led our forefathers to believe insane persons to be the wicked subjects of demoniacal possession. In a recent text-book dealing with the psychoses (viz. manic-depressive insanity, paranoia, 
dementia præcox, and paraphrenia), Stoddart says, "Like the neuroses and psycho-neuroses they have no morbid anatomy, and their basis is supposed to be purely psychical." 1

It were perhaps well to review very briefly the stages through which psycho-therapy has passed in the last fifty years.

Charcot's demonstrations of hypnotism, and his association of the hypnotic states with hysteria, introduced new ideas which gave a psychological basis to the conception of hysteria, and were the beginning of a scientific study of the disease. He showed that the symptoms were built upon fixed ideas which both originated the symptoms and kept them going, and which could be reproduced in the hypnotic state. Charcot did not use hypnotism therapeutically, rather he may be said to have exploited the hysteric in his impressive demonstrations. Dr. Liébeault of Nancy was the originator of the modern treatment by hypnotism. His work, which was prior to Charcot's, passed almost unnoticed by the scientific public. His undoubted cures aroused as much resistance as admiration, and scientific men began to ask what hypnotism really was. Failing to find an answer in the usual channels, they referred the method again to the sphere of magic, until Bernheim produced his book, "De la Suggestion et des applications à la Thérapeutique," which gave the subject a new start. But as Lloyd Tuckey says, "The lesson the study of mental suggestion teaches is not that disease is imaginary, but that the imagination has a powerful influence over its manifestations." 2 There is indeed in hypnotism much to puzzle the thoughtful, for the remedy is as mysterious as the disease it is curing. Why is it so uncertain? Why does it sometimes cure the symptoms and sometimes not? Why are some people hypnotisable and others not? When we have hypnotised our patients what have we done to them after all ? Why can the subconscious mind apparently bring about cures which the conscious mind cannot influence, and so forth ?

1 "Mind and its Disorders," p. 253. Lewis \& Co., Ltd., 1919. p. 37.

2 "Hypnotism and Suggestion," Bailliere, Tindali \& Cox, Sixth Edition, 
Analytic researches have thrown much light on the character of the hypnotic cure. ${ }^{1}$ We now know that hypnosis belongs to the phenomena of the unconscious, and that it cannot be called a scientific method in itself. Its effects are obtained by the transference of the unconscious affects of the patient to the physician. Through the use of hypnotism we have arrived at an idea that is really scientific, viz. that it is essential to differentiate between psychical and physical factors in etiology, and that the remedy for psychic disease must proceed aloug psychic lines.

Whilst Charcot was carrying on his demonstrations in Paris, another important discovery was made quite independently about 1880 by an Austrian physician, Dr. Joseph Breuer. He had under his care a very intelligent girl of twenty-one who was suffering from physical and mental disturbances. She had paralysis and anæsthesia of the right arm and leg, disturbances of eye movements, impairment of vision, tussis nervosa, nausea whenever she tried to eat, and at one time she refused to drink in spite of tormenting thirst. She had systematic aphasia-that is, her power of speech was disturbed; she was unable to speak her mother-tongue (German), and could only express herself in English. She finally developed twilight states, with confusion, and changes of character. In her twilight states she would mutter words, and recount phantasies or day-dreams. Breuer saw that alterations of mood resulted from these fancies, and that the emotions attached to them were of deep significance for her illness. Whenever the patient had poured out these phantasies, and the memories that sprang up with them, her condition improved for some hours. Breuer began to make systematic use of this catharsis, which the girl called the "chimney-sweeping cure." This was the first time that a connection between dreams and hysterical symptoms was therapeutically established, and it was the beginning of the

1 For the historical account of the beginnings of hypnotism see "Treatment by Hypnotism and Suggestion," Dr. Lloyd Tuckey; "Introduction to the Study of Hypnotism," E. H. Wingfield. For its relation to Psychoanalysis, see "Contributions to Psychoanalysis," Ferenczi, chap. ii., and Freud's "Clark University Lecture," 1910. "Analytical Psychology," Jung, chap. ix. 
development of the modern psychological theories of hysteria. When Breuer made this original analysis, Freud was a senior student; but when, a few years later, he began to follow Breuer's methods in the treatment of his own cases, he found his experiences entirely coincided with those of his chief. These observers were led to the confirmation of Charcot's trauma theory. With the aid of hypnotism an effort was made to re-awaken the memory of the incidents and feelings which were present when the first hysterical symptoms appeared. It was found that emotions of fear, shame, and anxiety were invariably present, and it was further noted that any experience that could rouse these affects could act as a psychic trauma. Where the special memories had been related, the observers found, to their great surprise, "that the individual hysterical symptoms immediately disappeared, and did not return if they succeeded in thoroughly awakening the memories of the causal process, with its accompanying affect, and if the patient circumstantially discussed the process, giving free play to the affect." 1 (Abreaction.)

Charcot had designated hypnotism as "artificial hysteria." Freud now observed that the presence of states of reverie (hypnoid states) was the determining basis of hysteria. In the course of treatment he found that not all his patients were hypnotisable, but he continued to press them for information which they were quite unconscious of possessing. When he had reached a point where they declared they knew nothing more, he writes, "I would assure them that they did know, that they must speak out. I would venture the assertion that the memory which would emerge at the moment that I laid my hand on the patient's forehead would be the right one. In this way I succeeded in learning without hypnosis all that was necessary." 2 Freud did not give up the use of hypnotism, however, until he had succeeded in substantiating the fact that "forgotten memories were not lost . . . they were ready to emerge ... but hindered from becoming conscious by some sort of force ... one could get an idea of this force

1 "Hysteria and other Psychoneuroses," Freud, p. 4.

2 "Origin and Development of Psycho-analysis," Freud. 
which maintained the pathological situation from the resistance of the patient. . . . It is on this idea of resistance that I base my theory of the psychic processes of hystericals." Hypnotism was now seen to have covered up resistances; whereas the analytical work proceeded by overcoming the resistances; because these forces which "opposed the emergence into consciousness of the forgotten ideas must themselves have caused the forgetting, and repressed the pathogenic experiences from consciousness." This process was called "repression"; its presence was considered proved by the existence of the resistance. Frend conceived that the strength of the repressive force lay in the fact that a wish had been involuntarily aroused which was "in sharp opposition to the other desires of the individual, and was not capable of being reconciled with the ethical, æsthetic, and personal pretensions of the patient's personality." This wish then formed the unbearable idea which was the basis of the unconscious mental conflict. The conflict arose because, on the one hand, the conscious was striving to drag up the unbearable idea, and, on the other, the unconscious was resisting this tendency. The neurotic symptoms and obsessive thoughts were surrogates (compromise-formations) for the unbearable idea with which they were unconsciously linked.

Freud no longer attached any etiological importance to the sexual trauma; nor did he find the cure of the neurosis lay in abreaction. He came to regard the infantile sexual phantasies as the pathogenic agents, tracing them back to early sexual activities, and to find the predisposition in a fixation of libido (here "sexual hunger") on one or other parent, forming the complex characterised as the Edipus or Electra complex.

The characteristic moment of hysteria for Freud does not lie in the "weakening of the faculty of psychological synthesis," upon which Pierre Janet has laid so much stress. ${ }^{1}$ Janet speaks of a "psychological insufficiency," and regards the hysteric as the victim of heredity and degeneration. He finds a congenital tendency to dissociation, a relative weakness in synthesis. But, as Freud has pointed out, one can observe

1 "The Mental State of Hystericals." Putnams, New York and London. 
" besides the phenomena of lessened functioning, examples of partial increase of functional capacity as a sort of compensation." I In support of this, he quotes Breuer's patient to whom I have previously referred. She had "forgotten her mother tongue and all languages save English, but if a German book was put before her she could give a perfect translation of its contents at sight." 2

In Freud's conception, therefore, the symptoms are brought about as a defence against the unbearable idea, and are due to a conversion of psychical energy into physical innervation. If by forcible repression the idea can be treated as "non arrivée," the sum of excitement may be transferred to the somatic sphere-producing a paralysis or pain, for exampleor to an idea, producing a phobia or obsession.

Adler ${ }^{3}$ has also contributed ideas that are of value to the problem of neurosis. He regards the symptoms as an unconscious compensation for a definite organ inferiority. They represent a striving for power, and a safeguarding of the ego by a "masculine protest," by means of which the individual in question is always above, i.e. in a position of fictitious superiority. The symptoms are the result of the "fictions directrices"; and by the attention they attract, and the arrangements they provide, add an importance to the personality which would otherwise be lacking.

Jung, like Freud, also attributes neurosis to repression. He does not, however, base its whole etiology on sexual repression, nor on a safeguarding of the ego (Adler); but on a one-sided development of the predominating psychological

1 "Origin and Development of Psycho-analysis." Clark Lecture, 1909.

2 "There are certain acquisitions as well as losses of faculty," says F. W. Myers. Joan of Aro and St. Francis of Assisi both gained values to their personalities from their seeondary states. Weir Mitchell's case, of Mary Reynolds, passed into a second state in which her character was completely changed from melancholy to cheerfulness, from reserve to sociability, and from being timid she became brave and adventurous. In sleep-walking somnambulists perform feats that are impossible in waking consciousness.

3 "The Nourotic Constitution," Adler. Moffat, Yard \& Co. Babinski's definition that "Hysteria is a pathological state manifested by disorders which it is possiblo to reproduce exactly by suggestion in certain subjects, and which can be made to disappear by the influence of persuasion alone," adds nothing oither to our understanding or knowledge. 
function, the other functions being relatively repressed. Dreams, phantasies, and neurotic symptoms are regarded both as compromise-formations and as compensations. The function or functions missing from consciousness appear in a symbolic form.

Jung has also introduced a concept of the libido as psychic energy, which manifests itself in every function of body or soul. He looks for the exciting cause (the obstacle) of the neurosis in the present, and the predisposing cause in the past (the unconscious). When the libido, in the service of adaptation, meets with the obstacle, it tends to accumulate till it surmounts it; or till it flows back into regressive channels, and takes up a former mode of reaction. In such case, the infantile sexual phantasies, and the old adaptation to the parents reappear, which is no longer suitable. Each psychological type has a characteristic way of applying the libido. In the extraverted type it is applied to the object and the objective world; in the introverted type, to the subject and the idea. Whichever function is repressed remains under-developed, and far behind the level of the conscious function; thus the conditions for an unconscious conflict are present.

In this view the neurosis is not originated by the infantile sexual phantasies, nor by the CEdipus-complex, but is due to a failure to apply the stored-up libido in a suitable human way, whereby the infantile sexual phantasies, and the parent imago become "puffed up by the regressed libido, which has not found its natural outlet into a new form of adjustment to life. . . . The psychological trouble in neurosis, and neurosis itself, can be considered as an act of adaptation that has failed." 1

These, and many others, are current views of the etiology of neurosis. Each has its special value. We cannot exclude heredity, nor organ inferiority, nor congenital weakness of synthesis, nor degeneration. We cannot deny the compensatory character of the neurosis, or fail to see that sensationalism adds importance to some temperaments. There are, however, 1 “Analytical Psychology," p. 234. 
certain factors which are found in every case, and upon the existence of which the analytic therapy is based: viz., the presence of systems of phantasies, and the existence of the unconscious conflict.

The most important discoveries connected with the new medical psychology have been made through the study of dreams, because neurotic symptoms, like dreams, are the creation of the unconscious mind. They serve an unconscious purpose, and are an attempt, though a mistaken one, to find a solution for the unbearable idea.

The symptoms are constructed on numerous determinants, and their psychological meaning is to be found in the phantasies that lie behind them. The most strenuous conflicts occur in relation to the development of the individual in opposition to the claims of the herd-life, and in respect of the human relations. Life demands, as Jung says, the "sacrifice of the infantile personality"; the obstacles occur primarily where this is threatened, and it is at these moments that the regressive phantasies arise. There are certain typical themes to be found in the phantasies which merit the term "myths"; one of the most notable among them being the re-birth myth. In psychological analysis it is of the utmost importance to reveal the existence of such phantasy systems to the patient. The following case illustrates the presence of the directing phantasy.

Mrs. P., a woman of forty-eight, complained of a feeling of suffocation, and a terrible sense of fear which prevented her from going out alone, and which for several weeks had kept her to her room and bed. The complaints were made in a weak and fretful voice, and she entreated me to "say nothing discouraging, as she was already full of doubts as to her recovery." She wept frequently throughout the early interviews. She attributed her symptoms to post-influenzal weakness, which undoubtedly played some part therein. After a little analysis, a psychological conflict revealed itself. It appeared that the real "villain in the piece" was an aunt, a

1 See Dr. Nieoll, British Journal of Psychology, 1921 (Medical Section), "Outline of the Idea of Rebirth in Dreams." 
woman but little older than herself, who had "been like a sister" to her. This lady was extremely rich, she had exercised great influence upon my patient in her girlhood, and they were once more often together. Having no children of her own, she lavished gifts on Mrs. P., and relied upon her for companionship. Mrs. P. declared that the aunt tried to control her opinions as well as her occupations. The two lived in neighbouring houses, and visits were exchanged once or twice daily. Mrs. P. resented this, but she said her aunt was "so kind and so deroted," she could not possibly hurt her by refusal. On the contrary, she felt compelled to carry out every wish, expressed or unexpressed. Her conduct to her aunt was amiable, but her feelings were full of resentment which she repressed, and for which she constantly reproached herself. Ultimately, the conflict became so severe that in the course of the last few months she broke down repeatedly in the way I have indicated.

This case is typical of many where there is no external necessity for such a foolish adaptation. The adaptation is related to the unconscious rather than the conscious. The husband was unusually kind. Though less wealthy than her aunt, Mrs. P. had no lack of means to lead a pleasant and comfortable life. Nor could I ever gather that the aunt was more unreasonable or exacting than most people who have too much money and too little to do. The basic factor lay in Mrs. P.'s childish psychology. She was unequal to evading the problem of the aunt's domination on any basis save that of invalidism. She might have freed herself from the aunt by a quarrel, or by putting the claims of her husband first. For either expedient she lacked the moral courage. - To rationalise her conduct she declared she had a Christian duty to this aunt, in the fulfilling of which she broke down. By her unconscious attitude she put herself in the power of her aunt, and by a re-animation of the imago of the mother, endowed her with the rôle of the "Terrible Mother," who thwarted her at every turn, and against whose malignent power she was helpless. All her feelings of fear, hatred, envy, and desire for superiority, were projected on to this image, which thus became 
a trap for a large quantity of her libido. Depleted of her energy in this way, Mrs. P. could only play the rôle of invalid. The phantasies were wish-fulfilling, because the illness brought about by the unconscious conflict allowed her to escape from her aunt and the difficulties of the external situation.

In tracing dreams and phantasies to their source, the "myth" which has hitherto dominated the patient's life becomes uncovered. Dream analysis brings us by the shortest route to private and otherwise inaccessible things. What we must remember is that owing to the mechanism of repression, these things are just as inaccessible to the sufferer as to the physician. The method really brings to light material of which the patient is unconscious. Psychotherapists who use methods of suggestion and persuasion, do not necessarily arrive at the unconscious material at all. Nor is it merely a question of obtaining an unusually thorough history of the case, nor of reviving certain memories under hypnosis and obtaining an abreaction-that is, the working-off of the pent-up emotion through re-living it. Psychotherapists are still held by this attractive theory.

Abreaction opens as it were the first portal of the unconscious. It acts effectively up to a point. Certain resistances are broken down, there is a relief of tension as the emotion is gradually transferred from the unconscious of the patient to the physician. There is a sort of "absolution" experienced, a feeling of having submitted to the collective judgment in the person of the physician, who, in the capacity of judge and saviour, becomes the helper and redeemer in the new life of effort and the one at whose instigation a fresh adaptation is undertaken. Abreaction works in a crisis. It often allows some of the hidden values of the sufferer to come to realisation so that he can once more get on with life. In so far as it succeeds, it does so on account of a leading out into consciousness the sum of libido formerly occupied with the complex, and by restoring the complex itself to conscious control. This in many cases is all that we as physicians are permitted to do, and also in many cases this is all that we need to do. But do not let us be 
deceived. Abreaction introduces us merely to the ante-room of the unconscions. We have not touched the root causes of the dissociation. The general system of phantasies remains unattacked, and indeed it is through the transference of the father or mother image to the physician that the dynamic force for the alleviation is provided. In this respect it has a similar therapeutic effect to hypnotism, but goes a degree further. In this connection I cannot forbear quoting from the Persian of Jámí, since it shows that the value of abreaction was well understood by the Easterns in the fifteenth century. The story is called "The Afflicted Poet."

"A poet paid a visit to a doctor and said: "Something has become knotted in my heart which makes me uncomfortable; it makes also my limbs wither, and causes the hairs on my body to stand on end.'

"The physician, who was a shrewd man, asked: 'Very likely thou hast not yet recited to any one thy latest verses?' The poet replied: 'Just so.' The doctor continued: 'Then recite them.' He complied, was requested to repeat them, and again to rehearse them for a third time.

"After he had done so, the doctor said: 'Now arise, for thou art saved. This poetry had become knotted in thy heart, and the dryness of it took effect upon the outside; but as thou hast relieved thy heart, thou art cured."

The analysis of every neurosis discloses a childish or primitive ill-adapted way of reacting. The cure depends on the overcoming of this unconscious infantile attitnde. Such a state is characterised by indecision, and every new step is productire of more or less useless " argument." Even with normal people, opposing tendencies are always present in the mind. One of these is mainly conscious, the other mainly unconscious. Every idea implies its opposite, as, for example, sadism and masochism. The capacity to see both sides, while selecting one for our allegiance, gives value to our decisions. It has a compensatory character, softening or strengthening a given judgment. This balancing of one impulse by its opposite is called by Bleuler "ambitendency"; the association of the pairs is called "ambivalency." Normally an inner 
association of the opposites is present; in the neurotic individual, however, the pairs are in a state of separation. $\mathrm{He}$ is always conscious of opposing ideas and impulses in a way that disturbs his conduct. No sooner does he decide upon a course of action, than the superiority of the rejected one strikes him.

I do not want to deepen the erroneous view that the psycho-neurotic is an inferior person. Until recently it was the custom to start our medical career under this false impression. Practice, however, soon surprised us with the fact that many of the patients whose characters we had reason to admire were neurotic, although they were among the most valuable members of the family and community. The hysteric is far from being a person of blunt moral feelings. His difficulty is that he feels things too much. In experiment Binet actually found the hysteric was fifty times more sensitive than the normal. Hysteria, in spite of the popular idea (and not a few fairly recent text-books), is not malingering. Malingering is conscious fraud. Hysteria is an illness based on unconscious phantasies, and no one is more thoroughly deceived than the sufferer himself.

The following is a fairly typical case of hysteria. A woman of thirty-two, married (with a husband on active service), the mother of two boys, came to me complaining that she had suffered for five years from pain in her right arm. She carried her arm in a sling, because after using it the pain kept her awake at night. She had taken to writing with her left hand; and had given up every occupation which involved the use of the right arm. She had been under treatment throughout these five years, and had consulted eminent physicians and surgeons. She informed me the last surgeon had told her that there "were adhesions between the muscles of her scapular region," and advised an operation to break them down. She felt certain he had made a correct diagnosis, us he was the only one who had allowed that the symptoms had an organic basis. She wished to have the operation, but yielding to the persuasions of her relatives came to me as a last resource before undergoing it. I examined her present 
condition with the utmost care, with a negative result; therefore, without paying any further attention to her symptoms, $I$ began an analysis. In a few weeks the symptoms subsided. The patient gradually took up her ordinary life again, and was soon able to drive an automobile for war service.

Not only did the pain disappear, but a number of misleading ideas that had influenced her conduct were vanquished. The symptoms were a phantastic defence against society and its demands upon herself; they were the result of an unconscious mental conflict. It was to the resolution of the conflict that the analytic work was directed.

The conflict lay between the psychological functions of thinking and feeling, or between the claims of the ego and the objective world. Her development was extremely onesided, the extraversion tendency being relatively repressed and unconscious. The neurosis was precipitated by the war. The patient was unexpectedly confronted with the need to adapt to new conditions of life, in which an extraverted attitude was urgently needed. The husband was called away from home, and the sole care of the children and household devolved upon her. She was too conscientious to be able to escape from her duties, for which she felt inadequate. A neurosis arose which disabled her right arm, and served as the expression of the unconscious wish. By the time she reached my consulting-room she had already given up her house, and returned with her children to the house of her own parents. This makeshift solution pointed to the deepest roots of her conflict, which lay in her unconscious infantile adaptation to her parents.

Observation of the neurosis shows us, again and again, that the sufferer is actuated by factors which are not to be found in consciousness, for "consciousness is never more than a small fraction of the personality" (Ribot). We may well ask ourselves what the unconscious mind is, since we see its effects so plainly in symptoms, dreams, hallucinations, alterations of mood or of personality, and so forth. What is below the threshold of consciousness can rise above it from time to 
time, temporarily or permanently. According to Myers, ${ }^{1}$ all the subliminal contents have once been in consciousness and sunk below the threshold. This could happen because they have served their purpose and are no longer wanted in consciousness-or because, owing to lack of interest, their associated ideas are few and unimportant.

Freud considers that the unconscious exists as the result of repression, and that its function is to wish. The unconscious wishes are always striving for gratification, and supply the dynamic of the personality. The unconscious is also the passive receptacle of the entire memories of a lifetime. To quote Jones, "he regards the mental life as a continuity; the appearance of discontinuity is due to the ignorance of the preceding conscious influences. For instance, when a person at twenty chooses a profession, the real reason why he reacts in a specific way is associated with deeper unconscious trends which arose early in childhood. Freud holds in general that owing to our ignorance of the most important mental processes of early childhood, and our personal amnesia for this period, the significance for later life of these early trends is vastly underestimated." 2 The importance of this view can hardly be overvalued, but determinism does not cover the whole ground.

Jung lays stress upon the view that the unconscious has not only a retrospective causal meaning but also a teleological one. That is to say, it is not only the result of repression, but is the creative mind, expressing itself in symbols and symptomatic acts because it can only express itself in a nonrational manner. The unconscious has a Janus head, it faces both ways, it is a shutter and opener of doors. F. W. Myers also, recognising its prospective meaning, regarded the man of genius as the best type of normal, and for him genius lay in an increased control over subliminal mentation. He did not claim that all that was unconscious bore the character of inspiration, but rather that those who gained an effective contact with the unconscious were able by this means to utilise a wider range of faculties that are in some degree innate

¿ "Human Personality," F. W. Myers.

2 "Psycho-analysis," Dr. E. Jones. 
in all. ${ }^{1}$ It is just this effective contact that we strive for in the analytical work. If the patient in pursuit of a better adaptation can acquire courage to be a little peculiar if necessary, or different from others, he can often carry out his life task with satisfaction to himself and with benefit to his neighbours. To do this he needs to find new values in himself. Values hitherto unknown to him lie in the unconscious mind. In searching for the roots of his illness he finds unexpected and interesting material. The new outlook upon life thus provided, goes far to carry him over the difficult conquest of his neurosis.

The neurotic or psychotic person shows in his symptoms and morbid ideas traces, not only of his personal, but of his racial history. In mild cases he goes back to his own infantile past; in severe cases he falls back upon old instincts and manners which were once well adapted in the remote history of anthropoid or primitive man. In the last stages of mental dissociation the patient entirely loses his adaptation to the objective world of to-day, and the unconscious contents of the mind turn out the conscious. An insane person becomes identified with his unconscious, and for him the phenomena of consciousness have become the dream.

In normal health there is an effective diaphragm between the conscious and unconscious. This allows an advantageous play between the two portions of the mind and yet serves for a separation. The natural "go-between" is the dream or phantasy. In neurosis the diaphragm is too permeable. In mania its function is abrogated.

We are helped in our understanding of dream and phantasy, and also in the comprehension of neurosis, by a study of primitive man. The primitive mind works by means of images or representations of an idea, not by abstract thought. The idea is seized in a picture. Just as the young child cannot differentiate between the inner and outer life, no more can the primitive separate subject and object. His subjective interpretations cover everything, he animises and anthropomorphises everything. He mixes up the imaginary and I "Human Personality," F, IV. Myers. 
the real. Persons and things are confused with their attributes, and causes with effects. Out of his confusion intuitions emerge which are often erroneous. Schultze records " that a Kafir once broke off a piece of an anchor, and died soon afterwards. Subsequently Kafirs attributed divine significance to the anchor, which they reverenced, greeting it whenever they passed, in order to avoid its wrath." "Man," says Professor Hobhouse, "has travelled far when image making has developed into thinking." 1 Thus we normally follow two kinds of thinking. ${ }^{2}$ Directed thinking is conscious, purposive and abstract. It is responsible, and represents mental work and achievement. It is a function of adaptation. Undirected thinking is subconscious, irresponsible, and is a means of turning away from reality and gaining pleasure. It is restful, generally unproductive. This is what Bleuler calls "Autistic thinking." "It is characterised by the predominance of the inner life with active turning away from the outer world." ${ }^{3}$ It is not adapted to reality.

The unconscious, like the primitive, cannot think otherwise than by representation, that is symbolically. Freud attributes symbolism to the action of the censor, who tries to keep the repressed wish from consciousness. But this condensation and distortion is similar to the primitive blurring of things with their attributes, causes with their effects. In the dream we are on the level with what Jane Harrison calls the "Totemistic Thinker." ${ }^{4}$ Neurotic symptoms are often the result of equally false inferences with those of the Kafirs just cited, inferences also made unconsciously. Dr. Samuel Johnson's compulsion neurosis forced him to touch posts, ${ }^{5}$ he knew no more why he

1 "Morals in Evolution," L. T. Hobhouse. Vol. 2, pp. 264 et seq.

2 "Psychology of the Unconscious," chap. i.

3 "The Psycho-analytic Method," Pfister, p. 303.

4 "Themis," Jane Harrison.

s Mr. S. Whyte ("Miscellanea Nova," p. 49) tells how, from old Mr. Sheridan's house in Bedford Street, opposite Henrietta Street, with an opera glass he watched Johnson approaching. "I perceived him at a good distance working along with a peculiar solemnity of deportment, and an awkward sort of measured step. Upon every post as he passed along, he deliberately laid his hand; but, missing one of them, when he had got at some distance, he seemed suddenly to recollect himself, and immediately returning carefully performed 
did it than the Kafir now knows why he salutes the anchor. All compulsive acts, like washing ceremonies, covering of timepieces, and clothing rituals, belong to the category of fetichism and taboo.

When we turn to the question of the phantasies themselves we find they occur whenever conscious attention is relaxed. In most people they pass by subliminally, unheeded. We gradually become aware of them when we look out for them. Consciously directed phantasies are called "day dreams." Other types spring into consciousness fully formed as it were-having a pictorial or dramatic form. They are similar in character to the creations of the poet or novelist. If the phantasies are of great or universal value we allow them to be "inspired." Dreams occurring during sleep are of the same involuntary material, so are hypnagogic and hypnapompic visions which occur in the state between sleep and waking. Visions such as A. E. describes in "The Candle of Vision" are subjectirely formed, and should be estimated as subjective material. "What a savage experiences during a dream is just as real to him as what he sees when he is awake." (Spencer and Gillen). To believe in the objectivity of the vision is to put oneself back on the level of the primitive thinking. It means that we become hallucinated by belief in the objective reality of the psychic perceptions. This happened in the case of one of my patients, who was one day looking at the Albert Memorial. Suddenly one of the figures in the frieze appeared to step out and threaten her. She ran panting and terrified for a considerable distance before she was able to shake off the hallucination.

The following cases further illustrate the significance of phantasy in the production of the psycho-neuroses.

Mrs. X, aged forty-seven, was complaining of symptoms attributed to the menopause. She had hot flushes, of such violence that she woke from sleep several times every night drenched with

the accustomed ceremony, and resumed his former course, not omitting one till he gained the crossing. This, Mr. Sheridan assured me, was his constant practice." Birkbeck Hill's "Boswell's Life of Johnson," vol. i., note 1, p. 481. 
perspiration. In the day she had attacks of dry burning heat which lasted for hours, and which completely unnerved her. The physical examination gave a negative result.

She spoke of home troubles. It appeared that she and her husband were living in the house of her aged father. $\mathrm{He}$ was eighty-two, and latterly almost confined to his room. She could never leave the house without evoking a scene and severe criticism from her father, consequently she rarely went out. She had always been afraid of him. When she was about sixteen she could never take a meal in his presence without vomiting afterwards. He sometimes used to beat her. She told me her married life was "thoroughly satisfactory," and that she and her husband had been very happy till they went to live with her father a few years ago, on the death of her mother whom she loved devotedly. It appeared Mrs. X's mother was very unhappy in her married life, the daughter had always sympathised with her and shared her sufferings. Mrs. X was quite alive to the drama of her situation, and rather enjoyed the recital of her martyrdom, speaking about it in short breathless sentences.

I cannot detail the dream analysis by means of which I found the patient was unconsciously identified with her mother. Not only did she sympathise with her mother, but she actually.bore her sufferings in her lifetime, and must needs take her place after her death, and bring herself once more into outward subjection to her father.

It transpired that she had never had conjugal relations with her husband. Her marriage was preceded by a long engagement, drawn out for no valid reason. She said her husband "treated her more like a mother than a wife"; that is, he made no sexual demands upon her. He seemed to think it quite natural they should go to live with the old father. To cut a long story short : the vomiting after puberty proved to be a pregnancy identification; it was "as if" she were in a situation like her mother's. Here is a case where an unconscious relation to the father, though covered by conscious hostility, has operated like a fate throughout the woman's life. She married a man who did not make the ordinary demands 
upon her, and she drifted back, years later, into the paternal home to take her dead mother's place. The identification is the predisposing cause of the breakdown for which the menopause supplies an occasion. Her dreams showed her to be extremely prudish; her phantasies were those of an adolescent girl. It seems probable that every symptom of puberty and the menopause that is very pronounced or distressing is evidence of an unconscious conflict, which will be found to lie in the psycho-sexual sphere.

The next case is one of dissociated personality. At puberty this sufferer was exposed to a severe sexual shock. Once, on coming home from school, Ellen was followed by a roughlooking man. She ran away from him. It is pertinent to the unconscious motivation that, instead of continuing on the main road, she ran up a side road into a wood, "it seemed safer" (the unconscious wish). She was overtaken, and after a desperate struggle with the man she was thrown down, previous to an intended rape. At the critical moment her shrieks brought rescue (libido against the unconscious wish). The man was subsequently prosecuted. The girl had to appear in court, and experienced a good deal of reaction of a conscious kind. But the tension aroused got no relief, and was relegated to the unconscious. She was now frightened to sleep alone, so her mother took her into her bed, and mourned over her unhappy experience, and crooned out mysterious warnings about sex. Ellen determined to forget the whole thing. She succeeded in doing this, but was not very successful in her attempt to secure comfort, for she was constantly ill, suffered from dysmenorrhoea, and was often nervous and irritable. She became deeply religious, and took up social work with fervour. When she came to me she was over thirty. She was then suffering from lapses of memory, and had a history of fugue-like attacks which lasted for days, and even so long as a couple of weeks. In these attacks she was in another state of consciousness, and would re-enact the unhappy experience of puberty. She looked wild, threw herself about, struggled and made incoherent cries. She was habitually constipated, and in these attacks she became still 
more so, and an enema was finally resorted to. She had no memory of the attacks on waking.

In her normal state she was in many respects brilliantly clever, but she had frequent emotional phases which were spoken of as "Ellen's childish unreasonableness." Any strain or emotional difficulty would serve to bring on an attack which might develop into a fugue. During her fugues she was extremely suggestible, which tendency was used to her advantage by those in medical charge of her.

The analysis soon brought the dissociated mental state into consciousness. The constipation was seen to have been the means of bringing about a certain local tension; the use of the enema as a symbolic substitution in the attacks served to carry the coitus symbol to its conclusion.

In this case, the making conscious of the underlying motives of the attack aroused very great resistances. However, it says much for the excellent goodwill of the patient, that once the libido was detached from the dominating phantasies, she never had a recurrence of the fugue.

These cases, in common with many published cases, show the far-reaching effects of phantasy. Some very striking cases have been reported in connection with the war. It was a surprise to a considerable portion of the medical profession to find that hysteria is of common occurrence among men as well as among women. The neuroses of war and peace are on a similar basis; although the exciting factors are different, there is no difference in the unconscious mechanisms at work. The peace neuroses generally have a less dramatic onset, and naturally attract less interest.

It is indeed a welcome sign of the times that physicians ${ }^{1}$

1 In a paper on "Differential Diagnosis," Dr. Riddock points out that we have reached a stage of reaction against the exclusive study of morbid anatomy in our search into disturbances of function. He says, "The study of isolated signs has lost interest for the growing school of medical research. Investiga. tion as to whether the knee jerk as a solitary phenomenon is present or absent, no longer casts a glamour over us: we want to know what functional systems are out of order, and how the individual as a whole is reacting to altered conditions. ... Disordered function does not necessarily imply disordered structure, but if it goes on long enough it may do so. . . . Broadly speaking symptoms are the evidence of deranged function, signs are the evidence of gross 


\section{PRODUCTION OF THE PSYCHONEUROSES 181}

and patients alike are beginning to recognise the importance of mental factors in the production of disease.

structural change. . . To understand symptoms we must listen to the patient. .. The mass of eridence produced by the war has opened our eyes to the profound influence exerted by abnormal mental states on bodily function, and vice verst. We see more clearly that the prime function of the nerrous system is its integrative action, and that its guiding and controlling force is the mind. . . . One of the lessons to be learned is the necessity for psychological methods as part of the equipment for diagnosis." - "Functional Nerve Disease," Ed. H. Crichton Miller, 1920, p. 115. Frowde and Hodder \& Stoughton. 


\section{$\mathrm{X}$ \\ REVIEW OF "IHE PSYCHOLOGY OF THE UNCONSCIOUS" 1}

The book under review is one that is of great value to advanced students of analytical psychology. It needs many readings, for in spite of Dr. Beatrice Hinkle's excellent introduction, it remains a peculiar "formless" book. Though it is full of deep thought and valuable conclusions, it has the air of being an impromptu composition. If this is not a merit from the literary standpoint, it is a merit from the standpoint of the evolution of thought.

The writer devoted his leisure of several years to the production of this book. There is internal evidence of the gradual loosening from certain of the Freudian theories, and the formulation of new views, which have led to the separation of the Viennese and Swiss schools. The writer quotes Guglielmo Ferrero, and expresses his own mental attitude in the words, "It is a moral duty for a man of science to expose himself to the risk of committing error, and to submit to criticism, in order that science may continue to progress."

Miss Miller, who forms the subject of Dr. Jung's psychological analysis, is a certain young American woman, of good education and considerable attainments, and of high personal character. This lady supplied her physician, Dr. Flournoy, with some very interesting subconscious material, and expressed the hope that it might prove of value to others. Dr. Flournoy published it, together with some remarks of his own, in the Archives de Psychologie, 1906, vol. v.

Dr. Jung regarded these phantasies as typical subconscious material (which every psycho-analyst would recognise them

1 "Psyohology of the Unconscious," Jung. Translated by B. M. Hinkle, M.D. Moffat, Yard \& Co., New York. 
to be), and investigated this "individual phantasy system," by means of the free associations supplied by Miss Miller herself, in her original text; and also by a study of analogous material for comparison, derived from mythology, religion, literature, philology, and analytical experience. The limitation of the associative material in this case is a practical advantage, because it allows the analyst to place the emphasis on the universal aspects, rather than the personal ones. A justification for the conclusions arrived at lies in the fact that, no matter how unlike people are in the conscious contents of their minds, they are much more alike in the unconscious. For while each person has a particular personal memory or background (the personal unconscious), each shares in one that is universal and racial (the impersonal unconscious). The social environment changes greatly, but the main psychological problems remain the same for individuals in all ages, and under all conditions.

The book opens with a reference to the Edipus myth, now familiar to all students of psycho-analysis. This myth is of great importance analytically, for it represents the incestuous bond to the parents which is present in every neurosis, and of which traces are found in all normal people. "Incest" is understood very concretely by the Freudians, but a merely materialistic interpretation of it restricts its meaning and value. The incest is psychological, not physical. It is seen in the bond of the young child to the mother, which is one of dependence and irresponsibility. What adult does not know moments of danger, difficulty, or doubt, in which the wish for a comforting touch, for oblivion, for deliverance from the need to decide, or to suffer, is a paramount longing of the soul? A writer in The Nation remarked during the war that "among the French wounded he had almost invariably heard the cry in the first anguish of pain, ' $\mathrm{Oh}$, maman, maman!' the innocent, childlike cry for the mother's comfort."

The intention of "The Psychology of the Unconscious" was not so much to present an analysis of a special individual, as to illustrate from the unconscious material provided, 
the symbolisations and transformations which the libido undergoes in the course of life.

These changes are based upon an energic conception of the libido; the idea of psychic energy embraces a concept of biological energy, in which what is psychic is a specific part. It comprises relations between body and soul. This biopsychological energy must be accepted hypothetically as libido.

Where energy disappears from one place it reappears in another, and one psychic activity is immediately replaced by another. Whenever an activity that has occupied the libido comes to an end, another activity begins either in the conscious or unconscious. The total sum of energy always remains constant; ${ }^{1}$ an equivalent expression can always be found.

If we pass from the general concept of libido to a more particular understanding of it, we find it has something of the meaning of "mana," which Gilbert Murray describes as "that fine primitive word which comprises force, vitality, prestige, holiness, and power of magic, and which belong equally to a lion, a chief, a medicine man or a battle axe. . . . Mana is the positive power or force that man tries to acquire from his totem animal or his god. But there is also a negative side to be considered: there is not only the mana but the tabu, the Forbidden, the Thing Feared." 2

Or if we use the word "wakonda" we get a similar idea from McGee, who says: "In Dakotan tribes the sun is Wakonda-not the Wakonda, the moon is Wakonda, and so are thunder, lightning, and stars, the winds, cedars, and even man, especially a Shaman might be Wakonda. The term is applied to mythic monsters of earth, air, and water, to fetiches, ceremonial objects, and places of striking character."

1 When Robert Mayer introduced this idea into dynamics it "removed their character as elements from the forces, imparting to them the character of manifestations of energy, so the libido theory similarly removes from the sexual components the idea of mental 'faculties,' and ascribes to them merely phenomenal value." "Theory of Psycho-analysis," Jung. Monograph Series, p. 28.

" "Four Stages of Greek Religion." Gilbert Murray. 
Under what wide aspects the author regards the libido is seen throughout "The Psychology of the Unconscious." $\mathrm{He}$ answers the question, "What is God?" by "A thought which humanity everywhere, and in all ages, has brought forth from itself, ever and again in new and similar forms; a power in the world to which man gives praise; a power which creates as well as destroys, an idea necessary to life. ..." "God is our own longing to which we pay divine honours. ...2 Psychologically God is a projected representation complex accentuated in feeling according to the degree of religiousness of the individual, so God is to be considered as the representative of a certain sum of energy (libido). ... To bear a god within oneself signifies to be a god." Hence we see libido is not only effect, but the energy which produces it. God is not only the object of longing, but the longing itself.

To return to the Miller phantasies: it is a matter of experience in analysis that the dream deals with the most important and most painful problem of the moment, hence these phantasies introduce us to intimate problems of life. When the libido retires into the unconscious (introversion) it must of necessity reappear in a form which portrays unconscious activity, viz. some form of phantasy. In Miss Miller's case, the wish-tendencies are expressed in a subliminal poem, "The Hymn of Creation." Analysis of this poem, as in the case of the dream, leads directly to the most important and painful problems of the soul.

The first two lines of the three verses run as follows : ${ }^{8}$

When the Eternal first made Sound

A myriad ears sprang out to hear;

When the Eternal first made Light

A myriad eyes sprang out to look;

When the Eternal first gave Love

A myriad hearts sprang into life;

The poem was written after a period of travel, followed by a time of introversion, for which a long sea journey gave the opportunity. During this time Miss Miller was ruminating
1 Pp. 70, 71.
2 P. 96.
3 P. 53. 
upon all she had seen and experienced in her travels. Towards the end of the royage, the personal beauty and charm of the Italian officers of the ship strikes her, and one of them makes "a great impression" upon her. She then produced the afore-mentioned dream-poem, a phenomenon of the unconscious, which "can only be explained as arising from a disturbance which reaches to the very depths of her being." It indicates that feelings of love are involved. The significance of the poem is discussed from the psychological standpoint only. It is evident that the feelings of the anthoress have been aroused, but she has either undervalued the impression made, or forbidden its entry into consciousness. In spite of this, or because of it, the amount of libido devoted to the lore-object still operates in the psyche, and being denied an external expression becomes transferred in a regressive manner, via the creative deity back to an earlier object, viz. the father image, or the Father-Imago. The term "imago" is borrowed from Spitteler's novel of that name, a story in which the hero turns the woman he loves into a phantasy, whom he calls "Imago." He endows her with a number of ideal qualities which she did not possess at all, but which were a projection of his own infantile phantasy founded upon the mother. Under the Father-Imago, in Miss Miller's phantasy, appear successively God, Creator, Sun, Light, Fire, which, as libido symbols, are mythologically synonymous.

Miss Miller next supplies certain important associations including Milton's "Paradise Lost," the Book of Job, Haydn's Oratorio "The Creation," and some adolescent phantasies connected with the "don d'amour." These are linked together" in the unconscious; a sum of evidence going to prove that undervaluation of the love problem quickly leads to repression; "the erotic impression works in the unconscious, and in its stead pushes up symbols into consciousness." 1 The love conflict in this case is recast as religious feeling; this recasting is, from the ethical point of view, worthless, and practically ineffectual, because it is not consciously undertaken, the libido

2 P. 67. 
being automatically transferred from one field to another. This unconscious transference is contrasted with the demands made by Christianity, where "the burdening complex of the soul" 1 is consciously given over to the Deity. ". . . whoever to his conscious sin (or sorrow) just as consciously places religion in opposition, does something the greatness of which cannot be denied." 2 Though the psychological origin of the deity is unknown to the believer, "he after all bears his own burden, overcomes his own conflict, and achieves sublimation of his immediate erotic feelings by a conscious process."

The sterility of Miss Miller's repression is shown in her next poem, "The Moth to the Sun." Because the conflict was repressed and unconscious, it was bound to return again and again, as it does now. ${ }^{3}$ The writer identifies herself with the moth, and this identification with the insect is indicative of her self-depreciation. "Her longing for God resembles the longing of the moth for the star" $;{ }^{4}$ by association the ship's officer is the star or sun. $\mathrm{He}$ is thus put effectually out of reach, and the libido which might have been consciously put on the love-object, is unconsciously transferred to the sun which symbolises on the one side God, on the other side the officer. "It is by such a mechanism of transference of the libido, that in the realm of pathology objects which have no intrinsic sexual value obtain a sexual significance. These transferences aim at alleviation or cure of the illness or psychic pain, hence they have a teleological meaning."

Dr. Jung conceives the libido from the genetic standpoint, and regards the "multiplicity of instincts as issuing from a relative unity of the primary libido." 5 The deflection of the libido from the purely sexual aim of seed-production, to that of allurement, of nest-building, and protection of the young, is, as it were, to de-sexualise or differentiate it. This tendency brings about a heightened adaptation to reality. The "fonction du réel" is not to be regarded as a sexual function in the

1 P. 75.

P. 82.

3 Pfister calls this the "law of the return of the complex," p. 56. Complexes worked over in the unconscious lose none of their original affest (p. 92). 1 P. 93. 3 P. 150 .

- P. 142. 
manner of the Viennese school, but consists to-day "only in its smaller part of libido sexualis, and in its greater part of other impulses." 1

In human life every new step demands a new adjustment, and may cause a disturbance in the application and manifestation of the libido. By primitive man, who is the prototype for the undeveloped tendencies in the unconscions, new objects are always regarded with fear, and they demand a gradual process of understanding and adaptation. This involves new and increasing differentiation and a further de-sexualising of the libido. The only way in which man can assimilate the new objects is by analogy as sexual symbols, and so by degrees "an enormous broadening of the world-idea takes place." 2 This "carrying over of the libido to a phantastic correlate" (which has its origin in a resistance which opposes primitive sexuality), "has led primitive man to a number of most important discoveries " $;^{2}$ the production of speech, language, and fire were some of the firstfruits of this differentiation of libido.

Miss Miller's next piece of symbolism shows the libido personified in the form of a hero. She supplies a hypnagogic poem, which is created in a mental state " similar to that which usually precedes an intentional somnambulism as described by spiritualistic mediums." 3 The dreamer, who has turned away more or less consciously from the fate of loving, is forced to make an introversion of that portion of libido which should have been applied to life, and in so doing she conjures up from the unconscious the figure of "Chiwantopel," a very feminine and infantile hero who represents her own subjective longing." At such a moment, if the biological task is rejected, under given conditions a neurosis may supervene, owing to the ambitendency (Bleuler) or dualism of the will, which tears

1 P. 144.

2 P. 156.

P. 192.

4 We are dealing here with an unconscious conflict. "The external object cannot be loved, because a predominant amount of libido prefers a phantastic object, which must be brought up from the depths of the unconscious as com. pensation for the missing reality," p. 197. 
asunder the pairs of opposites. "The resistance against loving produces the inability to love." 1

The psychological root of this conflict, as revealed by analysis, strikes deep into the incest problem. The difficulty in detaching the libido from the mother is described by Nietzsche as "the sacrilegious backward grasp." 2 It is the tendency which "scorns real solutions, and prefers phantastic substitutes." 3 The childish personality turns ever to the mother. She is the perilously loved object who represents dangers to the soul, because she is loved too long, and too exclusively. She thus becomes the "Terrible Mother," on account of the resistances aroused by the forward-striving libido. When she is overcome, she again wears the aspect of the beneficent life-giving mother.

Miss Miller's phantasies "must be understood as schemes or plans whereby the obstacles may be overcome." The author of the "Psychology of the Unconscious" shows by numerous examples, that whenever an obstacle occurs in life, in the pause that comes before it is either swept away, or succumbed to, an introversion of libido takes place which floods the unconscious, and a creation of phantasy arises in consequence. It is only in psychological analysis, or in special psychic states (such as Miss Miller's introverted state), or under certain definite conditions of study having the unconscious mind as their object, that we are sufficiently alive to these things, to realise how invariably under such circumstances, phantasies with specific meanings arise.

The normal person usually finds his way by bringing judgment to bear on imagination; the neurotic remains with the phantasy, which may erect substitutes for reality in the form of symptoms. Thus, as the writer says, "the temporary withdrawal into the self which signifies a regression to the childish bond to the parent, seems to act favourably within limits in its effects on the psychologic condition of the individual. It is generally to be expected that the two fundamental mechanisms of the psychoses, transference and introversion, are to a wide extent extremely appropriate

$$
\text { I P. } 194 . \quad 2 \text { P. } 195 . \quad 3 \text { P. } 196 .
$$


methods of normal reaction against complexes; transference as a means of escaping from the complex into reality, introversion as a means of detaching oneself from reality through the complex." 1 The author adduces many examples to prove how constant is the tendency to represent the repressed libido in the image of the parents.

Analysis always leads back ultimately to the mother bond. The libido becomes spiritualised by the use of symbols, "the incestuous desire aims at being a child again, not at incest itself," it turns from the concrete sexuality which cannot be lived, to the formation of a phantasy or belief by means of which it may be spiritually transformed. Religion fosters the formation of symbols. In response to the question put by Nicodemus, can a man "enter a second time into his mother's womb and be born?" 2, Christ's answer shows that the libido must be withdrawn from the concrete idea of a re-birth, and transferred to a spiritual comprehension of it. "The symbol considered from the standpoint of actual truth is misleading, but it is psychologically true." 3 The libido, however, should be consciously taken possession of ; in this way man is freed from compulsion, and he replaces a belief in the symbol itself, by understanding. Man needs the dynamic energy bound up with the incest phantasy; then only is he in a condition to overcome the "Terrible Mother," to gain his complete independence, and proceed with his life-task.

In the chapter on "The Dual Mother Rôle" the meaning of the miraculous or mythical birth of the hero is discussed. The birth of the hero is always different from that of an ordinary mortal, it is irregular in some way (such as a re-birth from a Mother-spouse), and is accompanied by mysterious ceremonies. Sometimes the hero is subjected to exposure, and in this way acquires foster-parents, either human beings, as in Moses' case, or animals, as in the case of Romulus and Remus. The twofold mother is sometimes replaced by the twofold birth, an idea which has become familiar to us in the Christian teaching, namely, through baptism. By this re-birth man becomes a participator with God. The death of Christ on the
1 P. 201,
st. John iii. 4.
${ }^{3}$ P. 262. 
Cross is a baptism ${ }^{1}$ or re-birth through the second mother, the mysterious Tree of Death. "A hero is he who may again produce himself through his Mother." ${ }^{2} \mathrm{He}$ must be re-born through introversion of the libido, by which means he comes to himself by self-sacrifice.

The story of Hiawatha and of Siegfried and Brunhilda, both introduced by Miss Miller's associations, bear out all the aforementioned stages of the myth. The dual mother phantasy is founded upon a "primordial. image belonging to the secrets of the universal history of the human mind." 3

The last chapter in the book deals with the sacrifice man must make of the libido which is invested in the mother, since it is required for other purposes of life. Sexuality is shown not as the goal but as the symbol of the unconscious longing for "creation out of the self." A long training in sublimation is required in order that man may love that which he is bound to do, and not only find life but also joy in it. "Man discovers the world when he sacrifices the mother." The incest barrier is set up by his aspirational striving, and beyond it lies the attainment of his own thinking and feeling. This overcoming of the mother is also conceived as the realisation of the difference between subject and object, and the individuation tendency, which strives to free itself from what is collective, in order to create a new form out of itself. It involves a sacrifice of the lower nature, and, indeed, of the whole personality, for, expressed in another way, the personality is but the mask (the persona) of the individual.

The writer sums up the meaning of the book as follows: "The object of psycho-analysis has been wrongly understood to mean the renunciation or gratification of the ordinary sexual wish; in reality the problem is one of the sublimation of the infantile personality, or, expressed mythologically, the sacrifice and re-birth of the hero. In psycho-analysis the

1 "Can ye drink of the cup that I drink of, and be baptised with the baptismithat I am baptised with?" St. Mark x. 38. "We are buried with him by baptism into death . . . if we be dead with Christ we believe we shall also live with Him," Rom. vi.

2 P. 357.

3 "Collected Papers," p. 410. 
infantile personality is deprived of its libido fixations in a rational manner; the libido which is thus set free serves for the building up of a personality, matured and adapted to reality who does willingly and without complaint everything required by necessity." 1

The book deals largely with the meaning of the symbolic and mythologic representations of sexual phantasies. Readers who are unwilling to admit that sexual phantasies exist, or that, if existing, they are of value, will find the book long and tedious. Those, on the other hand, who want to find out why phantasies are sexual, and how it is they are so, will read it with the care and study it requires. Attentive self-observation soon discloses what the author points out in Part I. of the "Psychology of the Unconscious," viz. that "We have two forms of thinking-directed thinking, and dream or phantasy thinking. The former, working for communication with speech elements, is troublesome and exhausting; the latter, on the contrary, goes on without trouble, working spontaneously, so to speak, with reminiscences. The former creates innovations, adaptations, imitates reality and seeks to act upon it. The latter turns away from reality, sets free subjective wishes, and is, in regard to immediate adaptation, wholly unproductive." 2

The achievement of rational thinking has been extremely slow. Long ages before anything approximating to thinking existed, in the modern sense, man's thought was by means of what we now call phantasy. Archaic man created, not science, but mythology. His best knowledge is handed down to us in his myths. We need only instance the myths of creation, or such an one as the miraculous gift of the Decalogue upon Mount Sinai. Fairy tales which are childish myths, folk-lore and legend are attempts to explain the why and wherefore of the world's happenings. "Man in his phantastic thinking has kept a condensation of the psychic history of his development." 8 The production of language, and of ideas by means of myths, is a tearing loose of libido in the service of

1 P. 479.

2 P. 22.

${ }^{3}$ P. 36. 
sublimation. "The secret of the development of culture lies in the mobility of the libido and its capacity for transference."

Dr. Jung controverts the idea that inclinations to mythmaking are implanted merely by education, and claims that, if all the myths of civilisation were swept away to-day, the tendency would immediately break out de novo, because a specifically human need for it exists. "Has humanity ever broken free from myths?" he asks. "Every man has eyes and all his senses to perceive that the world is dead, cold, and unending, and he has never yet seen a God, nor brought to light the existence of such from empirical necessity. On the contrary, there was need of a phantastic, indestructible optimism, and one far removed from all sense of reality, in order, for example, to discover in the shameful death of Christ the really highest salvation and the redemption of the world." 1 A ferv supermen claim to get beyond the human, but though they destroy the form of the myth they cannot destroy the creating impulse.

When man's chief problem lay in how to find food for himself, when he knew nothing of the principles of agriculture, phallic cults and the use of fertility symbols were widespread. The same symbols are found to-day where the conditions are unchanged. Wallis Budge ${ }^{2}$ tells us that the symbolism present in the ancient Egyptian papyri still prevails among many African tribes. Fertility symbols are abundantly used to enchant the powers and placate the malevolent gods, in order that the rains may fall and the crops be abundant. So little does our psychology change that the moment we are confronted by a new situation in history, or a new custom in society, or by subversive ideas in thought, we show our inclination to resist it or assimilate it in our phantasies. Our childish and archaic inclinations appear again and again as we fall away from our adapted thinking, either on account of regression, due to resistances, or at the demands of a completely fresh adaptation.

Something of this feeling is present from time to time in

1 "Psychology of the Unconscious," p. 30.

" "Osiris and the Egyptian Resurrection." 
the reading of the book under review, and of other analytical literature. Resistances against what is new and strange in it are inevitably aroused. 'This is a perfectly natural process; all advance is made against resistances, and such resistances neither condemn nor approve the reader. They arise partly in resistances against the unconscious itself, and are testimony to the deep psychological problems with which the book deals, problems in which every reader participates to a certain extent. To students of symbolism, of primitive culture, or of analytical psychology, this book offers many lines that are suggestive for further inquiry. They will read it many times, each time with increasing appreciation. It is almost too rich in examples, and this super-abundance makes it difficult reading. It is, however, a treasure-house of reference, and for this reason one wishes it had a much more extensive index. Not the least valuable part of the book is to be found in the notes and references culled from many ancient and modern languages and peoples, all trauslated into English. It is obvious that the translator has had a very difficult task, and we are much indebted to her for the way she has accomplished it. It would make the analysis clearer, if in a future edition of the book, the whole of the Miller phantasies were published as originally presented in Dr. Flournoy's monograph. 'The reader could then estimate for himself the continuity and quality of the material used for analysis. 


\section{$\mathrm{XI}$ \\ PSYCHOLOGICAL ADAPTATION ${ }^{1}$}

ADAPTATION is a term used in connection with theories of evolution to describe the processes by means of which organisms become adjusted to the conditions of their life. It is a twofold process; firstly, the organism responds passively to changes in the environment; secondly, to active variations arising from within, in response to an inherent impulse.

Psychological adaptation proceeds in a similar manner, in response to the social environment, and to movements in the creative libido within the organism.

Changes affecting the species are preserved and accentuated throughout the ages, and well adapted organisms are those in which there is a harmonious adjustment to all the conditions. We know, however, that countless sacrifices have been made before any given species has become adapted.

Analytical psychology regards neurosis as a failure in adaptation. We are confronted with the fact that civilisation, which has been so laboriously built up, has reached a point where its achievements, and the collective customs it has imposed, are no longer in harmony with the needs of the human organisms.

Society itself has reached a stage of neurosis; special failures in adaptation are to be seen in such events as the world-war and in the industrial war. The times are extraordinarily complex : and it is fortunate that just now, when all the old shibboleths are vanishing, new psychological theories have arisen which give us an insight into some of the reasons for the intolerable strain from which we are suffering.

The new psychology has proved both dream and phantasy

1 Reprinted from the British Journal of Psychology (Medical Section), October, 1920, by kind permission of the Editor. 
to be functions of the psyche. In ancient times the dream was more or less valued, but it could only be accepted by the modern spirit when it could be placed upon a basis of scientific research. The re-discovered function can now be applied to the further adjustment of the human problem, for the solution of which new means of adaptation are necessary.

The dream is built up upon non-rational mental and emotional processes, of a nature that is compensatory and complementary to consciousness, and for the first time in modern life all the factors are given a share of consideration. The first use of the new methods is to set us exploring the uncharted regions of the mind, and bring us into contact with the unconscious psyche, whose very existence our one-sided scientific views had almost ignored.

The recognition that adaptation to the inner reality is as important in human life as adaptation to the outer reality, necessarily has very far-reaching results on our methods of analysis. The well-being of the individual lies in the adjustment between two sets of equally valid claims. The antagonism between the conscious and unconscious now has the appearance of being a claim for better understanding between the objective necessity and the subjective necessity. It is the injustice done to the one or the other that produces a loss of balance and disharmony in the individual. Dreams and phantasies are "schemes or plans" which have a meaning for the solution of the problems of the moment. They are corrective and compensatory ${ }^{1}$ to the merely conscious view. 'Thus regarded they demand both objective and subjective interpretation. ${ }^{2}$ The analogical character of the dream is valued, and the manifest content is credited with a meaning of equal importance with the latent one. The Viennese school of psychoanalysts rejects this kind of analysis. Its position is the logical outcome of the theory that the unconscious contains only incompatible wish-tendencies; in consequence of which, everything has to be explained on the p. 280.

1 "Dream Psychology," Nicoll, chap. vi. "Analytical Psychology,"

\footnotetext{
"See chap. vi.
} 
basis of the primitive instincts, hence the "remedy for neurosis would necessarily appear to be as complete as possible a life of instinct, in the presence of suitably chosen objects" (Jung). If, on the other hand, the unconscious is regarded as compensatory to consciousness, then we shall expect to find in it representations and symbolisations of principles, functions, and points of view missing from consciousness. When the unconscious is regarded as the creative mind, we are forced to allow that it has claims upon our attention, at least as great as those which belong to the world of created things.

I propose to approach the question of adaptation from the point of view of the psychological types into which collectively men are grouped. Men are born into a type just as they are born into a family, with a natural tendency to the use of one psychological function, somewhat at the expense of the other functions. Latterly in analysing my patients I have mentally divided them into two main classes: viz. those who are orientated to the unconscious, and those who are orientated to the conscious. This is actually a different division from the types of introversion and extraversion already described to us by Dr. Jung, although it arises out of it. In his further work on types Dr. Jung has discriminated four types, dividing them into groups under the four psychological functions of thinking, feeling, intuition, and sensation. Two of these types adapt themselves to life by processes we call rational; viz. the introverted type by thinking, and the extraverted type by feeling. The other two types adapt themselves by instinctive and unconscious processes; viz. by intuition or by sensation, that is to say, by non-rational processes. Dr. Jung has been working on the types for several years. He was early aware that the two types he first described included others. He has very greatly extended his conceptions, and a comprehensive work dealing with this subject is about to be published. It has become habitual for me to work with the underlying idea of types in my mind, but until the question is better understood it must be tentatively handled; I' have, however, found it so illuminating that I cannot forbear introducing it; what follows is based upon my own experience of the matter. 
The names of types given above are abstract definitionstoo abstract for reality. The ideal type exists in pathological states alone, since an over-accentuated type-development involves such severe repressions as can only occur in neurotic or psychotic forms. Most people have mixed qualities; their main tendency and their most highly adapted function is indicated in their type-name.

In the introverted type, thought is the most highly prized function. The ego is the object of the libido, and its flow is centripetal. The feelings in this type are introverted, and they too are related to the ego. This produces anlappearance of reserve and coldness. The feelings are present, but they are deep and repressed. Such a type is embarrassed when it is suddenly confronted with a situation wherein thought offers no solution. Examples of statesmen of this type are President Wilson and Mr. Asquith. "Wait and see" is really typical of the introvert's method. It means, wait till I have been able to detach myself from this concrete situation; wait till I have been able to think it out. Sight for this type means arriving at the abstract idea. The idea is valued as being impersonal and above humanity. The feelings are really too "tender" to bear the strain of close contact with the object, since this threatens the integrity of the ego.

In the extraverted type, feeling is the most highly adapted function. The external world is the object of the libido, and its current is centrifugal. ${ }^{1}$ The thoughts as well as the feelings turn to the object, and too little attention is paid to the subject, and to principles and ideas. This type is embarrassed when it is suddenly confronted with a situation which cannot be solved by considerations affecting the object.

The late President Roosevelt is an example of this type, also Mr. Lloyd George: although the latter inclines to the intuitive type to be described later. Lloyd George is, in a

"The late Furneaux Jordan, F.R.C.S., in the third edition of a book published in 1896 called "Character as seen in Body and Parentage," divided men and women into two classes, viz. the less impassioned and the more impassioned. They approximate to the extraverted and introverted types respectively, although without any consideration of the compensatory co-functions. 
sense, very accessible because he goes close up to persons and to the situation, in order to feel himself into it. At the same time he lacks the quality of abstract thinking; acting first somewhat impulsively and thinking later, he produces the effect of changeability.

In the subconscious types, viz. the intuitive and sensational, the unconscious is the object of the libido. The psychology here is subjective and somewhat primitive. The mode of adaptation natural to these types has been rendered of secondary importance in the process of evolution by the development of rational thought and feeling.

The subconscious types react less to the external world than to a subjective image of that world. In these types intuition and sensation bear the same relation to each other that thinking and feeling occupy in the rational types. The strictly intuitive person represses sensation, and the extreme sensationalist represses intuition; they are co-functions, mutually corrective and compensatory.

Artists naturally belong to these types, although not exclusively so. The artist is essentially a medium of the unconscious. His works do not come out of nothing. When he is not otherwise inhibited he transfers the content of his unconscious into creative forms, by the use of his symbolic function. In this way we get work of great universal value on the one hand, and on the other of very small merit and of a very "personal" kind. In the absence of an expression which can work itself out in art, or some other form, the unconscious is apt to create compulsions for itself.

It is characteristic of these types that they find the greatest difficulty in adapting themselves to the demands of society. They are impatient of responsibility, and often come to grief over money matters, or in marriage relations. They find fetters where other men find incentives.

Walt Whitman is a pertinent example of the mental and emotional reactions of a subconscious type that has achiered self-consciousness. He begins a poem called "Song of Myself" in this way ${ }^{1}$ :-

1 "Leares of Grass." Centenary Edition. D. Appleton \& Co., New York. 
"I celebrate myself:

And what I assume you shall assume;

For every atom belonging to $\mathrm{me}$, as good belongs to you.

Stop this day and night with me, and you sball possess the origin of all poems;

You shall possess the good of the earth and sun (there are millions of suns left);

You shall no longer take things at second or third hand, nor look through the eyes of the dead, nor feed on spectres in books;

You shall not look through my eyes either, nor take things from me;

You shall listen to all sides, and filter them from yourself."

Or again, "I loaf and invite my soul"; whereupon he experiences an immediate contact with the whole of intuitive and sensational life. In another phase of feeling, the insufficiency and one-sidedness of the adaptation to the soul brings about a necessity to lay stress on the object. As when he says :

"I will go to the bank by the wood, and become undisguised and naked;

I am mad for it to be in contact with me."

At this moment intuition needs that contact with passion to attain a sense of reality.

In the uncompensated state these non-rational types are unstable in their human relations, because in so far as they are orientated to the unconscious, they are cut off from being understood, or from understanding the rational types. The primordial images and instincts comprised in the collective unconscious are more valid for them than the external world, and form the partially corrected basis of their impulsive ideas and actions.

For the sensational type, the instinct side of the unconscious forms the object. Unless persons of this type are under the sway of some passionate emotion they hardly feel themselves to be alive. Unless their contact with others is productive of sensational effect they hardly realise the fact of the existence of others. Perhaps these people express themselves most happily in the histrionic arts and in dancing. Under this denomination cases of extreme sadism and masochism belong, and here also we may expect to find those patients whose physical sensations play the chief rôle-such, 
for instance, as a hypochondriac whose life is dominated by a disgusting taste in the mouth, or a subjective odour. A psychotic patient of mine recently refused to take food because directly she swallowed it she "felt it creeping about under her skin, and passing down her arms and legs." In this class the mental conflict is expressed in bodily sensations.

Imperative and compulsive thoughts belong more especially to the intuitional type, because they are greatly influenced by the primordial images, which, if uncorrected by reality, produce obsessions. These instinct forms of thought enter the mind with terrible power, and are accepted without judgment or evaluation. A certain patient has a phobia of murder-germs. She claims to have been infected by clothing bought from a shop where a murder was committed. She has burnt hundreds of pounds' worth of clothes because they came from this place, or have been touched by infected things. The mere utterance of the word "murder" infects the environment. Anything that touches a newspaper is contaminated if the word is there. She counteracts the effect of the murder-germs by countless rituals, and is actuated by the principles of totem and taboo.

Compulsion neurosis is the typical neurosis for this type. Many criminals are to be found in it. There is also a special tendency to form identifications. Adaptation to the external world by means of identification with a parent, or friend, or teacher, is fairly common. People of this type are driven to express their emotions vicariously or collectively, if they have found no form of individual expression of an objective kind. They act as the parent acts, feel as the friend or husband feels, and get on pretty well till something disturbs the adaptation. By an unconscious pose the reactions of another personality may be successfully imitated. The intuitive type appears to be exquisitely sympathetic, owing to the tendency to project or introject. This is productive of perfect harmony so long as the mutual relation lasts. But when separation befalls, through the occurrence of conflicting interests, or unforeseen circumstances, the pulling apart is a painful affair. One person being orientated to the conscious, the other to the 
unconscious, or both being related to different aspects of the unconscious, reconciliation is very difficult, because they look at the same thing from totally different standpoints. The separation is as complete as the former identification was complete.

Mr. Clutton Brock in his able book, "Shelley: the Man and the Poet," has given us a picture of an individual of the intuitive type. He writes as follows:-

"Shelley was scarcely aware of imperfection in himself; and when he found it in others, and in external circumstances, it seemed to him to be inexplicable evil, which ought to be, not improved, but abolished. Thus there is some excuse for those admirers who think him perfect, and some for those of his contemporaries who thought him a fiend incarnate. There was, or appeared to be, no conflict between different parts of his nature, but only a conflict between his nature and the world outside him. ${ }^{1}$ He saw that such a conflict existed, but thought it was produced altogether by some external tyranny, or some inexplicable perversity in men. There seemed to be a perfect harmony in himself, so he thought perfect harmony was possible in the world if it would only get rid of those inhibitions which express men's consciousness of an existing discord. . . . He never in the course of his short life, attained to a full consciousness of himself. . . . He loved people, not for themselves, but for what he thought of them. He was like those artists who paint the ideal of their own imaginations, not the excellence and promise of the real things."

Difficulties for this type arise in another way also, viz. from the animation of the pairs of opposites. For example, a certain man had a good deal of success as an academic painter. This success made him feel cheap. He thought he was not following his highest feeling for art, whereupon he relinquished the academic style for a less popular one more in accordance with his ideas. He was soon reduced to poverty. Now the value of money naturally assumed great importance, because it was, in a manner of speaking, in the unconscious; whereupon he indicted society, which ought to endow him with a few hundreds a year, in order that he might express

s The italics are mine.-C. E. I. 
himself and repay it with real works of art. However, at a later stage a modicum of well-merited success came to him, whereupon he declared himself hampered by it. He needs must once more burn his boats and go to a new country, where he had to begin all over again. To the onlooker this conduct is completely irrational, but with this type the accent of value always moves to the pole which is in the unconscious. They are animated by the pairs of opposites, although without the morbid effects that one sees in the neurotic, in whom the pairs of opposites are more or less violently torn asunder, and in whom regression of the libido to the unconscious is a pathological condition. Incidentally we owe things of great value to this type. They are of more value to us than they are to themselves. They interpret our hidden selves to us, and enlarge our perceptions. They have the run of the unconscious, but as a gift, and not by personal differentiation. We need only instance Shelley's work to recognise that on the creative side the type needs no apologist. It is perhaps what might be called a feminine type, not that it really belongs more to woman than man, but it contains tendencies that are somewhat arbitrarily called feminine.

Those who study the types, ${ }^{1}$ come to the conclusion that people are even more unlike in their mental or emotional reactions on account of type, than on account of sex. They can reckon more certainly on the way a person of marked type will behave, than on the way he will behave because he is a man. There are necessarily certain conventional reactions he adopts on account of sex, which do not really belong to his individual character at all.

Philosophers like Bergson and Kidd lay enormous stress upon intuition. Indeed, intuition often finds a way where

1 Dr. Beatrice Hinkle, following in a discussion with G. Stanley Hall, Ph.D., on "Points of Difference between Men and Women," said, "A very large and intimate analytical experience of the lives of men and women has forced me away from thinking of people according to sex, and led me to the substitution of types instead. When an individual consults me my collectire classification is not sexual, but is determined by the answer to my mental question: "To what type does he or she belong?" " Proceedings," Int. Conf. Wom. Phys., Now York, vol. iv. 
every other psychological function fails to find one, the reason being that there are times when nothing short of a completely new adaptation will serve; at such a time the primordial images, mingled with the other functions, give a value to the idea which fits the unique occasion. Kidd says in his "Science of Power": "It is the mind of woman that is destined to take the lead in the future of civilisation as the principal instrument of Power." Personally I think he is mistaken in thinking that the future redemption of the world is with woman qua woman. It is rather with the feminine principle, the fructifying power of those who will nourish the seed of the future in patience, who will submit to the burdens of to-day in order that the new era shall arise. Schopenhauer's indictment against woman, that "The race is always more to her than the individual," is the hostility of the rational intellectual thinker against the super-validity, on many occasions, of the intuitive perceptions which reach beyond the present. The psychological bisexuality of the human being permits each person to carry within himself a male and female partner; an intellectual $v$, an intuitive function, a conscious rational $v$. an unconscious non-rational judgment. There is a radical hostility between the two, they are pairs of opposites. The hostility is constantly projected into consciousness, as in Schopenhauer's case. He makes an imago of woman which has many of the characteristics of the terrible side of the "Great Mother" of mythology. The same is true of Otto Weininger.

Just as this conflict between the sexes has to be resolved in the process of individuation, so the opposing psychological functions have to be united into a new harmony. Our presentday civilisation is tormented with problems for which there appears to be no rational solution. Perhaps it is to the more primitive function of intuition that we must return, with the added wisdom that centuries of scientific thinking have given us. We give far too little credit to intuition to-day; no doubt this results from the observation that it has sometimes misled us. It perceives, but does not judge. Nor is it sense-perception which leads to consciousness; it is intuitive perception 
which leads to the unconscious. Bergson says, "Although intuition transcends intellect, it is by means of intellect that it has grown beyond the limits of mere instinct." 1

The study of the primitive has attracted a great amount of interest in recent years, perhaps because we unconsciously feel we have lost as well as gained something in the process of evolution. We half realise in him the prototype of our own "subconscious man: a being for whom the unknown is full of magic, who can be withered by the evil eye, or stricken dead by fear. Dr. Rivers 2 says, "There is a general agreement that in neurosis and psychosis there is in action a process of regression to primitive and infantile states. ... In so far as the thought and behaviour of savage man are primitive, they furnish material which helps us to understand and to deal with regressive states exhibited by sufferers from disorder of mental functions." He goes on to say that medicine standing alone and ethnology standing alone are helpless, but he bases wide hopes upon the union of these lines of research. It seems to me that the union will be found in a closer and deeper study applied to the unconscious mind itself through personal experience of it, but only when we can detach ourselves from the idea that we have yet learnt all its laws, or even that we have followed to their conclusion those we begin to understand. We certainly need a wider conception of the unconscious than that which believes it to be only the result of repression. In the view of the unconscious presented here it would be impossible to acquiesce in Dr. Jones's statement that "only what is repressed is symbolised; only what is repressed needs to be symbolised." 3 This is a necessary correlate of the Freudian view of the unconscious.

The existence of the unconscious being regarded by science as proved, it is natural that a great controversy should range round the question of what it really is. The method of research is so new, and the field of inquiry so vast, that we

\footnotetext{
1 "Henri Bergson," Ruhe and Paul, p. 225.

2 British Journal of Psychology, March, 1920.

3 "Papers on Psycho-analysis," p. 158.
} 
must expect different investigators to arrive at different interpretations as a result of their particular interests and individual psychology.

Jung's investigations have led him to a formulation which is quite different in its ultimate conclusion from Freud's, and yet which includes Freud's view as a part.

Jung divides the unconscious into personal and impersonal contents. The impersonal contents form the collective psyche, which embraces collective thought and collective feeling ${ }^{1}$ : all these contents are universal and impersonal ; they are inherited and potentially present in every one. It is the unconditioned, undifferentiated basis of all, the "mother foundation" which is constantly represented symbolically in myth and dream as the "Great Mother," with her double aspect as Destroyer and Preserver.

The conscious and personal unconscious, on the other hand, contain certain contents of the collective psyche as personal differentiation, that is, as personal acquisitions of the individual life as opposed to what is inherited.

In the personal unconscious, all the lost memories are stored. New products arise from a new combination of unconscious contents, of which dreams are a common example. In addition to the lost memories and the new combinations, intentional repressions of painful and incompatible thoughts and feelings form an important part of the contents. This may be regarded as the infantile mind, whereas the primitive aspects belong to the impersonal unconscious.

As a correlate to this, and to distinguish the ego contents of the collective unconscious from the non-ego contents, the Persona, as distinguished from the Individual, is postulated. "The persona is an excerpt from the collective psyche." The persona was the mask worn by actors through which they spoke. The mask constituted the appropriate appearance for the part played. The persona, then, is what a man appears to be both to himself and others. A man's type determines his persona to a great extent; he is as he is by nature. The

2 "Analytical Psychology," ohaps. xiv. and xv. Also British Journal of Psychology, Nov., 1919. 
individual, on the other hand, is what he becomes, and is the product of a life-enduring differentiation from what is general and collective and inherited. The persona and the individual are, in a sense, pairs of opposites. The idea of the persona and the individual comprises as great a difference as that of a person and a personage, save that a personage as often as not attains distinction by conforming to collective opinion, and gaining collective approval; whereas the individual person differentiates himself from what is customary and average, and is only approved when he has given an equivalent to Society in exchange for the exemptions, licenses, or heresies through which he has established his freedom. "The unconscious being collective psyche, is the psychological representation of Society " ; the persona has no relation to it, because, being itself collective, it is identical with collectivity. Thus the persona is both an excerpt and a component of the general collective psychological function. As it is obvious we have originally nothing but collective material at our disposal, what is individual lies in the uniqueness of the combination of the psychological elements. If individuation takes place, it is subsequent to the dissolution of the persona into the collective psyche, whereupon a principle arises that selects and limits the contents that shall now be consciously chosen to be accepted as individual. Individuation demands the surpassing of the type, first by recognition of what is missing or unconscious in the functions; then by consciously endeavouring to develop what is lacking, in order to become free from the inordinate demands of what is collective in the personality.

In the course of analysis, what is unconscious in the mind is gradually made conscious. We get deeper and deeper into the collective psyche, and phantasies appear which have no connection with the actual experiences of the person being analysed. These phantasies are a "universal possession, dormant from immemorial ages," thus an impersonal layer of the unconscious is demonstrated. Here the "primordial images" are discovered; they are "the inherited potentialities of human

1 "Individuation and Collectivity." Jung. (Unpublished MS.) 
imagination." 1 These form the themes of myths and legends all over the world.

In this stage of the analysis it is not merely that myths once heard are reproduced, but a new creation of mythology takes place. Similar images are produced by the insane, and are found in the oldest of existing human records. "The primordial images are quite the most ancient, universal, and deep thoughts of mankind. They are feeling just as much as thought, and might therefore be termed thought-feelings." 2 Or, expressed differently, Jung says the collective unconscious is "the sum of the instincts and their correlates the archetypes of apprehension." 3 "Just as instinct is the intrusion of an unconsciously motivated impulse into conscious action, so intuition is the intrusion of the unconscious content of an image into conscious apperception. ... The mechanism of intuition is analogous to that of instinct, with this difference, that whereas instinct means a teleological impulse towards a highly complicated action, intuition means an unconscious teleological apprehension of a highly complicated situation. Intuition is a counterpart of instinct, not more or less incomprehensible and astounding than instinct itself.

The archetypes of apprehension are regarded as a priori determining constituents of all experience. Just as the instincts compel man to a conduct of life which is specifically human, so the archetypes coerce intuition and apprehension to forms specifically human.

"Just as the instincts are deeply covered over by processes of rationalisation, so also are the archetypes of apprehension overlaid. But man's conception of the world is just as regular and uniform as his instinctive actions. It is the determining factor of this latter uniformity which is conceived as the archetype, the primordial image.

"The image might be conceived as intuition of the instinct itself, analogous to the conception of consciousness as an internal image of our objective vital processes. . . Just as

1 "Analytical Psychology," p. 410.

2 Ibid., p. 411.

- British Journal of Psychology, vol, x., part 1. 
we believe instinct to be thoroughly adapted and sometimes incredibly clever, so we must assume that intuition, to which instinct owes its existence, must be of extraordinary precision."

The symptoms of neurosis, particularly of compulsion neurosis, and the symptoms of insanity, show atavistic tendencies, such, for instance, as interest in excreta, which are remnants of an adaptation which was entirely suitable at one stage of our animal or anthropoid existence.

In every psychotic state the unconscious gains a supervalue owing to the regression of libido to the collective unconscious, which it reanimates, having first flooded the ego feelings and stimulated a painful self-consciousness, in which the pairs of opposites, megalomania and feelings of inferiority, alternate. When Nebuchadnezzar, identified with the images of the unconscious, dwelt among wild asses, and ate grass, he responded to the inner compulsion to live his unconscious.

Jung has pointed out that in the introversion psychosis of dementia precox, the strange mythological phantasies indicate the replacement of "a recent adaptation to reality by an archaic one." 1 The libido of these patients is taken from the function of reality as a whole, not only from the sexual function, which is now replaced by an "intra-psychic equivalent." 2 What is peculiar to these patients is the "predominence of phantastic forms of thought," founded upon a pre-occupation of the libido which is applied to the ego, with the archetypal forms of thought.

In hysterical introversion, on the other hand, the libido designed for the outer object is introverted, and turns to the reanimation of the instincts with the production of autoerotism. In these pathological states it will easily be seen that the mechanisms approximate to those we have recognised as belonging collectively to the subconscious types, for the reason that they are less rational and nearer their instincts than the objective types. The adaptation that the objective world has demanded from us has necessarily contracted our

1 See "The Psychology of Dementia Præcox." Jung. "Psychology of the Unconscious," p. 462.

2 Ibid., 152. 
horizon to the things which it pays us to attend to, but all the same we are aware that when we work in close harmony with our instincts we are most efficient and get the best results. Hence regression of the libido to the subconscious brings about a creation of phantasy which is undoubtedly an attempt at self-cure. The complete cure (should it be possible) lies, as I have indicated earlier, in a better adaptation to the demands of both worlds of reality, which can only be achieved when we have learned to discriminate between the real facts and the unconscious facts. 


\section{INDEX}

ABreaction, 165, 170-1

Absent-minded acts, 27, 83

Actual neurosis, 160

Added phantasy, 33

Adler, 166

A. E., 112, 177

Adaptability, 131

Adaptation, 167

-, by identification, 201

-, biological, 195

-, directed thinking, a funation of, 176

- in war, 128

-, neurosis, a failure in, 167

—, psychological, 195

- to objective and subjective reality, $111,119,196$

- to parents, 65

Afflicted poet, the, 171

Aim of analysis, 108

- of education, 13

Ambitendency, 171

Ambivalency, 171

Amœba, consciousness in, 111

Analogical character of dream, 196

Analogical interpretation, 53

Analysis of analyst, 126

- of dream, bluebells and werewolf, 90-96

- - dragon, 46

- - grave-diggers, 113-16

- - favourite stories, 33,35

- of teachers and parents, 39

Appearance of dead in dream, 100-1

Archetypes, in colleotive unconscious,

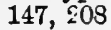

-, Lamb on, 146

Arrested thinking, example of, 49

Artists' opposing tendencies, 203

- type, 199

Asquith, Mr., 198

Assimilation of new ideas by phantasy, 193

Authority complex, 51

- idol, 44

Autistic thinking, 176

Auto-erotism, 133
BaptisM, 190

Belle indifference, 85

Beneficent Mother, 189

Bergson, cited, 203, 205

Bernheim, Dr., 162

Bisexuality, 132, 204

Blackwood, Algernon, 112

Bleuler, Dr., 171, 176

Boswell, quoted note, 176-7

Bradby, cited, 99

Brahma, 49

Breuer, Dr. J., 163-6

Brock, Clutton, quoted, 202

Browning, Robert, quoted, 97, 139

Budge, Wallis, cited, 193

Bullying, 61

Butler, Dr. Samuel, quoted, 2, 70-71

CaLdecotT Community, 63

Candle of Vision, 177

Case of dissociated personality, 179

- - hysterical hiccough, 85

- - identification with unconscious, 124

- neurosis at puberty, 36, 177-9

- - - menopause, 177-9

- - phobla of wasps, 35-6

Censor, Freud's, 79, 111

-, in dreams, 109 et seq., 122

- of resistance, 111

Character always incomplete, 127

- and sex, 127

Charcot, 162, 165

Child and parents, $28,35,39,43,51,64$

- and teacher, 11,51

Childish attitude, 86

- phantasies, 155

- identification with mother, 115

Christ, 190, 193

Clare Hartill, 140

Coitus, symbolic substitute, 120

Collective psyche, 207

- unconscious, 16, 147, 206

College plays, 133

Common sense, 110

Commonwealth, Little, 61 
Comparison of symptomatic acts with séance, 101

Compensatory character of neurosis, 167

- - unconscious, 84, 97, 122, 145

Complex, 4, 11, 49, 51, 187, 190

Compulsion, 45

Compulsive acts and thoughts, 177, 201

Conatus, Prof. J. W. Scott, 130 note

Condensation in dreams, 105-6

Constellated memories, 11

Continuity of mental life, 174

Conventional morality, 139

Creative mind, 79,174

Criticism in dream, 117

Cruelty, 61

Cryptic word, 105

Dane, Clemence, 137-40

David's problem, 157

Day-dreams, 23, 83, 131-2, 177

Delphic oracle, 116

Dementia præcox, 209

Diaphragm between conscious and unconscious, 175

Differentiation, 207

Direct questions to child, 28

- - primitive, 29

Directed thinking, 23, 176, 192

Discipline, 72-3, 61-3

Discretion in little boys, 29

Disordered function, 180

Disorientation through identification with unconscious, 75

Dissociated personality, 179

Dream, a cluster of intimate problems, 112

-, a dramatisation, 109

-, a function of the psyche, 195-6

一, a source of wisdom, 103

- a subliminal picture of dreamer, 103,120

-, analogical character of, 196

- analysed, 46, 88, 90, 100, 113, 116

- as art and allegory, 97

- as "schemes or plans," 196

- as suppressed wish, 111

- content, manifest, and latent, 86

$\rightarrow$, recurring character in, 104

Dream cited, anwliwimdwy, 105

-, Archie Hemel Hempsted, 106

-, Aunt's face falling off, 20

-, Bond Street tailor, 102

-, Dragon of, 46

-, Dolphin's visit, 102

-, Follow the grave-diggers, 113

-, Gosse's, 25, 26

-, Nebuchadnezzar's, 21, 209

-, Slough of Despond, 85

-, Travelling by Virginia Creeper, 100

-, Woman and werewolf, 90
Dream cited, Wooden horse, 85

Dual Mother, 190

Du Prel, 109 note, 110, 112

EDER, Dr. M. D., 3

Educational system, 71-2, 75

Emotional curve, 9

End of analysis, 107

Energic conception of libido, 131

Equivalence principle of libido, 184

"Essays of Elia," 146 note

European War, effect of, 138

Evolution of man, 111

Exhibitionist, 87

Expulsion from school, 53

Extraversion, 55, 80, 173, 197

- and hysteria, 80

"Father and Son," quoted, 25, 29, cited, 39,41

Father-complex, 66, 155

Father-imago, 44, 171, 186

Favourite story in analysis, 33, 35

Fear in child, 57, 40

Ferenzi, 163 note

Ferrero Guglielmo, 182

Fertility symbols, 193

Fictions directrices, 166

First impressions, importance of, 16

Flournoy, Dr., 182, 194

Fonction du réel, 187

Forcing interpretation, 107

Forgetting, 27

Frazer, quoted, 120-1 note

Free association in dream analysis, 85 , 100

Freud, cited, 1, 64, 78, 123, 160, 164 et seq., 174

-, quoted, $77-9,99,105,111,118$, $120,156,164$

Freud's censor, 79, 111, 122

- classification of neurosis, 160

- definition of unconscious, 77

- discovery of key to unconscious, 130

- interpretation of dreams, 79

- preconscious, 77, 111

Friendship and sex, 143

Frink, Dr. H. W., cited, 137

Fugue-like attacks, 179

Function of dream and phantasy, 196

Functional symbolism, 119

GoD, libido, representation of, 185

Gosse, Edmund, 25 et seq, 41-3

HaLI, G. Stanley, 203 note

Hallucination, example of, 177 ; Luther, 87 ; Miss A., case of, 86

Harrison, Jane, cited, 176 and note 
Herd-life, development of individual opposed to, 168

Heredity, 65

Hermaphroditic character of human being, 132

Hermeneutic method, 92

Hero, attitude, 57

-, birth of the, 190

-, libido personified as, 188

Hetero-sexuality, 134, 142

Hiccough, hysterical, Miss A., case of, 85-7

Hinkle, Dr. B., 182, quoted, 203 note

Hobhouse, Prof., quoted, 176

Homo-sexuality, 133, 137 et seq.; penal code and, 142

"Hymn of Creation," Miss Miller's, $185-6$

Hypnagogic vision, 100, 177 ; poem, 188

Hypnotism, 79-80, 164-5; cure by, 163

Hypochondria, 201

Hysteria, 41, 79, 86-71, 164

-, not malingering, 172

IDENTIFICATION, 52, 156, 187, 201

- with collectivity, 207

- with insane, 175

- with mother, 95, 115, 178-9

- with unconscious, 125-6, 175

Idols, prohibition of, 43

Imago, 44, 66, 155, 186, 204

-, of parents, $44,54-5,190$

Impersonal unconscious, $16,78,183$, 206-7

Impossible ideals, 74, 97

Incest barrier, 191

- motif, 47

- phantasies, 156

Individuality, 60, 95

— in child, 60

- versus herd, 168

Individuation, 71,207

Infantile personality, $81,86,168,191-2$

Inferiority, feeling of, 48,209

Inheritance, physical and psychical, 65

International Conference of Women Physicians, 127 note, 157 note.

Interpretation, objective and subjective, 196

Introversion, 197

-, hysterical, 80

-, neurosis, 19

- leading to phantasy, 185

- type, 12, 55-7

Intuition, 99, 126, 197, 204, 208

Intuitive type, 55, 201

JAMES, William, 12

Janet, Dr. Pierre, 165

Johnson, Dr., 110, 176
Jones, Dr. Ernest, quoted, 120, 129, 160 note, 174,205

Judgment in dream, 117

Jung, cited, $18,26,55,78,81,119,121$, 167,197

- quoted, 15, 23, 103, 107, 122, 137, 168, 207 et seq.

Jung's libido theory, 26, 81, 131, 167, 184

- "Psychology of the Unconscious," 182 et seq.

- psychological types, $12,55,173,196$ et seq.

- word-association test, 3 et seq.

Jung versus Freud, $r e$ censor, 79

- - interpretation of symbols, 79 , 119

- - , repression, 205

- - unconscious, 78, 206

KAFIR, greeting to anchor, 176

Kidd, 203, quoted, 204

Kleptomania, 45

LAMB, C., quoted, 146

Lane, Homer, Mr., 61, 72

Latent content of dream, 22, 86, 196

Lay, Wilfred, Ph.D., cited, 129

Libido, 26, 119

- against unconscious wish, 179

- available, 131

-, definitions of, 130

-, differentiation of, 187

-, energic conception of, 131

-, equivalence principle, 131, 184

-, genetic view of, 187

- in phantasy, 26,83

-, introversion of, $19,26,185$

-, Moltzer on, 82

-, regressive, 132, 167

- release of, 97

一, symbols of, 85, 184, 186

- theory, Jung, 81, 119, 167, 184

-, transformations of, 131, 184

Lloyd, Tuckey, Dr., 162, 163 note

Lloyd George, 198-9

"Loom of Youth," 137-40

Love conflict, 186

Lying in children, 27, 58

MAGIC, ideas of (Gosse), 42

- in animal, 98

Malingering, 172

Mana, 98, 184

Manifest content of dream, 22, 86, 116, 196

Masochism, 62, 171, 200

Masturbation, 136-7, 158

Mayer, Robert, 184 note

Mediumship, 123-4 
Menopause, neurotic symptoms at, 179

Mental confict as sensation, 201

Meredith, quoted, 48 note, 121

Messages from dead, 124-5

Miller, Dr. Crichton, 181 note

Miller phantasies, 182 et seq.

Mind of child, 2, 28, 39

Moltzer, Miss Maria, quoted, 82

Mother, as "love," 43

-, dragon, a personification of, 48

-, "Great," 48 note, 204, 206

-, identification with, 123, 178-9

-, imago, 54

-, perilously loved, 189

_, "Terrible," 48, 169, 189-90

Moral instincts, 78

- meaning in dream, 98

Murray, Prof. Gilbert, cited, 131 ; quoted, 97, 184

Myers, F. W., cited, 174 ; quoted, 77, 166 note

Mysticism, 123, 126

Mythological dreams of children, 47

Myths, 168-70, 192-3

NATion, The, 183

Nebuchadnezzar's dream, 21, 117, 209

Neurosis, actual, and psycho-neurosis, 160

- as compensation, 167

-, cause in past and present, 161

-, compromise formation, 165

-, failure in adaptation, 167, 195

-, unconscious conflict in, 167, 173

Neurotic character, 80

- 一, childish, 81,86

- -, extra-sensitive, 83

- - phantasies in, 82-4

- symptoms at puberty and menopause, 179

- Bystems of phantasies, 167

Nicoll, Dr. Maurice, 97 note, 168 note, 196 note

Night terrors, 19, 26, 44

OBJECT of analysis, 191

- of study of subliminal material, 108

Objective adaptation, 111

- interpretation, 88, 119, 196

Occultism, 123

Edipus complex, 165

- myth, 183

Orientation to parents, 155

Over-correction of child, 10

Over-compensation, 45,153

PaIrs of opposites, 3, 171-2, 189, 202, 209

Parental influence, 155-6

- quarrels, 68
Parents and children, 43

Persian poet quoted, 171

Persona, 191

- an excerpt, 206-7

Persunal unconscious, 78, 183, 206

- - infantile mind, 168

Peter Pan motif, 20 note, 36

Pfister, quoted, 176, 187 note

Phantasy, added, 33

-, a function of the psyche, 196

-, allurement of, 24

-, Anna's, 19 note

-, birth, 19, 30

-, child's, 3

- created by regressed libido, 209-10

-, dangers of, 95,98

-, excreta in, 18, 135

-, Miller, 182

- of neurotics, 82-4

Phobia, of murder germs, 201

Phobias, 80

Pindar, quoted, 75

Plotinus, cited, 134

Pragmatism, 12

Preconscious, 77, 111

Pregnancy identification, 177

Preparation for analyst, 38

Primitive man, 79, 98, 175, 188

- thinking, 177

Primordial images, 191, 200-4, 207-9

Problem of adaptation, 107

Projection, 13, 24, 41, 74, 156, 169

Psyche, functions of, 195-7

Psychic energy, 184

- life, a continuity, 64

- streams, 111

Psychical inheritance, 116

- Research Society, 7, 83

Psycho-analysis, 1, 38, 79

Psychological adaptation, 195 et seq.

- bisexuality, 204

- incest, 183

- insufficiency, 165

- problems, 183

- types, 12, 55, 173, 197 et seq.

Psychology of dementia præcox, 4 note, 209 note

- of the unconscious, 182

Psycho-neurosis, 160

Psychoses, the, 161

Puberty, 36, 179

Pugnacity, 58

Rationalisation, 19, 68, 154

Re-animation of unconscious, 209

Re-birth, 48, 190

- myth, 168

Recurring dream character, 103

Re-education, 39

"Regiment of Women," 137 
Regression, at puberty, Phyllis, 37

- In infancy, Anna, 19

- to mother, $19,37,86,189$

Repression, 17, 76, 78, 136, 154, 165, 174,206

-, Miss Miller's, 187

- of co-funotions, 167, 173, 199

Resistance, 165, 189

- against loving, 189

- sexuality, 121

- - the new, 193-4

- in children, 11

Ribot, quoted, 173

Riddock, Dr. G., quoted, 180 note

Riklin, Dr., 3

Rivers, Dr., quoted, 21 note, 205

Ruhe and Paul, quoted, 205 note

SACRIFICE of infantile personality, 168, 192

Sadism, 62, 171, 200

Saint Francis, 95

Schopenhauer, cited, 204

Secret of culture, 193

Self-depreciation, 60, 123, 139

- regulation, 65

Sense of guilt, 154

- - inferiority, $27,40,45,58,60$

Sex and character, 127

- - friendship, 143

-, confusion of, 148, 152

- ouriosity, 147

Sex-education, 157

- - unconscious factors in, 144

Sex in dream, 104

- instruotion in class, 144, 157

- phantasies, 147, 192

- problems, 132

- sublimation of, 135-6

Sexual wish, 191

Shakespeare, quoted, 148

Shelley, 202

Silberer, 119

Smith, Dr. G. Elliot, quoted, 48 notc

Smythe, Dr. Ethel, quoted, 158

Spencer and Gillen, quoted, 177

Spiritualism, 124

Spitteler, clted, 186

Spoilt children, 63

Stoddart, Dr. H. B., quoted, 162

Stormy childhood, 67-9

Subconscious types, 199

Subjective interpretation, 196

Subliminal material, 105-6

"Subliminal," Myers, 77

Swiss School, 107, 119

Symbolic symptoms, 37, 178, 180, 186

Symbols, archetypes, 146, 208

-, clvilisation and, 122

-, excretions as, 135
Symbols, fertility, 193

-, Jones, Dr. E., on, 120, 205

-, no fixed, 120

- of analysed person, 103

- - analyst, 102

- - libldo, 86, 187

- - parents, 43

- - phobia, 37

- qualities, 103

- rebirth, 48, 168, 190

- - religion, 190

-, sexual, 121, 188

-, stairs, 120, and note

-, use of, 190

-, word, a, 5

Symptomatic acts, 31,88

Synthesis in analysis, 80

Systems of phantasies, 168

Teachers and children, 66

-, bound and free, 68

-, problem re homo-sexuality, 140

-, psychology, 9-11

-, substitutes for parents, 51,67

"Terrible Mother," 48, 169, 189-90

Theft detected by word-association test, 5

Thieving by small boy, 44

Thinking, arrested, 49

- , directed and undirected, 23, 176, 192

-, totemistic, 98, 176

Thought, archetypal forms of, 209

Threshold of consciousness, 110

Totem animal, 98

Transference, 73, 163, 187, 190

— of libido, 193

Translator, Dr. Hinkle, 194

Tuckey, Dr. Lloyd, quoted, 162

Type, development contrary to, 14

-, names, too abstract, 198

-, psychology of, 13, 197 et seq.

Types, suboonscious, 197 et seq.

UNCHARTED region of mind, 97

Unconscious, acquired, 78

-, a trickster, 88, 124

- authority, 74

- characteristics, Dr. E. Jones, 129

-, compensatory character of, 84,97 , 122,145

- conflict, 8, 26, 37, 86, 98, 128, 168, 188, note

- mind, 2, 16, 77, 128, 145, 174

-, not educable, 99

-, not rational, 145

-, not repression only, 145

-, prospective meaning, 174

-, reanimation of, 209 
Unconscious, reflects progress in consoious, 99

- transference, 187

- wish, 19, 37, 179

Under-expressed Ideas, 17, 123

Undirected thinking, 23, 176

Unequal development, 36

WARONDA, 184

Waugh, Alec, 137
Weininger, cited, 204

Were-wolf in unconsclous, 98

Whipping, sense of humiliation, 59

Whitman, Walt, quoted, 199, 200

Wilson, President, 198

Wish fulfilment, 118

Women's male psychology, 138

Word, as symbol, 5

Word-association test, 3, 31

Wordsworth, quoted, 47

THE END

Printed by William Clowes \& Sons, Limited, Beccles, for Bailliere, Tindall $\&$ Cox, 8, Henrietta Street, Covent Garden, W.C. 2. 


\section{An Abridged List of Works}

\section{PUBLISHED BY \\ BAILLIẼRE, TINDALL \& COX.}

BALFOUR's War Against Tropical Disease.

Crown 4to. Pp. 220, with 180 Illustrations. Price 12s. 6d. net.

BJORKEGREN'S Handbook of Anatomy for Students of Massage. Second Edition. Demy 8vo. Pp. $x+233$, with 73 Illustrations. Price 6s. net.

BLACKHALL-MORISON'S Sensory and Motor Disorders of the Heart: Their Nature and Treatment. Demy $8 \mathrm{vo}$. $\mathrm{Pp}$. viii + 260 , with 51 Illustrations. Price 78. 6d. net.

BLAIR BELL'S The Principles of Gynæcology. Third Edition. Pp. xxviii +660 , with 7 Coloured Plates and 392 Illustrations. Royal 8vo. Price 38s, net.

BLAIR BELL'S The Sex Complex : A Study of the Relationships of the Internal Secretions to the Female Characteristics and Functions in Health and Disease. Demy $8 \mathrm{vo}$. With Coloured Plates. Second Edition in the Press.

BLAIR BELL'S The Pituitary. Royal 8vo. Pp. $x x+348$. With 190 Original Illustrations, and 7 Coloured Plates. Price 30s. net.

BLOMFIELD'S Anæsthetics.

Fourth Edition. Crown 8 vo. Pp. viii +147 , with 22 Hlustrations. Price 6s. net.

BROOKE'S Marine Hygiene and Sanitation.

Deniy 8 vo. Pp. $x+409$, with 4 Coloured Plates and 27 other Illustrations. Price 15s. net.

BROWN's Advanced Suggestion (Neuroinduction). Crown 8vo. Pp. viii +242 . Price 7s. 6d. net.

BRowN's Physiological Principles in Treatment. Fourth Edition. Pp. $x+408$. Price 8s. 6d. net.

BUCHANAN'S Manual of Anatomy, Systematic and Practical, including Embryology. Fourth Edition. Complete in 1 volume. Demy 8vo. Pp. 1780, with 670 Illustrations, mostly original and in several colours. Price 30s. net. (University Series.)

CASTELLANI \& CHALMERS' Manual of Tropical Medicine. Third Edition. Pp. xii +2436 . With 16 Coloured Plates and 909 Illustrations. Price $45 \mathrm{~s}$. net. 
CLARKE'S Errors of Accommodation and Refraction of the Eye. Fourth Edition. Crown 8vo. Pp. viii +243 , with Coloured Plate and 92 figures in text. Price 7s. 6d. net.

COBB'S Manual of Neurasthenia.

Demy 8vo. Pp. xvi +366 . Price 12s. 6d. net.

COBB'S The Organs of Internal Secretion: their Diseases and Therapeutic Applications. Second Edition. Crown 8vo. Pp. $x+236$. Price 8s. 6d. net.

\section{DIEOLAFOY'S Text-Book of Medicine.}

Translated by V. E. Collins and.J. A. Liebmann. In 2 volumes. Second Edition. Royal 8vo. Pp. xxiv +2156 , with 9 Coloured Plates and 99 Illustrations. Price 25s. net.

DOYEN'S Surgical Therapeutics and Operative Technique. Prepared by the Author in collaboration with H. SPENCER Browne, M.B. Cantab. Complete in 3 Large Royal 8vo. volumes. Vol. I., Pp. $x+782$, with 1,038 Illustrations. Vol. II., Pp. $x i i+680$, with 982 Illustrations. Vol. III., Pp. $\mathrm{x}+811$, with 963 Illustrations. Price £5 complete.

FITZWILLIAMs' Operative Surgery, with Surgical Anatomy and Surface Markings. Demy 8vo. Pp. viii +450 , with 284 Illustrations. Price 10s. 6d. net.

FRENCH'S Medical Laboratory Methods and Tests. Third Edition. $\mathrm{Pp}$. viii +202 , with 88 Figures, plain and coloured. Leather, gilt tops. Price 6s. net.

GARDNER's Manual of Surgical Anæsthesia.

Second Edition. Demy 8vo. Pp. xii +220 , with 8 Plates and 36 other Illustrations. Price 8s. 6d. net.

GREEN'S Pathology.

Twelfth Edition. Demy 8vo. Pp. $\mathrm{x}+603$, with 4 Coloured Plates and 243 Illustrations. Price 21s. net. (University Series.)

GRIMSDALE BREWERTON'S Text-book of Ophthalmic Operations. Second Edition. Demy 8vo. Pp. viii +438 , with 129 Illustrations. Price 18s, net.

HUGHES \& BANKS' War Surgery from Firing-Line to Base. Royal 8vo. Pp. xvi +623 , with 373 Original Illustrations and 8 Coloured Plates. Price 30s. net.

JONES' Papers on Psycho-Analysis.

Second Edition. Demy 8vo. Pp. $x+718$. Price 30s. net.

JONES' Treatment of the Neuroses.

Demy 8vo. Pp. viii +233. Price 10s. 6d. net. 
JUNG's Collected Papers on Analytical Psychology. Authorized Translation. Edited by Dr. Constance E. Long. Demy 8vo. Second Edition. Pp. xviii +492. Illustrated. Price 18s. net.

KERR'S Operative Midwifery.

Third Edition. Royal 8vo. Pp. xvi+726, with 308 Illustrations, mostly original. Price $30 \mathrm{~s}$. net.

LAMB'S Diseases of the Throat, Nose, and Ear.

Fourth Edition. Crown 8vo. Pp. xvi +372 , with 61 Illustrations. Price 10s. 6d. net.

LAROQUETTE'S Atlas of Electro-Diagnosis and Therapeuties. Translated by M. G. Снеeтham. Demy 8vo. Pp. xvi + 180, with 69 Plates and Illustrations. Price 15s. net.

\section{LEA'S Heart : Past and Present.}

Crown 8vo. Pp. viii +300 . Price 7s. 6d. net.

MCCARRISON'S The Thy roid Gland in Health and Disease. Royal 8vo. Pp. xviii +286 with 82 Illustrations. Price 14s. net.

McCAW'S Diseases of Children.

Demy 8vo. Pp. xii +524.. With 14 Plates and Illustrations. Price 12s. net.

\section{MACEWEN'S Surgical Anatomy.}

Second Edition. Demy 8vo. Pp. xiv +498, with 79 Illustrations, plain and coloured. Price 12s. net.

McKISACK'S Dictionary of Medical Diagnosis.

Second Edition. Demy 8vo. Pp. xii +590 , with 76 Illustrations. Price 12s. net.

MAY \& WORTH'S Diseases of the Eye.

Fourth Edition. Demy 8vo. Pp. viii +442 , with 336 Illustrations, including 22 Coloured Plates. Price 15s. net.

MONRO's Manual of Medicine.

Fourth Edition. Demy 8vo. Pp. xxiv +1045 , with 47 Illustrations, plain and coloured. Price 21s. net. (University Series.)

MUMMERY'S After-Treatment of Operations.

Fourth Edition. Crown 8vo. Pp. $x+276$, with 39 Illustrations. Price 6s. net.

ORRIN'S X-Ray Atlas of the Systemic Arteries of the Body. Demy 4to. Pp. viii +92 , with 21 Original Plates. Price 12s. $6 \mathrm{~d}$. net.

PALMER'S Lessons on Massage, including Swedish Remedial Gymnasties and Bandaging. Fifth Edition. Demy 8 vo. Pp. xvi +340 , with 136 Illustrations, plain and coloured. Price 10s. 6d. net. 
ROSE \& CARLESS' Manual of Surgery.

Tenth Edition. Demy 8vo. Pp. xii +1560 . With 18 Colonred

Plates and $60 \mathrm{C}$ other Illustrations. Price 30s. net. (University Series.)

SCHMIEDEN \& TURNBULL'S Operative Surgery

Second Edition. Royal 8vo. Pp. xx +350 , with 436 plain and coloured Illustrations. Price 25s, net.

SOLOMONS' Handbook of Gynæcology.

Demy 8vo. Pp. xii +236 , with 196 Illustrations. Price 10s. 6d. net.

SOMMERVILLE'S Practical Sanitary Science.

Demy 8vo. Second Edition. Pp. viii +328 , with 79 Illustrations. Price 108. 6d. net.

STEWART'S Manual of Physiology.

Eighth Edition. Demy 8vo. Pp. xxiv +1245 , with Coloured Plate and 492 Illustrations. Price 21s. net. (University Series.)

TIBBLES' Dietetics; or, Food in Health and Disease, inciuding Vitamines and Defleieney Diseases. Demy 8 vo. Pp. $x+628$. Price 148. net.

TINEL'S Nerve Wounds: Symptomatology of Peripheral Nerve Lesions caused by War Wounds. Revised and Edited by CeCIl A. Joll, F.R.C.S. Royal 8vo. Pp. xii +317 , with 323 Illustrations. Price 178. 6d. net.

TREDGOLD'S Mental Deficiency.

Third Edition. Demy 8 vo. Pp. xviii +532 , with 29 Original Illustrations. Price 25s. net.

WALSH'S Diseases of the Skin.

Demy 8vo. Pp. xvi +300 , with 29 Illnstrations. Price 78. 6d. net.

WHEELER'S Handbook of Operative Surgery.

Third Edition. Demy 8vo. Pp. viii +364 , with 226 Figs. Price 12s. net.

WHITLA's Pharmacy, Materia Medica, and Therapeutics.

Tenth Edition. $\mathrm{P}_{1}$. xii +680 , with 23 Illustrations. Price 108. 6d. net.

WHITLA'S Dictionary of Treatment.

Sixth Edition. Demy 8vo. Pp. $\mathrm{x}+1080$. Prico 25s. net.

WILLIAMS' Minor Maladies and their Treatment.

Fourth Edition. Crown 8vo. $\mathrm{P}_{\mathrm{p}}$. xii +402 . Price 8s. 6d. net.

WINGFIELD's Introduction to the Study of Hypnotism.

Crown 8vo. Pl. viii + 195. Price 7s. 6d. net.

YOUNGER'S Insanity in Everyday Practice.

Fourth Edition. Crown 8vo. Pp. $\mathrm{x}+134$. Price 6s. net.

BAILLIËRE, TINDALL \& COX,

8, Henhietta Street, Covent Garden, London, W.C. 2

$5000 \quad 28 / 8 / 20$ 



\section{UNIVERSITY OF CALIFORNIA LIBRARY \\ Los Angeles}

This book is DUE on the last date stamped below.

SUBJECT TP FINE IF NOT RETURNED TO

Form L9-17m-8,'55(133333s4) 444 


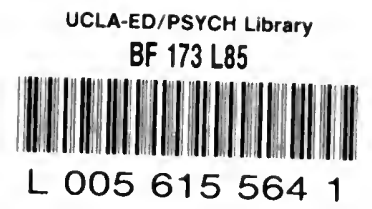

BF

173

A $001140282 \quad 3$

485

cop. 2 
